\title{
Maxims or Myths of Beauty? A Meta-Analytic and Theoretical Review
}

\author{
Judith H. Langlois, Lisa Kalakanis, Adam J. Rubenstein, Andrea Larson, Monica Hallam, and Monica Smoot \\ University of Texas at Austin
}

\begin{abstract}
Common maxims about beauty suggest that attractiveness is not important in life. In contrast, both fitness-related evolutionary theory and socialization theory suggest that attractiveness influences development and interaction. In 11 meta-analyses, the authors evaluate these contradictory claims, demonstrating that (a) raters agree about who is and is not attractive, both within and across cultures; (b) attractive children and adults are judged more positively than unattractive children and adults, even by those who know them; (c) attractive children and adults are treated more positively than unattractive children and adults, even by those who know them; and (d) attractive children and adults exhibit more positive behaviors and traits than unattractive children and adults. Results are used to evaluate social and fitness-related evolutionary theories and the veracity of maxims about beauty.
\end{abstract}

I cannot say often enough how much I consider beauty a powerful and advantageous quality. Socrates called it "A short tyranny," and Plato, "The privilege of nature." We have no quality that surpasses it in credit. It holds the first place in human relations; it presents itself before the rest, seduces and prepossesses our judgment with great authority and a wondrous impression.

-Montaigne, Essays

"Beauty is truth, truth beauty," - that is all

Ye know on earth, and all ye need to know.

$$
\text { -Keats, Ode on a Grecian Urn }
$$

Beauty has interested poets, philosophers, and scientists for centuries. Indeed, the ancient Greeks believed that there is a fundamental relation between beauty and positive qualities: Those who are beautiful are also good (Sappho, Fragment No. 101). "Beauty is good" was empirically tested in a seminal study by Dion, Berscheid, and Walster (1972), who demonstrated that, even in modern times, human beings attribute positive qualities to attractive people and negative qualities to unattractive people. Since this important study, much research has focused on the effects of attractiveness, especially facial attractiveness, on, the attributions, impressions, and stereotypes of strangers. These studies primarily have investigated attributions made by college students about attractive and unattractive strangers based on a photograph of the face and, sometimes, minimal printed "background information" about the hypothetical individuals. This strangerattribution literature has been summarized by earlier meta-analyses

Judith H. Langlois, Lisa Kalakanis, Adam J. Rubenstein, Andrea Larson, Monica Hallam, and Monica Smoot, Department of Psychology, University of Texas at Austin.

This work was supported by a grant from the National Institute of Child Health and Human Development to Judith H. Langlois.

We thank Rebecca Bigler, David Buss, David Cohen, Alan Feingold, George Holden, Don Kalick, Pam Miller, William B. Swann, and Leslie Zebrowitz for their helpful comments.

Correspondence conceming this article should be addressed to Judith $\mathrm{H}$. Langlois, Department of Psychology, Mezes 330/B3800, University of Texas at Austin, Austin, Texas 78712. Electronic mail may be sent to langlois@mail.utexas.edu. (see, e.g., Eagly, Ashmore, Makhijani, \& Longo, 1991; Feingold, 1992b), which have confirmed the association between attractiveness and many attributions of positive characteristics. ${ }^{1}$

Contrary to these findings of a reliable relation between attractiveness and attributions of positive qualities, however, are several age-old maxims and precepts holding that attractiveness either is not or should not be a significant factor in social interactions or behaviors. Three maxims in particular are heard frequently: (a) Beauty is in the eye of the beholder, (b) never judge a book by its cover, and (c) beauty is only skin-deep. These maxims generally reflect received wisdom about the role of attractiveness in human interaction. It is curious that these maxims are at such odds with the stranger-attribution literature. Received wisdom suggests that attractiveness is either not important at all or relevant only to first impressions but not as people become more familiar with each other. Perhaps it is the case that both are accurate: Perhaps people make attributions about strangers based on attractiveness, but there are no practical effects of being attractive or unattractive in real life. Alternatively, perhaps the attribution literature does indeed generalize to actual interactions between people who are familiar with each other. Assessing the relevance of the maxims to everyday life and evaluating the mediating influence of familiarity on attractiveness effects are important yet unaddressed issues.

\section{Beauty Is in the Eye of the Beholder}

Beauty is not judged objectively, but according to the beholder's estimation.

-Theocritus, The Idyll

According to the maxim Beauty is in the eye of the beholder, "different people have different ideas about what is beautiful"

\footnotetext{
${ }^{1}$ Defining attractiveness theoretically is a topic of great interest and controversy. Until recently, empirical work proceeded without any conceptual or scientific definition of attractiveness: Researchers simply defined people as attractive when raters agreed they were attractive. Although this issue is beyond the scope of the current article, the interested reader is referred to Cunningham (1986); Farkas, Munro, and Kolar (1987); Langlois and Roggman (1990); and Langlois, Roggman, and Musselman (1994), among others.
} 
(Spears, 1993, p. 45) and, therefore, do not agree about who is and is not attractive. Although this maxim is invoked both within and between cultures, it is believed to be true especially between cultures because different cultures presumably have very dissimilar standards of beauty (see, e.g., Darwin, 1871; Ford \& Beach, 1951). Assessing the veracity of this maxim is important because without consensus in judgments of attractiveness, there can be no consistent effect of attractiveness on social judgments, interactions, or behavior. Empirically, if beauty is only in the eye of the beholder, judgments of attractiveness should show little consistency among raters and, thus, low reliability coefficients. Only one meta-analysis we know of has quantitatively evaluated the reliability coefficients of attractiveness judgments. Feingold (1992a) examined panels of raters from within the United States and Canada and found a high level of agreement among adult raters. However, we do not know of any meta-analysis that has examined reliability coefficients of attractiveness judgments made by or about children nor do we know of any meta-analysis investigating agreement across raters of different ethnicities and cultures.

\section{Never Judge a Book by Its Cover}

Judge not according to the appearance.--John 7:24

Wilkinson (1993) defined this maxim as meaning "do not judge by externals" (p. 407). The maxim urges people to disregard external appearance and to judge and treat others only on the basis of the "contents of the book." Research has yet to determine whether this maxim accurately reflects judgments and treatment of others in actual interactions or whether the maxim represents an ideal. To determine if there is adherence to this maxim, we divided and operationalized it into two components: (a) Judgments of others should not be based on their appearance, and (b) treatment of others should not be based on their appearance. If people conform to the maxim, then meta-analysis should find no significant effects of attractiveness on judgments or treatment of others. Attractiveness should be particularly unlikely to influence the interactions of people who know each other because such individuals have more than mere external appearance on which to base their judgments.

As previously mentioned, numerous individual studies and a few meta-analyses have demonstrated the robust effects of attractiveness on the attributions or judgments people make of others based primarily on photographs. For example, Eagly et al. (1991) quantitatively summarized the strength and generality of the physical attractiveness stereotype by examining studies in which participants inferred attributes of people whom they did not know and who were depicted in photographs. Although such reviews are extremely important in consolidating the stranger-attribution literature, they ignore more ecologically relevant studies in which informed judgments of others are made following actual interactions. Whether involving individuals known well or strangers encountered at the bank, grocery store, job interviews, or work, actual interactions are undoubtedly more typical of daily life than making attributions about the characteristics of individuals depicted in photographs. Although several individual studies have indicated that people do interact differently with others based on attractiveness (Dion, 1974; Langlois, Ritter, Casey, \& Sawin, 1995; Snyder, Tanke,
\& Berscheid, 1977; Stewart, 1980; 1984), no meta-analysis is currently available to assess judgment and treatment of individuals following actual interactions or to assess judgment and treatment of individuals people know.

\section{Beauty Is Only Skin-Deep}

All the beauty of the world, 'tis but skin-deep. -Ralph Venning, The Triumph of Assurance

According to this maxim, there is no necessary correspondence between external appearance and the behavior or personality of an individual (Ammer, 1992). Two meta-analyses have examined the relation between attractiveness and some behaviors and traits (Feingold, 1992b ${ }^{2}$; L. A. Jackson, Hunter, \& Hodge, 1995). Feingold (1992b) reported significant relations between attractiveness and measures of mental health, social anxiety, popularity, and sexual activity but nonsignificant relations between attractiveness and sociability, internal locus of control, freedom from selfabsorption and manipulativeness, and sexual permissiveness in adults. Feingold also found a nonsignificant relation between attractiveness and intelligence $(r=.04)$ for adults, whereas L. A. Jackson et al. found a significant relation for both adults $(d=.24$ overall, $d=.02$ once selected studies were removed) and for children $(d=.41)$.

These meta-analyses suggest that there may be a relation between behavior and attractiveness, but the inconsistencies in results call for additional attention. Moreover, the vast majority of dependent variables analyzed by Feingold (1992b) and L. A. Jackson et al. (1995) assessed traits as defined by psychometric tests (e.g., IQ) rather than behavior as defined by observations of behaviors in actual interactions. Thus, to fully understand the relations among appearance, behaviors, and traits, it is important to broaden the conception of behavior beyond that used by Feingold and L. A. Jackson et al. If beauty is only skin-deep, then a comprehensive meta-analysis of the literature should find no significant differences between attractive and unattractive people in their behaviors, traits, or self-views.

\section{Theoretical Mechanisms}

In contrast to the three maxims, both general socialization and social expectancy theories (behavioral confirmation and selffulfilling prophecy) and fitness-related evolutionary theories (good genes, mate selection, and parental investment) predict that attractiveness should and does have a significant impact on the judgments and treatment of others by perceivers and on the behaviors and traits of targets. Although these perspectives were not originally conceptualized to account for the origin or causal mechanism underlying attractiveness effects, both have been successfully invoked to understand attractiveness effects, and a number of predictions about attractiveness can be deduced from them (see, e.g.,

\footnotetext{
${ }^{2}$ Feingold (1990) also meta-analyzed behavioral and trait variables. However, the studies included in his 1990 meta-analysis were virtually identical to those included in Feingold (1992b) and are therefore not cited here as a third meta-analysis.
} 
Barber, 1995; Berscheid \& Walster, 1974; Buss, 1998, 1999; Buss \& Schmitt, 1993; Cunningham, Druen, \& Barbee, 1997; Eagly et al., 1991; Feingold, 1992a; L. A. Jackson, 1992; D. Jones, 1996; Kalick, Zebrowitz, Langlois, \& Johnson, 1998; Langlois, 1986; Langlois \& Roggman, 1990; Zebrowitz, 1997). Although some aspects of these predictions have been evaluated by previous research, many important pieces of the theories have not yet been addressed. Table 1 provides a list of predictions suggested by the different theories that we elaborate on below.

Although we present them separately for purposes of clear exposition, we do not believe that any one theory or mechanism operates to the exclusion of the others. For example, within fitnessrelated evolutionary theory, several different evolutionary mechanisms are relevant, are not necessarily mutually exclusive, and may be operating simultaneously (Gangestad \& Thomhill, 1997; Kirkpatrick, 1996). The usefulness of the systematic, modular approach we take here is in beginning to paint a more constrained picture of the domains, conditions, and developmental trajectories of the relevant evolutionary and social mechanisms and in understanding where they do and do not intersect.

\section{Socialization/Social Expectancy Theories}

Two core assumptions underlie socialization and social expectancy theories: (a) Cultural norms and experiences influence the behavior of both targets and perceivers, and (b) social stereotypes create their own reality (see, e.g., Langlois, 1986; Snyder et al., 1977). These core assumptions map on to the three maxims about attractiveness. According to the first assumption, people should agree about who is and is not attractive within cultures because of cultural similarities in standards of attractiveness. In contrast, the theories predict lack of agreement in cross-cultural judgments of attractiveness because different cultures have different cultural standards of beauty (Darwin, 1871; Ford \& Beach, 1951). We evaluate agreement about target attractiveness both within and across cultures in our first set of meta-analyses (reliability).

Social stereotypes create their own reality through a multistep causal mechanism: (a) Facial appearance elicits social stereotypes or expectations for the behavior and traits of attractive and unattractive targets, (b) these expectations are acted on by the perceiver in the form of differential judgments and treatment of attractive and unattractive targets, (c) differential judgment and treatment cause the development of differential behavior and traits in attractive and unattractive targets, and (d) attractive and unattractive targets internalize differential judgment and treatment and eventually, develop differential behavior and self-views (for detailed discussions, see Darley \& Fazio, 1980; and Zebrowitz, 1997).

The stranger-attribution literature and meta-analyses of it have firmly established the existence of the "beauty is good" stereotype (see, e.g., Adams \& Crane, 1980; Berscheid \& Walster, 1974; Dion, 1973; Downs \& Harrison, 1985; Eagly et al., 1991; Feingold, 1992b; Langlois, 1986; Ritter, Casey, \& Langlois, 1991; Snyder, Berscheid, \& Glick, 1985). At least among strangers, attractiveness clearly elicits differential expectations for the behavior and traits of attractive and unattractive targets. In our second set of meta-analyses (judgments), we examine studies in

Table 1

Predictions Derived From Social Expectancy and Fitness-Related Evolutionary Theories

\begin{tabular}{|c|c|c|c|c|}
\hline \multirow[b]{2}{*}{ Prediction } & \multicolumn{4}{|c|}{ Theory } \\
\hline & Social & Mate selection & $\begin{array}{l}\text { Good } \\
\text { genes }\end{array}$ & $\begin{array}{c}\text { Differential } \\
\text { parental solicitude }\end{array}$ \\
\hline \multicolumn{5}{|l|}{ Reliability of judgments } \\
\hline Within-culture agreement & Yes & Yes & Yes & Yes \\
\hline Across-culture agreement & No & Yes & Yes & Yes \\
\hline Gender differences & Yes & Yes & No & No \\
\hline Age differences & Yes & NCP & No & NCP \\
\hline \multicolumn{5}{|l|}{ Judgment and treatment } \\
\hline Differential judgment & Yes & Yes for adults & Yes & Yes for children \\
\hline Gender differences & Yes & Yes for adults & No & No \\
\hline Age differences & Yes & NCP & No & NCP \\
\hline Differential treatment & Yes & Yes for adults & Yes & Yes for children \\
\hline Gender differences & Yes & Yes for adults & No & No \\
\hline Behavior/trait differences & Yes & Yes for adults & Yes & Yes \\
\hline $\begin{array}{l}\text { Attractiveness is honest indicator of } \\
\text { fitness }\end{array}$ & No & Yes for women & Yes & Yes \\
\hline Gender differences & Yes & No & No & No \\
\hline Age differences & Yes & NCP & No & NCP \\
\hline Differential self-perceptions & Yes & NCP & NCP & NCP \\
\hline Gender differences & Yes & No & No & No \\
\hline Age differences & Yes & NCP & No & NCP \\
\hline \multicolumn{5}{|l|}{ Causality } \\
\hline $\begin{array}{l}\text { Judgment/treatment causes behavioral/ } \\
\text { trait differences }\end{array}$ & Yes & No & No & No \\
\hline $\begin{array}{l}\text { Behaviors/traits cause judgment and } \\
\text { treatment }\end{array}$ & No & Yes & Yes & Yes \\
\hline
\end{tabular}

Note. $\mathrm{NCP}=$ no clear prediction. 
which participants make informed judgments of attractive and unattractive targets following actual interaction or on the basis of role relationships (e.g., real teachers and their students), thereby extending results from the stranger-attribution literature to more ecologically valid situations.

Stereotypes and differential expectations about attractive and unattractive people also cause differential treatment of them according to social theory. In our third set of meta-analyses (treatment), we examine whether attractive and unattractive people are actually treated differently, especially by those who know them.

Finally, the theories hold that attractive and unattractive targets come to behave differently and develop different traits as a function of differential judgment and treatment. Our fourth set of meta-analyses (behavior/traits) reveals whether or not attractive and unattractive people behave differently and possess different traits.

Confirmation of these core assumptions is necessary for social theories to unambiguously explain attractiveness effects. However, several ancillary premises regarding age and gender differences would provide further support for the theories. First, age should influence the reliability of attractiveness ratings because, relative to younger judges, older judges have internalized societal standards of attractiveness. Second, because many interactions between adults and children involve socialization in which adults deliberately encourage some behaviors and discourage others, attractiveness should have more opportunities to influence the judgments and treatment of child than adult targets. Thus, these perspectives should predict that attractive and unattractive children will receive more differential treatment and judgment than will adults. Third, the accounts should predict age differences in targets' behaviors and traits as a result of cumulative socialization. If behavioral differences result from differential treatment based on attractiveness, as assumed by the theories, behavioral differences as a function of attractiveness should not be evident very early in life yet, as children are exposed to more socialization effort and as a result of cumulative differential judgment and treatment, should become increasingly present with age. Analyses examining attractiveness effects for both children and adults are required to evaluate these age-related ancillary premises of social theory and are performed below.

In addition to predictions about age differences in the importance of attractiveness, socialization and social expectancy theories make ancillary predictions about gender differences in the importance of attractiveness. Because human culture values attractiveness more in females than in males, agreement about the attractiveness of females should be greater than agreement about males, and females should experience more differential judgment and treatment based on attractiveness than males (Hatfield \& Sprecher, 1986; L. A. Jackson, 1992; Zebrowitz, 1997). Moreover, the effects of attractiveness on behaviors, traits, and self-views should be larger for females than males because females receive more differential judgment and treatment as a function of their attractiveness. To evaluate these predictions, we examine gender differences in all our analyses.

\section{Fitness-Related Evolutionary Theories}

Fitness-related evolutionary theories (human mate selection, good genes, differential parental solicitude) posit that morpholog- ical characteristics such as attractiveness are honest indicators of fitness, health, quality, and reproductive value, and, therefore, that attractiveness is important in human interactions (Barber, 1995; Buss \& Schmitt, 1993; Daly \& Wilson, 1995; Gangestad \& Thornhill, 1997; Symons, 1979; Thornhill \& Gangestad, 1993). All three perspectives agree about the necessity of one a priori condition: Because humans have evolved universal standards of attractiveness based on clues to health and reproductive fitness, perceivers both within and across cultures should consistently detect and recognize attractiveness. Other predictions about attractiveness differ across mechanisms and are described below.

\section{Mate Selection}

Mate selection is the most commonly invoked evolutionary mechanism offered to explain attractiveness effects in both humans and animals. A central tenant of mate-selection theory is that attractiveness is differentially important for the two sexes (Andersson, 1994; Buss, 1998, 1999; Buss \& Barnes, 1986; Buss \& Schmitt, 1993; G. F. Miller, 1998; Symons, 1979). With most nonhuman species, it is the male for whom attractiveness and "showiness" is more important. Peacock feathers, turkey snoods, and colorful cichlid bellies in males are all assumed to have evolved as sexual enticements for females. However, with humans, it is almost always the female for whom attractiveness and showiness is more important. Thus, according to human mate-selection theory, men seek attractive women because attractiveness signals youth and reproductive fitness (Buss, 1998, 1999; Thornhill, 1998). In contrast, women seek men with resources, rather than attractiveness, because such men are able to provide for offspring (see, e.g., Buss, 1998). Because this review is concerned with how attractiveness affects human development and interaction, our discussion of mate-selection theory focuses on humans (see, e.g., Buss, 1999).

In humans, because attractiveness is especially important as an indicator of reproductive fitness in women, the reliability of attractiveness ratings should be higher when judging females than when judging males, especially as evaluated by male perceivers (L. A. Jackson, 1992). This prediction is examined by our reliability analyses.

Mate-selection research often focuses its predictions on preferences rather than behaviors (see, e.g., Buss, 1999). However, because "mate choice is the behavioral outcome of mate preferences" (G. F. Miller, 1998, p. 92), there should be some correspondence between preferences and behavior. Therefore, because men prefer and seek attractive women, men should also judge and treat them more positively. Because women favor men with resources more than merely attractive men, attractiveness should be more important in how men judge and treat women than in how women judge and treat men (Buss \& Barnes, 1986; Buss \& Schmitt, 1993; L. A. Jackson, 1992). We evaluate these predictions in our analyses of judgment and treatment.

In contrast to the gender difference predictions for reliability, judgments, and treatment, mate-selection theory predicts no gender differences in the importance of attractiveness for most target 
behaviors and traits. ${ }^{3}$ Rather, the theory predicts that initially unrelated traits coevolve because of assortative mating (Buss, 1985; G. F. Miller, 1998). Thus, attractive women tend to choose intelligent males because such mates have the ability to acquire resources. Offspring of both sexes then tend to inherit both characteristics, attractiveness and intelligence. Therefore, both attractive male and female offspring might be expected to be more intelligent than unattractive male and female offspring. Such a view would be supported if we find no gender differences as a function of attractiveness in our behavior/traits analyses.

Finally, unlike socialization theory, mate selection theory makes no predictions regarding the importance of attractiveness for children. Because young children are not involved in selecting a mate, this mechanism is not designed to explain children's behavior.

\section{Good Genes}

Good-genes theory predicts that attractiveness should be meaningful in human interactions because attractiveness accurately advertises health, quality, and heterozygosity (Barber, 1995; Gangestad \& Buss, 1993; Gangestad \& Thornhill, 1997; Shackelford \& Larsen, 1999; Thornhill, 1998; Thornhill \& Gangestad, 1993; but see Kalick et al., 1998, for an alternative). Thus, good-genes theory should predict differential judgment and treatment as a function of attractiveness because perceivers have evolved to prefer attractive people for their good health. The theory also should predict behavioral differences in targets as a function of attractiveness because attractiveness signals health, fitness, and quality. In contrast, the theory should predict no differences in behaviors unrelated to status and fitness (e.g., attitudes). Differential judgment and treatment should be responses to (rather than causes of, as per social theory) these preexisting differential behaviors and traits of attractive and unattractive individuals.

In addition, because good health is critical to survival, attractiveness should be equally relevant and important to both sexes (Thiessen, 1996; Thornhill \& Gangestad, 1993), a prediction that explicitly disagrees with socialization and social expectancy theories, as well as with mate-selection theory. Similarly, because good health is important for all ages, attractiveness should be as important for children as for adults. This prediction again contrasts sharply with socialization and social expectancy theories, which regard behavioral differences as the result of cumulative socialization. We evaluate these competing predictions in our behavior/ trait analyses.

\section{Differential Parental Solicitude}

Differential parental solicitude theory (a derivative of Trivers's [1972] parental investment theory) conjectures that, to enhance their own reproductive success, parents invest differently in children depending on each child's fitness, quality, and reproductive potential (Buss, 1999; Daly, 1990; Daly \& Wilson, 1988, 1995). Parents and other adults should allocate more energy, resources, attention, and care to higher quality offspring (Mann, 1992; Scrimshaw, 1984). Thus, if attractiveness is an indicator of quality, adults should invest more in attractive than unattractive children and, presumably, treat attractive children more favorably than unattractive children (Barden, Ford, Jensen, Rogers-Salyer, \&
Salyer, 1989; Buss, 1999; Field \& Vega-Lahr, 1984; Langlois et al., 1995).

Second, as with good-genes theory, differential parental solicitude theory assumes that differences in health and quality should be manifested by differences in behavior exhibited by attractive and unattractive children and adults. Thus, attractive individuals should possess more positive behaviors and traits than do unattractive individuals.

Third, because the theory is focused on adults' treatment of children, it places more importance than the other fitness-related evolutionary theories on differential treatment of children. By this logic, attractiveness is perhaps even more important for children than for adults, but the theory does not make any explicit predictions about age differences in the importance of attractiveness. Finally, because the theory assumes that attractiveness is an equally valid indicator of health and quality in boys and girls, no gender differences would be expected in how boys and girls are judged and treated as a function of attractiveness (Daly \& Wilson, 1995).

\section{Purpose}

This article has three primary goals. The first goal is to extend knowledge of attractiveness effects beyond stranger-attribution paradigms to determine the extent to which attractiveness influences daily lives and real interactions. The second goal is to examine the contradiction between common knowledge, as exemplified by the three maxims, and empirical findings about facial attractiveness. The third goal is to use extant research to evaluate the current status of socialization/social expectancy theory and fitness-related evolutionary theory as theoretical accounts of attractiveness effects. Although no single theory is likely to be uniformly supported or disconfirmed, our hope is that the review will highlight areas of strongest support and, more importantly, will show where future research is needed to comprehensively evaluate the different theoretical perspectives.

To accomplish these goals, we conducted a variety of metaanalyses. Four meta-analyses of attractiveness reliability coefficients evaluated interrater agreement about attractiveness, both within and across cultures. Two metà-analyses summarized research investigating global but informed evaluations of attractive and unattractive people, and two meta-analyses summarized studies of differential treatment of attractive and unattractive people. Three meta-analyses evaluated assessments of behavior and personal characteristics as a function of attractiveness.

Finally, our analyses assessed whether the effects of attractiveness apply to some groups more than to others. Because of the gender and age predictions made by the different theories, we evaluated the moderating influences of gender and age on the

\footnotetext{
${ }^{3}$ Although the theory at first glance seems to predict that attractiveness should be more important in the dating and sexual experiences of women than in those of men, it is not possible to make such a straightforward prediction. First, most men may not be able to successfully date very attractive women and thus may not ask them out (Buss \& Schmitt, 1993). Furthermore, men may have less stringent standards for attractiveness when seeking a short-term mate than when seeking a long-term mate (Buss, 1999; Buss \& Schmitt, 1993), and the particular strategy used by men in most of the retrieved studies cannot be determined.
} 
effects of attractiveness. Although there are many empirical studies about the importance of attractiveness for children (see, e.g., Dion, 1974; Hildebrandt \& Fitzgerald, 1978; Langlois \& Stephan, 1977), ours is the first meta-analysis to include them in a comprehensive analysis.

\section{Method}

\section{Retrieval of Studies}

We began by examining the adult and child attractiveness literature obtained from APA databases (PsycLIT, PsycINFO), Cash's (1981) annotated bibliography, and the ERIC database of published, unpublished, and conference papers using key terms beauty, facial attractiveness, and physical attractiveness. We also examined every relevant article from the reference sections of all retrieved articles. This search resulted in obtaining references from 1932 through June 1999.

Because there are many forms of attractiveness and our primary interest was in objectively rated facial attractiveness within the normal distribution, we excluded studies in which the face was not available for assessment (body attractiveness, e.g., Singh, 1993; vocal attractiveness, e.g., Zuckerman \& Driver, 1989; grooming, e.g., Mack \& Rainey, 1990) or if the study instructed judges to evaluate a different type of attractiveness (sexual attractiveness, e.g., Townsend \& Wasserman, 1997; self-evaluations of attractiveness, e.g., N. Cavior \& Dokecki, 1971), if the study measured another variable such as popularity but labeled the variable as attractiveness (e.g., Krantz, 1987), if the study confounded attractiveness with other variables (e.g., targets were selected to be both attractive and high in self-monitoring, Snyder et al., 1985), or if the study compared facially disfigured targets to nondisfigured targets (e.g., Field \& Vega-Lahr, 1984).

Because we wanted to understand the role of attractiveness in actual interactions, we excluded studies if they were pure attribution experiments (i.e., a study in which behavioral, trait, or personality attributions are made only by strangers and based solely on a photograph as per the studies included in Eagly et al., 1991), if they failed to report useable statistics; if the unit of analysis was more than a single individual (e.g., if dyads were analyzed together, Clark \& Ayers, 1988), if variables were curvilinear and it was not clear that either extreme was positive or negative, or if we could not place the variable into a meaningful category (e.g., there was only one study of child self-perceived traits, Lerner, Delaney, Hess, Jovanovic \& von Eye, 1990).

From an initial sample of over 1,800 empirical articles, we obtained a final data set of 919 useable effect sizes with some studies contributing more than one independent sample. To control for the possibility that our analysis overestimated the effect of attractiveness by excluding studies we did not retrieve (i.e., the file-drawer problem, Rosenthal, 1979), we computed the fail-safe $n$ for each analysis (Hedges \& Olkin, 1985). This statistic determines the number of additional nonsignificant effect sizes necessary to reduce the effect sizes we report to null differences between attractive and unattractive groups. The results of these fail-safe analyses indicate how resistant the findings are to the file-drawer problem and highlight which results, if any, should be interpreted with caution.

\section{Description of and Assignment to Categories}

The three maxims provided the initial conceptual basis for our categorization of effect sizes. We examined five overall categories for adults and four overall categories for children: reliability of attractiveness ratings, judgment, treatment, behavior/traits, and (for adults only) self-perceptions. Within each of these categories, we created subcategories by grouping conceptually similar variables. Whenever possible, we constructed parallel subcategories for adults and children, but often the dependent variables examined for children did not correspond to those investigated for adults.

\section{Reliability}

All reliability coefficients of attractiveness ratings from retrieved studies were analyzed. The vast majority of these studies asked raters to evaluate attractiveness from photographs (generally these raters were not the same participants analyzed for judgment or treatment); the remaining studies asked raters to evaluate attractiveness in situ or from videotapes. In almost all cases, judges used either a Likert-type scale or rank orders to evaluate attractiveness.

We were interested in whether children would evaluate attractiveness similarly to adults, whether raters of different ethniçity would evaluate attractiveness similarly when residing in similar cultures with similar exposure to media standards of beauty, and whether raters of different ethnicity within different cultures and presumably different media exposure would evaluate attractiveness similarly. Thus, four analyses were performed to evaluate: (a) Adult within-culture, within-ethnic agreement, including only studies in which adults residing in the same culture were rated by others of the same ethnicity as the targets; (b) child within-culture, within-ethnic agreement, including only studies in which children residing in the sarne culture were rated by others of the same ethnicity as the targets; (c) adult within-culture, cross-ethnic agreement, in which correlations among raters residing within the same culture but from different ethnic groups were analyzed (e.g., African Americans judging European Americans); and (d) adult cross-cultural, cross-ethnic agreement, in which correlations among raters residing in different countries and from different ethnic groups were analyzed (e.g., Koreans judging African Americans). We located insufficient numbers of studies of children from different ethnic groups from either their own or other cultures, precluding analyzing cross-ethnic reliability for children. See Appendix A for information about studies included in the meta-analyses of cross-cultural and cross-ethnic agreement and Appendix B for studies included in the within-culture, within-ethnic analyses.

\section{Judgment and Treatment}

Assignment of effect sizes to both this set of analyses and to the behavior/traits analyses was more complex than assignment to our reliability analyses because of the diversity of research measures found in retrieved studies. The studies retrieved for judgment, treatment and behavior/ traits used standardized and unstandardized measures, global and molecular measures, ratings by experts and nonexperts, and self-versus other-reports of behaviors, traits, and treatments. Separating different types of measures that seemingly assessed the same construct but in fact had significantly different conceptual foundations was necessary to successfully differentiate measures of judgment, treatment, and behavior. For example, friendliness could be assessed by global judgments made casually by a rater or by molecular behavioral counts of smiling made by a highly trained observer. Although both may have been construed as indexes of the construct "friendliness" in different studies, these two measures have important conceptual differences. Distinguishing between global and molecular measures is crucial because global ratings and judgments of individuals can be influenced by the "beauty is good" stereotype: Global ratings of friendliness reflect opinions of the rater as much as, if not more than, they reflect the behavior of the target (Ritter \& Langlois, 1988). Therefore, we assigned global measures to the judgment category. In contrast, molecular measures correspond closely to actual behaviors (Ritter \& Langlois, 1988) and thus were assigned to behavior/traits. Descriptions of the particular types of measures included in each category created for judgments, treatment, and behavior/traits are provided below.

Judgment. This category was conceptualized as infonmed opinions about attractive and unattractive targets. The category of judgment was thus defined as global ratings (e.g., friendliness, intelligence) made by others based on actual incidents of observable behavior.

Studies investigating judgments about children typically consisted of peer and adult ratings of behavioral traits and personality characteristics. 
Subcategories were academic/developmental competence, adjustment, interpersonal competence, and social appeal. Studies examining judgments about adults were typically global judgments of behavioral traits and personality characteristics made by other adults. Subcategories were adjustment, interpersonal competence, occupational competence, and social appeal. See Table 2 for definitions and examples of each subcategory and Appendixes $\mathrm{C}$ and $\mathrm{D}$ for information about studies included in the meta-analysis.

Treatment. This category was defined as observable actions having or thought to have actual impact on a target. The crucial criterion for inclusion was that the measure must reflect actions toward a target by an agent. For example, actions such as punishing an attractive or unattractive child or smiling directed toward an attractive or unattractive target were included in this category.

Studies investigating treatment of children focused on the actions of peers, teachers, and caregivers. Subcategories were attention/caregiving, designation of academic ability, ${ }^{4}$ negative interaction, and positive interaction. Studies examining treatment of adults typically included actions of both adults and children in laboratory and naturalistic settings. Subcategories were attention, help giving/cooperation, negative interaction, positive impression management, positive interaction, and reward (see Table 2 and Appendixes $\mathrm{E}$ and F).

\section{Behavioral Differences}

To separate conceptually distinct types of measures, we created two overall categories for behavioral differences: behavior/traits and selfperceived traits. All molecular measures of behavior were classified as behavior/traits (Ritter \& Langlois, 1988). Standardized psychometric measures of traits (e.g., IQ tests) were also assigned to this category because they have been validated as reasonably accurate measures of their constructs. Furthermore, because experts (e.g., mental health professionals) who make behavioral assessments in their area of expertise should be unbiased and provide measures that are approximately equivalent in validity to standardized measures, we included such measures in behaviorf traits. ${ }^{5}$ Finally, we included measures of popularity in behavior/traits because peers are, by definition, experts in judging whom they like.

For children, behavior/traits were generally measured by observational or sociometric data and by standardized tests. Approximately $80 \%$ of the measures were based on observation of actual behavior. Subcategories included adjustment, intelligence/performance, and popularity. For adults, behavior/traits were generally measured through observational studies, standardized tests, or molecular assessments of interaction behavior. Approximately $60 \%$ of the measures were based on observations of actual behavior. Subcategories were extraversion, intelligence, occupational success, mental health, physical health, popularity, self-confidence/selfesteem, social skills, traditional attitudes, dating experience, and sexual experience (see Table 2 and Appendixes $\mathrm{G}$ and $\mathrm{H}$ ).

In addition to using molecular measures, standardized measures, or behavioral/trait assessments by experts, many studies used global, unstandardized self-reports of behaviors and traits. We analyzed these measures because differential judgments and treatment may lead both to differential behavior and to differential self-views as a function of attractiveness (Snyder et al., 1977). In addition, such measures may illustrate interesting differences between attractive and unattractive individuals. However, because unstandardized self-reports are less objective than standardized measures of traits and behaviors, we created a separate category for them. Self-perceptions included two subcategories for adults, competence and mental health. We were not able to analyze self-perceptions for children because only a single study representing this category was retrieved (see Table 2 and Appendix I)

\section{Classification Decisions}

Each potentially releyant article was reviewed by one of us and then presented to at least three others who were not familiar with the results of the study and who decided whether the study met inclusion criteria. Thus, knowledge of whether or not a study found a relation between the dependent variable and attractiveness could not influence the decision to include or exclude it. Each dependent variable was identified as representing one of the subcategories within judgment, treatment, behavior/traits, or self-perceptions. Because we established clear coding criteria that left little room for disagreement, there was almost complete consensus among us regarding overall category classification. However, in a few cases, there was not total consensus about what subcategory was measured by a particular dependent variable (e.g., is order of speaking in a group interaction a measure of social skills or extraversion?). We used the conceptual definition provided by the original author(s) when available. When this was not available, we discussed to consensus.

Effect sizes were coded so that a larger effect size indicated that attractive individuals received comparatively more treatment or had more of a particular trait or behavior than unattractive individuals. To ensure accuracy, at least two of us verified effect size and variable coding, as well as data entry.

\section{Description of Moderator Variables}

We coded characteristics of both the study participants and the studies themselves as potential moderators of attractiveness effects. Participant characteristics included gender and age. Study characteristics included year of publication, sample size, and the degree of familiarity between the target and the judge or the person behaving toward the target. Furthermore, because the type of attractiveness ratings used is of central importance to our findings, we created a number of moderator variables to explore effects of methodological differences on our findings. First, we coded whether the attractiveness ratings were obtained from photographs or videotapes, or were done in situ (method: photo vs. video vs. in situ ${ }^{6}$ ). Second, we coded whether the ratings were made from the face alone or whether the stimulus included any additional information, such as clothing (type: facial only vs. additional information). Third, we coded whether the study treated attractiveness as a dichotomous variable or whether the study treated attractiveness as a continuous variable (range: dichotomous vs. continuous). Finally, we coded whether the raters who made the attractiveness ratings also made judgments of other behaviors and traits or whether the attractiveness raters were a separate, independent panel of judges. Inclusion of this variable was important because the "beauty is good" stereotype may bias raters evaluating both physical attractiveness and behavior (raters: independent vs. nonindependent).

\footnotetext{
${ }^{4}$ We were unsure where to assign grades. Do grades reflect treatment by a teacher and belong in designation of academic ability? Or do they reflect attributes of the individual such as intelligence/performance and belong in behaviors/traits? For high school and college students, who often are in larger classes and who take multiple-choice tests, grades probably reflect teachers' stereotypes less than they reflect actual ability of the student. Therefore, we assigned grades of high school and college students to behavior/traits. However, the issue for young children is less clear. On the one hand, most so-called grades in elementary school are global assessments of excellent, satisfactory, or unsatisfactory rather than actual grades. Furthermore, some research has suggested that teacher expectations influence grade assignments to elementary school children (Jussim \& Eccles, 1992). Therefore, to be conservative in assessing children's ability, we initially assigned grades to differential treatment. However, we also analyzed the data with grades of young children assigned to behavior/traits, so the reader can decide for her- or himself.

${ }^{5}$ See Note 4.

${ }^{6}$ Because there were only a few studies that used attractiveness ratings made in situ, we collapsed video and in situ into a single category.
} 
Table 2

Category and Subcategory Definitions and Examples

\begin{tabular}{|c|c|}
\hline Category and subcategory & Definition and examples \\
\hline Judgment & $\begin{array}{l}\text { Informed opinions about attractive and unattractive targets. Defined as global ratings made by others } \\
\text { based on actual incidents of observable behavior. }\end{array}$ \\
\hline \multicolumn{2}{|r|}{ 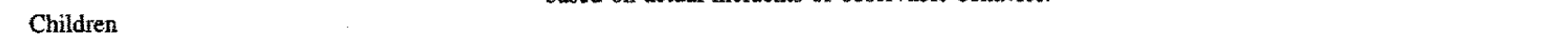 } \\
\hline Academic/developmental competence & Judgments of academic performance, skills, intelligence, alertness, acting grown up. \\
\hline Adjustment & Judgments of comfort in social settings, confidence, number of fears, aggression. \\
\hline Interpersonal competence & Judgments of success in social situations, leadership, social power, success in disputes, faimess. \\
\hline Social Appeal & Judgments of social desirability, sociability, temperament, getting along with others, positive mood. \\
\hline \multicolumn{2}{|r|}{ 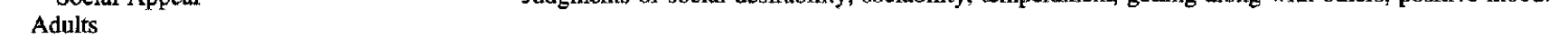 } \\
\hline Adjustment & Judgments of comfort, ratings of anxiety, loneliness, adjustment in clinical settings. \\
\hline Interpersonal competence & Judgments of success in social situations, assertiveness, conversational skills, general social skill. \\
\hline Occupational competence & Judgments of job performance, competence, motivation for success, suitability as potential employee. \\
\hline Social Appeal & Judgments of social desirability, friendliness, gracefulness, likeability. \\
\hline \multirow{2}{*}{\multicolumn{2}{|c|}{ Observable actions having or thought by the agent to have an actual impact on target. }} \\
\hline & \\
\hline Attention/caregiving & Visual attention and caregiving. \\
\hline Designations of academic ability & Grades and designations of ability assigned to pre-high school age children by teachers. \\
\hline Negative interaction & Punishment, negative feedback, rejection, aggression. \\
\hline Positive interaction & Prosocial behavior, social play, sharing, instructional assistance, positive reactions. \\
\hline \multicolumn{2}{|r|}{ 200 } \\
\hline Attention & Visual and social attention. \\
\hline Help-giving/cooperation & Providing assistance to targets by mailing letters, signing petitions, giving directions, financial help. \\
\hline Negative interaction & $\begin{array}{l}\text { Punishment, unfriendly behavior, length of prison incarceration and jail sentences, avoidance, } \\
\text { deception. }\end{array}$ \\
\hline Positive impression management & Positive or intimate self-disclosure, help-seeking. \\
\hline Positive interaction & Prosocial behavior, positive emotion, honesty, smiling, proximity-seeking, acceptance. \\
\hline Reward & $\begin{array}{l}\text { Providing positive outcomes or support for performance, recommendations for hiring, nominations } \\
\text { for monetary reward, number of election votes of political candidates. }\end{array}$ \\
\hline \multirow{2}{*}{\multicolumn{2}{|c|}{ Molecular measures, standardized measures, and expert assessments of behavior and traits. }} \\
\hline & \\
\hline Adjustment & Mental health, self-esteem, social skills; freedom from juvenile delinquency, depression, and anxiety. \\
\hline Intelligence/performance & $\begin{array}{l}\text { IQ and achievement: IQ tests (ACT, Iowa Test of Basic Skills, vocabulary, GPA of high school } \\
\text { students). }\end{array}$ \\
\hline Popularity & $\begin{array}{l}\text { Social standing in the peer group, popularity, positive peer relations, reciprocated friendships, peer } \\
\text { acceptance. }\end{array}$ \\
\hline \multicolumn{2}{|r|}{ - } \\
\hline Dating experience & Frequency of dating, lack of dating anxiety, dating assertiveness. \\
\hline Sexual experience & Frequency of sexual experience, number of sex partners. \\
\hline Extraversion & $\begin{array}{l}\text { Assertiveness/shyness in social situations assessed by personality inventories, conversational } \\
\text { behavior, assertiveness. }\end{array}$ \\
\hline Intelligence & IQ and academic performance (IQ tests, GPA of college students, SAT scores, honors). \\
\hline Occupational success & Occupational success and advancement in the workplace, income, military rank. \\
\hline Mental health & $\begin{array}{l}\text { Mental health and well-being; freedom from loneliness, narcissism, type A behavior, and depression; } \\
\text { emotional stability; social functioning. }\end{array}$ \\
\hline Physical health & Blood pressure, health center visits, freedom from substance abuse. \\
\hline Popularity & Social standing, liking, sorority membership, interpersonal attraction, number of social interactions. \\
\hline Self-confidence/self-esteem & Positive self-view, locus of control, ego functioning, positive self-disclosure. \\
\hline Social skills & $\begin{array}{l}\text { Comfort and competence in social situations, empathy, influence, smiling, persuasive effectiveness, } \\
\text { facial expressiveness, freedom from social anxiety and reticence. }\end{array}$ \\
\hline Traditional attitudes & $\begin{array}{l}\text { Conservatism and attitudes toward social roles assessed by Sex Role Inventories, social conformity, } \\
\text { support for the women's movement. }\end{array}$ \\
\hline Self-perceived traits & Unstandardized self-reports of traits. \\
\hline \multicolumn{2}{|l|}{ Adults } \\
\hline Competence & Global self-evaluations of intelligence, success, persuasiveness, social competence, social desirability. \\
\hline Mental health & $\begin{array}{l}\text { Self-perceptions of risk of mental disorders, susceptibility to mental illness, happiness, affect } \\
\text { balance, enjoyment of pleasant events, satisfaction with life domains, freedom from stress. }\end{array}$ \\
\hline
\end{tabular}

Thus, we assessed reliability as a function of the following moderators: target gender (we did not code the gender of the attractiveness raters because the majority of studies either did not report the appropriate statistics or analyzed both genders together), method, year of publication, and sample size. We were unable to analyze rater age because raters were almost always adults and there was insufficient variance to make this a meaningful analysis. For the other categories, we coded target gender, target age (for children only; almost all studies of adults involved only college students), year of publication, sample size, type, range, raters, and familiarity (except for behaviors/trats, which tid not involve a target). In addition, for the judgment and treatment categories, agent gender and agent age were coded 


\section{Data Analyses}

\section{Effect Sizes}

Using DSTAT (B. T. Johnson, 1989), we first calculated one effect size for the overall category (e.g., treatment), collapsing across all subcategories. Because each sample of participants should contribute only one entry per analysis (Hedges \& Olkin, 1985), multiple effect sizes obtained from the same participants were converted to $Z$ scores, averaged, and the average converted back to an $r$, resulting in only one effect size per sample (Rosenthal, 1995). When this process necessitated averaging $n s$ of slightly different sizes, usually due to participant attrition on certain measures but not others (e.g., Leinbach \& Fagot, 1991), we used the smallest $n$ to be most conservative. Most often, averaging was performed within individual studies, but on a few occasions, separate studies reported statistics from the same sample (e.g., Jovanovic, Lerner, \& Lerner, 1989; Lemer et al., 1990, 1991 ), and then the $r$ from more than one study were averaged. Second, we calculated separate effect sizes for each subcategory of dependent variables (e.g., social skills). At the subcategory level, multiple measures of the same construct obtained from the same participants were averaged, again resulting in only one effect size per sample in each subcategory.

For the reliability analyses, most studies provided correlational statistics that could be used directly. Because different studies reported different types of reliability coefficients, we converted the different coefficients (e.g., Kendall's tau) to an $r$ value. We computed both mean interrater and effective reliabilities (see Rosenthal, 1991, for conversion statistics). Mean interrater reliability estimates agreement between specific pairs of judges whereas effective reliabilities estimate the reliability of the mean of the judges' ratings (Rosenthal, 1991). We, like Rosenthal, prefer effective reliabilities because we are more interested in generalizing to how raters in general would agree than in the agreement of single pairs of judges evaluating a single face (Rosenthal, 1991). Just as a longer test is a more reliable assessment of a construct than a two-item test, the effective reliability coefficient is a more reliable estimate of attractiveness because it accounts for the sampling errors in small samples (Guilford \& Fruchter, 1973; Nunnally, 1978). Although we report both estimates of reliability in Table 3, we discuss the results of the analysis of effective reliabilities, and we analyze moderator variables only for effective reliability.

For judgment, treatment, and behaviors/traits, studies provided primarily group difference statistics from which effect size could be calculated $(t, p$, $F$, and $\chi^{2}$ ). If an effect size was reported only as nonsignificant (without a specific, numerical result reported), it was coded as zero (Rosenthal, 1991). Because including such effect sizes may underestimate the actual effect size whereas excluding them may overestimate it, we performed each category and subcategory analysis twice, first including studies in which effect sizes were coded as zero and then excluding these same studies (Rosenthal, 1991, 1995). We calculated the $Q(B)$ statistic to assess whether there were any differences between the data sets including or excluding nonsignificant effects coded as zero (see Hedges \& Olkin, 1985).

For each analysis, several statistics are reported (Rosenthal, 1991, 1995): $k$ (number of effect sizes in the analysis), $n$ (total number of participants in the analysis), Mdn $d$ (median effect size), $d_{+}$(averaged weighted effect size), $95 \%$ confidence interval, fail-safe $n$, and BESD (binomial effect-size display). The BESD is an estimate of the practical significance of the effect size and indicates the change in success rate in the dependent variable due to attractiveness. Thus, a BESD of .5 indicates a $50 \%$ higher success rate for attractive than unattractive people. The absolute success rate for each group is calculated by $.50+$ (BESD/2) (Rosenthal, 1991). We report the BESD statistic in the form of the two percentages reflecting, first, the proportion of attractive children above the mean in the category and, second, the proportion of unattractive children above the mean (i.e., $75 \%$ vs. $25 \%$ indicates that $75 \%$ of attractive children are judged more favorably than the average child whereas only $25 \%$ of unattractive children are judged more favorably than average). Finally, we report $Q$ (heterogeneity of the effect sizes).

\section{Moderator Variables}

Following the rationale and procedures of Knight, Fabes, and Higgins (1996), we assessed variance accounted for by moderator variables using weighted multiple regression analyses that control for relations among moderators. These analyses were performed only for the overall categories because, in most instances, the sample sizes of the subcategories were too small to allow meaningful subdivision by moderator variables.

\section{Data Reduction and Confirmatory Analyses}

\section{Including Versus Excluding Studies With Unspecified Nonsignificant Effect Size(s)}

On the basis of the recommendations of Rosenthal (1995), we performed analyses both including and excluding studies with nonsignificant effect size(s) coded as zero. Because the $Q(B)$ statistic (Hedges \& Olkin, 1985) indicated that there were no instances in which significant differences were found between the two data sets, in the interest of brevity we report

Table 3

Meta-Analyses of Reliability

\begin{tabular}{|c|c|c|c|c|c|c|c|}
\hline Type of judgment & $\begin{array}{l}\text { Type of } \\
\text { estimate }\end{array}$ & $r$ & $\begin{array}{c}95 \% \\
\mathrm{CI}\end{array}$ & $\underset{r}{M d n}$ & $\begin{array}{c}\text { Fail-safe } \\
\qquad N\end{array}$ & BESD & Heterogeneity $(p)$ \\
\hline \multicolumn{8}{|l|}{ Adult within-culture } \\
\hline$k=88(67$ studies $)$ & Effective & $.90^{*}$ & $.89 / .91$ & .91 & 36,608 & .90 & $1,304.32(<.001)$ \\
\hline$n=1,694$ & Mean & $.47 *$ & $.43 / .51$ & .67 & 9,240 & .47 & $782.95(<.001)$ \\
\hline \multicolumn{8}{|l|}{ Child within-culture } \\
\hline$k=28(20$ studies $)$ & Effective & $.85 *$ & $.83 / .86$ & .91 & 8,876 & .85 & $482.23(<.001)$ \\
\hline$n=1,182$ & Mean & $.21^{*}$ & $.16 / .26$ & .30 & 1,148 & .18 & $113.28(<.001)$ \\
\hline \multicolumn{8}{|l|}{ Adult cross-cultural } \\
\hline$k=17(9$ studies $)$ & Effective & $.94 *$ & $.93 / .95$ & .99 & 9,503 & .94 & $22,152.05(<.001)$ \\
\hline$n=12,146$ & Mean & $.71^{*}$ & $.70 / .72$ & .69 & 3,434 & .71 & $752.06(<.001)$ \\
\hline \multicolumn{8}{|l|}{ Adult cross-ethnic } \\
\hline$k=9(6$ studies $)$ & Effective & $.88^{*}$ & $.87 / .90$ & .99 & 3,411 & .88 & $617.13(<.001)$ \\
\hline$n=659$ & Mean & $.54 *$ & $.48 / .59$ & .74 & 1,134 & .54 & $238.00(<.001)$ \\
\hline
\end{tabular}

Note. $k=$ number of independent samples; $\mathrm{CI}=$ confidence interval; $\mathrm{BESD}=$ binomial effect-size display. ${ }^{*} p<.05$. 
the analyses excluding nonsignificant effect size(s) coded as zero. (For a list of those studies with nonsignificant effect sizes coded as zero, see Appendix J.)

\section{Fail-Safe Analyses}

Using the formula from Carson, Schriesheim, and Kinicki (1990), we conducted fail-safe analyses indicating that, on average, over 2,300 nonsignificant effect sizes must be added to each of our overall categories to change our results to indicate no differences between attractive and unattractive individuals. Thus, the inclusion of unpublished studies we did not locate would have been very unlikely to change the results we report.

\section{Heterogeneity}

Our analyses revealed heterogeneity, or high variability in effect sizes, for our overall categories and some subcategories. Whether heterogeneity of effect sizes is a problem or an asset depends on the goal of the meta-analysis. According to Glass (1978) and Rosenthal (1991), it is important to understand the nature of "fruit," as well as to examine the nature of "apples and oranges." We expected heterogeneity for our categories because we deliberately conceptualized them as broad constructs, or "fruit," generalizing to broad domains. Like other meta-analysts, we therefore chose to interpret comparisons between categories and subcategories, even if they were heterogeneous (Eagly et al., 1991; Feingold, 1992b). To reaffirm the robustness of the original analysis, we removed outliers to obtain homogeneity (Eagly et al., 1991; Hedges \& Olkin, 1985; B. T. Johnson, 1989). Most effect sizes remained the same or increased. In all cases, the mean $d s$ remained significant. On average, homogeneity was obtained following removal of only $18 \%$ of effect sizes, well within the guidelines and findings of others (Eagly et al., 1991; Hedges \& Olkin, 1985).

We also found heterogeneity for some categories of moderator variables. We report results for these moderator variables, but we caution the reader to note the heterogeneity statistics presented in the tables.

\section{Results and Discussion}

\section{Overview}

The meta-analyses showed that, both within and across cultures, people agreed about who is and is not attractive. Furthermore, attractiveness is an advantage in a variety of important, real-life situations. We found not a single gender difference and surprisingly few age differences, suggesting that attractiveness is as important for males as for females and for children as for adults. Other moderator variables had little consistent impact on effect sizes, although in some cases there were insufficient data to draw conclusions.

\section{Reliability of Attractiveness Ratings}

\section{Within-Culture Agreement}

The meta-analysis of effective reliability coefficients revealed that judges showed high and significant levels of agreement when evaluating the attractiveness of others. Overall, for adult raters, $r=$ .90 for ratings of adults and $r=.85$ for ratings of children, both $p s<.05$ (see Table 3 ).

Moderator variables were analyzed in a simultaneous weighted multiple regression analysis in which the unstandardized regression coefficients reveal the association of each moderator with the overall $r$ or $d$ while controlling for all the other moderators (Knight et al., 1996). The specific details of the moderator analyses are reported in Table 4 . There was a single significant moderator effect (sample size for adults) that did not account for much variance $(3.2 \%)$. Note that the mean reliabilities were lower than the effective reliabilities (see Table 3), but this is not surprising given that many studies reporting mean reliabilities used only two raters.

\section{Cross-Ethnic and Cross-Cultural Agreement}

For cross-ethnic agreement, the average effective reliability was $r=.88$. Cross-cultural agreement was even higher, $r=.94$. These reliabilities for both cross-ethnic and cross-cultural ratings of attractiveness were significant $(p<.05$ ), indicating meaningful and consistent agreement among raters (see Table 3 ). Once again, nothing surprising or consistent emerged from the moderator analyses (see Table 4).

These results indicate that beauty is not simply in the eye of the beholder. Rather, raters agreed about the attractiveness of both adults and children. Our findings for reliability of adult raters were consistent with Feingold (1992b), who meta-analyzed reliability

Table 4

Moderator Variable Analyses for Effective Reliability

\begin{tabular}{lcccc}
\hline \multicolumn{1}{c}{ Predictor } & $\begin{array}{c}\text { Aduit within-culture } \\
\text { unstandardized beta }\end{array}$ & $\begin{array}{c}\text { Child within-culture } \\
\text { unstandardized beta }\end{array}$ & $\begin{array}{c}\text { Adult cross-cultural } \\
\text { unstandardized beta }\end{array}$ & $\begin{array}{c}\text { Adult cross-ethnic } \\
\text { unstandardized beta }\end{array}$ \\
\hline Target gender & .061 & & 2.187 & -.489 \\
Method of rating & -.057 & & & \\
Year of publication & .102 & .067 & $.252^{* * * a}$ & .032 \\
Sample size & $.013^{* \mathrm{~b}}$ & -.007 & $.024 * * * \mathrm{~b}$ & .042 \\
$\quad$ Intercept & -198.25 & -128.61 & -496.62 & -62.67 \\
Overall $R^{2}$ & .088 & .124 & .981 & .561 \\
$Q_{\mathrm{R}}$ & 111.44 & 57.31 & $21,726.98^{* * * *}$ & 346.24 \\
$Q_{\mathrm{E}}$ & $1,153.86^{* * *}$ & $402.99 * * *$ & $425.18^{* * *}$ & $270.89^{* * *}$ \\
\hline
\end{tabular}

Note. Unstandardized beta weights are entered into the meta-analysis (Knight, Fabes, \& Higgins, 1996); $Q_{\mathrm{R}}=$ overall regression effect, $Q_{\mathrm{E}}=$ test of model specification.

${ }^{a}$ Recent $>$ older studies. ${ }^{\mathrm{b}}$ Larger $>$ smaller samples.

${ }^{*} p<.05$. ${ }^{* * *} p<.001$. 
coefficients from samples of U.S. and Canadian adults and obtained an average effective reliability of $r=83$. More importantly, our cross-cultural and cross-ethnic analyses showed that even diverse groups of raters readily agreed about who is and is not attractive. Both our cross-cultural and cross-ethnic agreement effect sizes are more than double the size necessary to be considered large (Cohen, 1988), suggesting a possibly universal standard by which attractiveness is judged. These analyses seriously question the common assumption that attractiveness ratings are culturally unique and merely represent media-induced standards. These findings are consistent with the fact that even young infants prefer the same faces as adults (Langlois, Ritter, Roggman, \& Vaughn, 1991; Langlois et al., 1987; Langlois, Roggman, \& Rieser-Danner, 1990).

\section{Judgment of Attractive and Unattractive People}

Both attractive children and adults were evaluated significantly more favorably than unattractive children and adults, even by familiar perceivers (see Table 5).

\section{Children}

The overall $d_{+}(1.11)$ and the BESD statistic showed that approximately $75 \%$ of attractive children, compared with only $25 \%$ of unattractive children, were judged to be above the mean for all categories combined. The subcategory analyses showed large effect sizes, especially in the domains of social appeal $\left(d_{+}=1.33 ; 78 \%\right.$ vs. $22 \%$ ) and academic/developmental competence ( $d_{+}=1.10 ; 74 \%$ vs. $26 \%$ ). Attractive children were also judged significantly more positively on the dimensions of adjustment $\left(d_{+}=.95 ; 72 \%\right.$ vs. $\left.28 \%\right)$ and interpersonal competence $\left(d_{+}=.92 ; 71 \%\right.$ vs. $\left.29 \%\right)$. No variable significantly moderated the findings (see Table 6).

\section{Adults}

Attractive adults were judged more positively than unattractive adults were (overall $d_{+}=.50 ; 62 \%$ vs. $38 \%$ ), particularly for occupational competence $\left(d_{+}=.90 ; 70 \%\right.$ vs. 30\%). Attractive adults were also judged as having more social appeal $\left(d_{+}=.49\right.$; $62 \%$ vs. $38 \%)$, as more interpersonally competent $\left(d_{+}=.45 ; 61 \%\right.$ vs. $39 \%)$, and as better adjusted $\left(d_{+}=.25 ; 56 \%\right.$ vs. $\left.44 \%\right)$ than unattractive adults.

The moderator analyses revealed a single significant influence of the coded variables on the effect sizes: Year of publication accounted for $10.7 \%$ of the variance. Studies published more recently produced larger effect sizes (see Table 6).

We expected that findings from the attribution literature might extend to more ecologically valid judgments of attractive and unattractive individuals and might indicate that attractiveness is more important for social judgments than for intellectual/academic judgments. We were surprised to find, however, that attractiveness was at least as important for judgments of academic (children) and occupational (adults) competence as it was for judgments in social domains, indicating that attractiveness is an important influence even in school (see Babad, Inbar, \& Rosenthal, 1982) and the workplace (see Hamermesh \& Biddle, 1994). Perhaps stranger-attribution research has underestimated the importance of attractiveness in the evaluation of intellectual and academic competence and success. It may be easier to conform to socially desirable maxims in experimental studies of attributions than to control automatic behavioral biases in the real world.

Overall, these results indicate that despite conventional teachings, people do indeed judge books by their covers even when they have behavioral or other information on which to base their judgments. The differences in the informed judgment about attractive and unattractive children were the strongest effect sizes we obtained and, compared with other effect sizes in the social sciences, were uncommonly large (none being

Table 5

Meta-Analyses of Judgment

\begin{tabular}{|c|c|c|c|c|c|c|c|c|}
\hline Judgment & $k$ & $n$ & $\underset{d}{M d n}$ & $d_{+}$ & $95 \% \mathrm{CI}$ & $\begin{array}{c}\text { Fail-safe } \\
\quad N\end{array}$ & BESD & $\begin{array}{l}\text { Heterogeneity } \\
\text { (p) }\end{array}$ \\
\hline About children ( 7 studies) & 13 & 1,668 & .75 & $1.11^{*}$ & $1.01 / 1.22$ & 1,430 & .49 & $74.24(<.001)$ \\
\hline $\begin{array}{l}\text { Academic/developmental } \\
\text { competence ( } 3 \text { studies) }\end{array}$ & 6 & 523 & .43 & $1.10^{*}$ & $.91 / 1.28$ & 654 & .48 & $34.98(<.001)$ \\
\hline Adjustment ( 3 studies) & 5 & 1,132 & 1.10 & $.95^{*}$ & $.82 / 1.07$ & 279 & .43 & $0.29(1.00)$ \\
\hline $\begin{array}{l}\text { Interpersonal competence } \\
\text { (3 studies) }\end{array}$ & 6 & 1,113 & .84 & $.92^{*}$ & $.80 / 1.05$ & 546 & .42 & $9.37(.15)$ \\
\hline Social appeal (3 studies) & 8 & 1,195 & .84 & $1.33^{*}$ & $1.20 / 1.46$ & 1,056 & .55 & $73.52(<.001)$ \\
\hline About adults (21 studies) & 30 & 1,880 & .59 & $.50^{*}$ & $.41 / .59$ & 1,470 & .24 & $66.49(<.001)$ \\
\hline Adjustment (6 studies) & 9 & 681 & .39 & $.25^{*}$ & $.10 / .40$ & 216 & .13 & $5.97(.74)$ \\
\hline $\begin{array}{l}\text { Interpersonal competence } \\
\text { (8 studies) }\end{array}$ & 9 & 559 & .55 & $.45^{*}$ & $.28 / .62$ & 396 & .22 & $12.49(.19)$ \\
\hline $\begin{array}{l}\text { Occupational competence } \\
\text { ( } 5 \text { studies })\end{array}$ & 7 & 246 & 1.05 & $.96^{*}$ & $.67 / 1.24$ & 665 & .41 & $9.96(.27)$ \\
\hline Social appeal (7 studies) & 11 & 777 & .66 & $.49 *$ & $.35 / .63$ & 528 & .24 & $31.06(.001)$ \\
\hline
\end{tabular}

Note. The sum of subcategory studies does not equal the total number of studies in the overall category because some studies contributed dependent variables to more than one subcategory. $k=$ number of independent samples; $d_{+}=$averaged weighted effect size; $\mathrm{CI}=$ confidence interval; $\mathrm{BESD}=$ binomial effect-size display $* p<.05$. 
Table 6

Moderator Variable Analyses for Differential Judgment, Treatment, and Behavior/Traits: Children and Adults

\begin{tabular}{|c|c|c|c|c|}
\hline Predictor & $\begin{array}{l}\text { Differential judgment } \\
\text { unstandardized beta }\end{array}$ & $\begin{array}{l}\text { Differential treatment } \\
\text { unstandardized beta }\end{array}$ & $\begin{array}{l}\text { Behavior/trait differences } \\
\text { unstandardized beta }\end{array}$ & $\begin{array}{l}\text { Self-perceived traits } \\
\text { unstandardized beta }\end{array}$ \\
\hline \multicolumn{5}{|l|}{ Children } \\
\hline Rater type & & & -.217 & \\
\hline Target gender & .175 & -.076 & .148 & \\
\hline Perceiver gender & & -.205 & & \\
\hline Type of measure & .724 & .124 & -.125 & \\
\hline Range of attractiveness & & -.401 & & \\
\hline Familiarity & & -.026 & & \\
\hline Year of publication & -.008 & .017 & -.006 & \\
\hline Sample size & .001 & .00003 & -.0002 & \\
\hline Age of target & .080 & $.068^{* \mathrm{a}}$ & -.015 & \\
\hline Age of perceiver & -.231 & & & \\
\hline Intercept & 14.38 & -32.59 & 11.95 & \\
\hline Overall $R^{2}$ & .683 & .748 & .210 & \\
\hline$Q_{\mathrm{R}}$ & 51.40 & $52.02 *$ & 41.45 & \\
\hline$Q_{\mathrm{E}}$ & $23.84 * *$ & 17.48 & $155.90 * * *$ & \\
\hline \multicolumn{5}{|l|}{ Adults } \\
\hline Rater type & -.236 & -.100 & -.057 & \\
\hline Target gender & .039 & .105 & .046 & \\
\hline Perceiver gender & -.632 & .054 & & -.15 \\
\hline Type of measure & -.236 & -.008 & $.544 * * * \mathrm{~b}$ & -.12 \\
\hline Range of attractiveness & -.314 & -.083 & & \\
\hline Familiarity & -.077 & .068 & & \\
\hline Year of publication & $.029^{* c}$ & .014 & .007 & -.01 \\
\hline Sample size & -.002 & -.064 & .00007 & .00002 \\
\hline Intercept & -55.13 & -27.28 & -15.21 & 22.83 \\
\hline Overall $R^{2}$ & .598 & .198 & .185 & .21 \\
\hline$Q_{\mathrm{R}}$ & $40.85^{*}$ & 25.13 & $247.09 * * *$ & 8.38 \\
\hline$Q_{\mathrm{E}}$ & 27.45 & $101.62 * * *$ & $1,088.52 * * *$ & $31.32 *$ \\
\hline
\end{tabular}

Note. Unstandardized beta weights are entered into the meta-analysis (Knight, Fabes, \& Higgins, 1996). $Q_{\mathrm{R}}=$ overall regression effect; $Q_{\mathrm{E}}=$ test of model specification.

a Older $>$ younger children. ${ }^{\mathrm{b}}$ Measures of facial $>$ general attractiveness. ${ }^{\mathrm{c}}$ Recent $>$ older studies.

${ }^{*} p<.05$. ${ }^{* *} p<.01 .{ }^{* * *} p<.001$.

smaller than $\left.d_{+}=.92\right)$. Although the effect sizes for informed opinions about adults were not as large as those for children, they were medium in size and among the larger effect sizes we obtained for adults.

\section{Treatment of Attractive and Unattractive People}

Results indicated that attractive children and adults were treated significantly more favorably than unattractive children and adults (see Table 7).

\section{Children}

For children (overall $d_{+}=.69^{7} ; 66 \%$ vs. $34 \%$ ), attractiveness had the largest effect on evaluations of competence $\left(d_{+}=.81\right.$; $69 \%$ vs. $31 \%$ ), followed by negative interaction $\left(d_{+}=-.64 ; 65 \%\right.$ vs. $35 \%)$ and positive interaction $\left(d_{+}=.52 ; 62 \%\right.$ vs. $\left.38 \%\right)$. A smaller yet still significant effect of attractiveness was found for the subcategory of attention/caregiving ( $d_{+}=.29 ; 57 \%$ vs. $43 \%$ ). Target age, accounting for $12.3 \%$ of the variance, was a significant moderator variable. Studies with older targets produced larger effect sizes (see Table 6).
Adults

Attractive adults were also treated significantly more favorably than unattractive adults were (overall $d_{+}=.54 ; 63 \%$ vs. $37 \%$ ). Attractiveness had the largest effect on attention $\left(d_{+}=1.09 ; 74 \%\right.$ vs. $26 \%$ ), followed by reward $\left(d_{+}=.68 ; 66 \%\right.$ vs. $34 \%$ ), positive interaction ( $d_{+}=.57 ; 64 \%$ vs. $36 \%$ ), positive impression management $\left(d_{+}=.53 ; 63 \%\right.$ vs. $\left.37 \%\right)$, negative interaction $\left(d_{+}=\right.$ $-.54,63 \%$ vs. $37 \%$ ), and help-giving/cooperation $\left(d_{+}=.36 ; 59 \%\right.$ vs. $41 \%$ ). No moderator variables were significant.

Surprisingly, in addition to being judged differently as a function of their attractiveness, attractive individuals on average were treated significantly better than unattractive individuals. These findings are powerful evidence that, contrary to popular belief attractiveness effects extend beyond mere "opinions" of others and permeate actual actions towards others, even though people may not be aware of it.

\footnotetext{
${ }^{7}$ The overall effect size for differential treatment was .69 , including teacher evaluations/grades. Without teacher evaluations/grades, $d_{+}=.41$ No moderator variables were significant when teacher evaluations/grades were excluded from the analysis.
} 
Table 7

Meta-Analyses of Treatment

\begin{tabular}{|c|c|c|c|c|c|c|c|c|}
\hline Treatment & $k$ & $n$ & $\begin{array}{c}M d n \\
d\end{array}$ & $d_{+}$ & $95 \% \mathrm{CI}$ & $\begin{array}{l}\text { Fail-safe } \\
\quad N\end{array}$ & BESD & $\begin{array}{l}\text { Homogeneity } \\
(p)\end{array}$ \\
\hline Of children ( 18 studies) & 26 & 2,685 & .58 & $.69 *$ & $.61 / .77$ & 1,768 & .33 & $85.74(.00)$ \\
\hline $\begin{array}{l}\text { Attention and caregiving } \\
\text { ( } 6 \text { studies) }\end{array}$ & 7 & 403 & .36 & $.29 *$ & $.09 / .48$ & 196 & .14 & $14.22(.05)$ \\
\hline $\begin{array}{l}\text { Designations of academic } \\
\text { ability ( } 7 \text { studies) }\end{array}$ & 8 & 1,900 & .63 & $.81 *$ & $.72 / .91$ & 640 & .38 & $34.68(.00)$ \\
\hline $\begin{array}{l}\text { Negative interaction } \\
\text { (4 studies) }\end{array}$ & 6 & 209 & -.76 & $-.64^{*}$ & $-.93 /-.36$ & 378 & .31 & $8.45(.21)$ \\
\hline $\begin{array}{l}\text { Positive interaction } \\
\text { (5 studies) }\end{array}$ & 7 & 246 & .42 & $.52 *$ & $.26 / .77$ & 357 & .25 & $4.88(.67)$ \\
\hline Of Adults ( 31 studies) & 39 & 3,315 & .66 & $.54 *$ & $.47 / .61$ & 2,067 & .26 & $148.81(.001)$ \\
\hline Attention ( 5 studies) & 8 & 291 & .90 & $1.09 *$ & $.83 / 1.36$ & 864 & .48 & $80.24(.001)$ \\
\hline $\begin{array}{l}\text { Help-giving \& cooperation } \\
\text { (5 studies) }\end{array}$ & 6 & 842 & .66 & $.36^{*}$ & $.22 / .49$ & 210 & .18 & $15.83(.01)$ \\
\hline $\begin{array}{l}\text { Negative interaction } \\
\text { (6 studies) }\end{array}$ & 6 & 451 & -.72 & $-.54^{*}$ & $-.73 /-.35$ & 318 & .26 & $7.26(.30)$ \\
\hline $\begin{array}{l}\text { Positive impression } \\
\text { management ( } 6 \text { studies) }\end{array}$ & 7 & 952 & .62 & $.53^{*}$ & $.40 / .66$ & 364 & .25 & $3.81(.80)$ \\
\hline $\begin{array}{l}\text { Positive interaction } \\
\text { (6 studies) }\end{array}$ & 9 & 446 & .53 & $.57^{*}$ & $.38 / .76$ & 504 & .27 & $15.03(.06)$ \\
\hline Reward (4 studies) & 4 & 393 & .66 & $.68 *$ & .471 .88 & 268 & .32 & $1.36(.85)$ \\
\hline
\end{tabular}

Note. The sum of subcategory studies does not equal the total number of studies in the overall category because some studies contributed dependent variables to more than one subcategory. $k=$ number of independent samples; $d_{+}=$averaged weighted effect size; $\mathrm{CI}=$ confidence interval; BESD $=$ binomial effect-size display. $* p<.05$.

\section{Do Attractive and Unattractive Individuals Behave Differently?-Behavior/Traits}

\section{Children}

Attractive children behaved more positively and possessed more positive traits than unattractive children (overall $d_{+}=.40^{8} ; 60 \%$ vs. $40 \%$ ). Compared with unattractive children, attractive children were more popular $\left(d_{+}=.77 ; 68 \%\right.$ vs. $32 \%$ ), better adjusted $\left(d_{+}=.32 ; 58 \%\right.$ vs. $\left.42 \%\right)$, and display greater intelligence/performance competence $\left(d_{+}=.39^{9} ; 60 \%\right.$ vs. $40 \%$; see Table 8 ). No moderator variables were significant (see Table 6).

\section{Adults}

Results for adults paralleled those for children (overall $d_{+}=$ $.40 ; 60 \%$ vs. $40 \%$ ). Compared with unattractive adults, attractive adults experienced much more occupational success $\left(d_{+}=.76\right.$; $68 \%$ vs. $32 \%$ ), were liked more as indicated by the subcategory of popularity $\left(d_{+}=.65 ; 65 \%\right.$ vs. $35 \%$ ), and had more dating experience $\left(d_{+}=.55 ; 63 \%\right.$ vs. $\left.37 \%\right)$, more sexual experience $\left(d_{+}=\right.$ $.31 ; 58 \%$ vs. $42 \%)$, and better physical health $\left(d_{+}=.39 ; 59 \%\right.$ vs. $41 \%$ ). In addition, attractive adults were somewhat more extraverted $\left(d_{+}=.26 ; 56 \%\right.$ vs. $44 \%$ ), had somewhat more traditional attitudes $\left(d_{+}=.27 ; 57 \%\right.$ vs. $\left.43 \%\right)$, were somewhat higher in self-confidence/self-esteem $\left(d_{+}=.24 ; 56 \%\right.$ vs. $\left.44 \%\right)$, possessed somewhat better social skills $\left(d_{+}=.20 ; 55 \%\right.$ vs. $\left.45 \%\right)$, had slightly better mental health $\left(d_{+}=.16 ; 54 \%\right.$ vs. $\left.46 \%\right)$, and were very slightly more intelligent $\left(d_{+}=.07 ; 52 \%\right.$ vs. $48 \%$; see Table 8).
One moderator accounted for a significant portion of the variance in the overall effect size. Type of attractiveness measure accounted for $14.6 \%$ of the variance; studies using measures of attractiveness that included the face plus additional cues had higher effect sizes than studies using measures of facial attractiveness only (see Table 6).

\section{Self-Perceptions}

Attractive adults exhibited somewhat more favorable selfperceptions than unattractive adults did (overall $d_{+}=.26 ; 56 \%$ vs. $44 \%$ ). Attractive adults perceived themselves as more competent $\left(d_{+}=.25 ; 56 \%\right.$ vs. $\left.44 \%\right)$ and more mentally healthy $\left(d_{+}=.31\right.$; $58 \%$ vs. $42 \%$ ) than unattractive adults (see Table 9 ). No moderator variable accounted for a significant portion of the variance. We were unable to meta-analyze self-perceptions for children because only one study was retrieved (Lerner et al., 1990). Lerner et al. (1990) found a small relation ( $r=.07$ ) between self-rated scholastic competence and attractiveness for sixth graders (see Table 9).

\section{Summary}

In conclusion, we found substantial behavioral and trait differences as a function of attractiveness. For both adults and children,

\footnotetext{
${ }^{8}$ With evaluations of competence included in the analysis, $d_{+}=.48$ for overall behavioral differences. See Note 4 .

${ }^{9}$ With evaluations of competence included in the analysis, $d_{+}=.55$ for intelligence/performance competence. See Note 4.
} 
Table 8

Meta-Analyses of Behavior/Traits

\begin{tabular}{|c|c|c|c|c|c|c|c|c|}
\hline Behavioral differences & $k$ & $n$ & $\underset{d}{M d n}$ & $d_{+}$ & $\begin{array}{c}95 \% \\
\mathrm{CI}\end{array}$ & $\begin{array}{c}\text { Fail-safe } \\
\quad N\end{array}$ & BESD & $\begin{array}{l}\text { Homogeneity } \\
(p)\end{array}$ \\
\hline hild (33 studies) & 55 & 7,384 & .47 & $.40^{*}$ & $.35 / .44$ & 2,145 & .19 & $197.52(.001)$ \\
\hline Adjustment (15 studies) & 21 & 3,876 & .27 & $.32 *$ & $.25 / .38$ & 651 & .16 & $41.37(.001)$ \\
\hline Intelligence \& performance ( 10 studies) & 14 & 3,043 & .32 & $.39 *$ & $.32 / .47$ & 532 & .19 & $41.13(.01)$ \\
\hline Popularity (15 studies) & 30 & 1,002 & .77 & $.77 *$ & $.64 / .90$ & 2,280 & .36 & $99.14(.001)$ \\
\hline Adult (79 studies) & 132 & 13,920 & .38 & $.40^{*}$ & $.37 / .44$ & 5,148 & .20 & $1,319.96(.001)$ \\
\hline Dating experienc & 18 & 1,631 & .59 & $.55^{*}$ & $.45 / .65$ & 972 & .26 & $37.78(.004)$ \\
\hline Sexual e & 11 & 1,678 & .36 & $.31 *$ & $.21 / .41$ & 330 & .15 & $19.68(.05)$ \\
\hline Extraversion ( 9 studies) & 15 & 527 & .51 & $.26 *$ & $.08 / .43$ & 375 & .13 & $59.00(.001)$ \\
\hline Intelligence (18 studies) & 30 & 3,853 & .13 & $.07^{*}$ & $.01 / .14$ & 180 & .04 & $84.54(.001)$ \\
\hline Occupational success (4 studies) & 8 & 3,188 & .52 & $.76 *$ & $.68 / .84$ & 600 & .35 & $708.35(.001)$ \\
\hline Mental health (19 studies) & 30 & 3,311 & .31 & $.16 *$ & $.09 / .23$ & 450 & .08 & $94.09(.001)$ \\
\hline Physi & 9 & 705 & .43 & $.38 *$ & $.24 / .53$ & 34 & .19 & $11.09(.27)$ \\
\hline Popu & 27 & 2,983 & .62 & $.65^{*}$ & $.57 / .72$ & 1,728 & .31 & $165.64(.00)$ \\
\hline Self & 26 & 1,747 & .24 & $.24 *$ & $.15 / .34$ & 598 & .12 & $57.91(.002)$ \\
\hline s (18 studies) & 20 & 1,432 & .36 & $.20 *$ & $.10 / .31$ & 380 & .10 & $56.29(.002)$ \\
\hline Traditional attitudes (4 studies) & 7 & 494 & .24 & $.27 *$ & $.09 / .45$ & 182 & .13 & $6.51(.48)$ \\
\hline
\end{tabular}

Note. The sum of subcategory studies does not equal the number of studies in the overall category because some studies contributed dependent variables to more than one subcategory. $k=$ number of independent samples; $d_{+}=$averaged weighted effect size; $\mathrm{CI}=$ confidence interval; $\mathrm{BESD}=$ binomial effect-size display. $* p<.05$.

attractiveness is strongly related to popularity, and to success for adults. Attractiveness is moderately related to both intelligence/ performance and adjustment in children and to both dating and sexual experience in adults. Interestingly, for children, our findings for intelligence/performance $\left(d_{+}=.39\right)$ corresponded closely with L. A. Jackson et al. (1995), who found an effect size of $d=.41$ for children. Likewise, our near-zero finding for the relation between intelligence and attractiveness in adults is consistent with Feingold (1992b).

Unlike the overall results for behavior/traits, the effect sizes for self-perceptions were relatively small. The significantly smaller overall effect size for self-perceptions relative to behavior/traits suggests that unstandardized self-reports are not accurate predictors of actual behaviors and traits or that selfviews are less susceptible to differential judgment and treatment than are behaviors. The latter interpretation, if true, suggests that social theory may be incorrect in its prediction that differential treatment, judgment, and behavior eventually become internalized. Alternatively, it may be that the constructs assessed by current self-perception measures are not as psychometrically sound as they might be.

\section{Additional Moderator Variables}

\section{Familiarity}

To determine whether attractiveness was more important in situations in which participants were less rather than more familiar with each other, we evaluated the role of familiarity as a moderator variable of particular interest. Familiarity was coded from 1 (brief interaction) to 3 (extensive interaction including relationships such as teacher-child and parent-child) and entered into the regression analyses for judgment and treatment. In no case was familiarity significant, suggesting the surprising conclusion that the effects of attractiveness are as strong when agents and targets know each other well as when they do not.

\section{Gender and Age Effects}

When controlling for all variables simultaneously, we found not a single significant gender effect. The overall lack of gender differences in ecologically valid situations suggests that, in most domains, attractiveness is equally important for men and women. These findings are consistent with the lack of gender differences

Table 9

Meta-Analyses of Adult Self-Perceptions

\begin{tabular}{lccccccccc}
\hline \multicolumn{1}{c}{ Adult self-perceptions } & $k$ & $n$ & $d$ & $d_{+}$ & $\begin{array}{c}95 \% \\
\text { CI }\end{array}$ & $\begin{array}{c}\text { Fail-safe } \\
N\end{array}$ & BESD & $\begin{array}{c}\text { Homogeneity } \\
(p)\end{array}$ \\
\hline Self-perceived traits (16 studies) & 23 & 5,779 & .38 & $.26^{*}$ & $.21 / 32$ & 598 & .13 & $38.53(.02)$ \\
Competence (10 studies) & 12 & 4,874 & .41 & $.25^{*}$ & $.19 / .30$ & 476 & .12 & $36.53(.01)$ \\
Mental health (9 studies) & 14 & 4,691 & .28 & $.31^{*}$ & $.26 / .37$ & 420 & .15 & $11.72(.63)$ \\
\hline
\end{tabular}

Note. The sum of subcategory studies does not equal the number of studies in the overall category because some studies contributed dependent variables to more than one subcategory. $k=$ number of independent samples; $d_{+}=$average weighted effect size; $\mathrm{CI}=$ confidence interval; BESD $=$ binomial effect-size display $* p<.05$. 
found in other meta-analyses of stranger attribution research (Eagly et al., 1991; Feingold, 1992b).

To evaluate developmental differences in attractiveness effects, we merged the overall category files for adults and children for reliability of attractiveness ratings, judgment, treatment, and behavior/traits. We then conducted multiple regression analyses as previously described (see Table 10). No age differences were obtained. Because most of the studies available for review in this meta-analysis examined children ages 6 and older, the lack of developmental differences could be explained by the omission of very young children in the reported literature. However, at this point, we conclude that attractiveness is as important, if not more so, for children as for adults.

\section{General Discussion}

The effects of facial attractiveness are robust and pandemic, extending beyond initial impressions of strangers to actual interactions with those whom people know and observe. Contrary to conventional wisdom, there is strong agreement both within and across cultures about who is and who is not attractive. Furthermore, attractiveness is a significant advantage for both children and adults in almost every domain of judgment, treatment, and behavior we examined. The magnitude of attractiveness effects is roughly the same as or larger than that of other important variables in the social sciences (Eagly, 1995). In most cases, the benefits of attractiveness are large enough to be "visible to the naked eye" (Cohen, 1988) and are of considerable practical significance (Lipsey \& Wilson, 1993; Rosenthal, 1991, 1995). These meta-analyses starkly illuminate the fundamental contradiction between empirical research and maxims about beauty. On the basis of our results, we conclude that the maxims we examined are myths, not reality: Beauty is more than just in the eye of the beholder; people do judge and treat others with whom they interact based on attractiveness; and, perhaps most surprisingly, beauty is more than just skin-deep.

\section{Theoretical Mechanisms}

One of our goals was to illuminate mechanisms explaining how and why attractiveness influences judgment, treatment, and behavior. Several predictions about how attractiveness functions in these different domains were derived from socialization/social expectancy theories and from fitness-related evolutionary theories.

\section{Socialization and Social Expectancy Theories}

Recall the assumptions underlying socialization and social expectancy theories set forth in the introduction. First, for appearance to have any consistent impact on differential judgment or treatment, individuals must agree about who is and is not attractive. As we have seen, there is remarkable similarity in attractiveness ratings. Indeed, we found substantial agreement about who is and is not attractive both within and across cultures. The finding of high cross-cultural agreement in attractiveness judgments, however, is not consistent with socialization and social expectancy theories because they emphasize cultural differences in perceptions of attractiveness.

Second, attractiveness must consistently elicit differential expectations from others. According to the theories, these expectations are acted on by perceivers in the form of differential judgment and treatment toward attractive and unattractive targets. Our results extend the findings from the stranger-attribution literature to the informed judgments of others based not on photographs alone but on actual interactions. Perceivers judged attractive targets more favorably than unattractive targets even when they knew them. Furthermore, these results show that perceivers treated even familiar children and adults differently based on attractiveness (see, e.g., Langlois et al., 1995).

Attractive and unattractive targets should then develop differential behaviors and traits as a result of differential evaluation and treatment. Behavioral and trait differences clearly exist between attractive and unattractive people, supporting this aspect of the

Table 10

Moderator Variable Analyses for Age Comparisons

\begin{tabular}{lccc}
\hline \multicolumn{1}{c}{ Predictor } & $\begin{array}{c}\text { Differential judgment } \\
\text { unstundardized beta }\end{array}$ & $\begin{array}{c}\text { Differential treatment } \\
\text { unstandardized beta }\end{array}$ & $\begin{array}{c}\text { Behavior/trait differences } \\
\text { unstandardized beta }\end{array}$ \\
\hline Rater type & -.088 & .177 & -.037 \\
Target gender & -.008 & .006 & -.032 \\
Treater gender & .193 & .032 & $-.372^{* * * a}$ \\
Physical attractiveness measure & & -.235 & \\
Physical attractiveness range & -.040 & -.058 & .003 \\
Familiarity & .019 & -.071 & -.005 \\
Year of publication & -.012 & .016 & -.0001 \\
Age & .00006 & .002 & -5.62 \\
Sample size & -35.77 & .00001 & .151 \\
$\quad$ Intercept & .335 & -31.85 & $231.20^{* * *}$ \\
Overall $R^{2}$ & 73.36 & .278 & $1,303.32^{* * *}$ \\
$Q_{\mathrm{R}}$ & $145.55^{* * *}$ & 57.91 & $150.32^{* * *}$ \\
$Q_{\mathrm{E}}$ & & &
\end{tabular}

Note. Unstandardized beta weights are entered into the meta-analysis (Knight, Fabes, \& Higgins, 1996). $Q_{\mathrm{R}}=$ overall regression effect; $Q_{\mathrm{E}}=$ test of model specification.

${ }^{a}$ Measures of general $>$ facial attractiveness.

$* * * p<.001$. 
theories. However, we could not examine the presumed causal link between treatment and behavior because only two studies examined the contemporaneous connections between treatment and behavior (S. M. Anderson \& Bem, 1981; Snyder et al., 1977). Furthermore, we found no studies longitudinally investigating the links among judgment, treatment, and behavior to determine antecedents and consequents. It is important for future research to take on the task of properly evaluating this perspective.

As the last step in the social model, targets should internalize the treatment they receive and develop different self-views. We found only weak support for the assertion that attractive and unattractive adults have different self-views: Attractive adults had more positive self-views than unattractive adults did, although the effect sizes are not large. Furthermore, we could not evaluate whether differential treatment causes different self-views because of the lack of such studies in the primary literature.

Although all of these assumptions must be documented for social theory to account for attractiveness effects, certain patterns of age and gender differences would provide additional support for the theory. Contrary to the predictions of the theory, however, our results showed that for judgment, treatment, and behavior/traits, attractiveness is just as important for children as for adults and for males as for females. Perhaps behavioral differences do increase with age but could not be detected in the research we retrieved, which primarily examined only children ages 6 and older. A similar explanation also may be pertinent for the lack of age differences in judgment and treatment. Thus, the lack of research with very young children seriously hampers either a strong endorsement or indictment of a social account.

\section{Socialization and Social Expectancy Theories: Evaluation and Future Directions}

On the basis of our overall effect sizes for reliability, judgment, treatment, and behavior/traits, we conclude that social theory is a plausible but largely unproven explanation of attractiveness effects (see Table 11). The theory accurately predicted within-culture agreement in evaluations of attractiveness but missed the mark in asserting the importance of cultural influences for judgments of attractiveness across cultures. We also observed a significant deficiency in the extant research evaluating social theory: the lack of research linking expectations to judgments, judgments to treatment, and treatment to behavioral outcomes. For the social account to be convincing, the components (judgment, treatment, and behavior) must be causally related to one another. Neither this meta-analysis nor primary research has shown causality; rather, we have shown that attractiveness is correlated independently with each of the components. When enough studies of relations among the components are available, future meta-analysts could model plausible causal pathways (see, e.g., Shadish, 1996). At a minimum, however, failure to find correlations among judgment, treatment, and behavior as a function of attractiveness could clearly rule out social theory as a plausible explanation.

Three types of future studies are necessary to establish a causal link among the components of social theory: studies using conceptually similar variables, studies that are longitudinal, and studies of very young children. First, studies of judgment, treatment, and behavior must assess variables that bear some conceptual relation to each other for each domain. Because the literature is currently fractionated into studies of impressions, studies of judgments, studies of treatment, and studies of target behavior, little attempt has been made to define variables conceptually and to measure them simultaneously across the different domains. Second, future research should conduct longitudinal studies to determine which components, if any, are antecedent. Attractive and unattractive children may behave differently at birth as a result of biologically based characteristics correlated with attractiveness (see, e.g., Field \& Vega-Lahr, 1984; Gangestad, Thornhill, \& Yeo, 1994; Halverson \& Victor, 1976; Waldrop \& Halverson, 1971). Perceivers may detect these differences accurately and, as a result, judge and treat attractive and unattractive individuals differently. In contrast, social theory makes a clear, falsifiable prediction about the order of emergence and the causal relations among judgment, treatment, and behavior: Differential judgment and treatment cause the development of different behaviors and, thus, must precede the emergence of behavioral differences. Longitudinal research would allow a clear demonstration of whether behavioral differences as a function of attractiveness precede, coincide with, or follow differential judgment and treatment. Thus, it is essential to conduct research on very young children to disentangle these hypotheses. We retrieved only four studies of behavioral differences as a function of attractiveness in children younger than age 6 . If such research finds that behavioral differences precede differential judgment and treatment, social theory could be eliminated as the sole theoretical account of attractiveness effects, although certainly subsequent differential judgment and treatment could augment the display of different behaviors and traits.

Another deficiency we observed is the divorce between social theory and the data concerning gender differences. We did not find the expected gender differences in the importance of attractiveness, although perhaps we could not detect them because much extant research examined only a single gender or did not distinguish between males and females in the data analysis. Future research must report differences in the effects of attractiveness for males and females separately before social theory can be conclusively evaluated.

\section{Fitness-Related Evolutionary Theories}

Fitness-related evolutionary theories (good genes, human mate selection, differential parental solicitude) all agree that because morphological characteristics such as facial attractiveness are honest indicators of fitness, health, quality, and reproductive value, attractiveness should be important in human interactions (Barber, 1995; Buss \& Schmitt, 1993; Daly \& Wilson, 1995; Symons, 1979; Thornhill \& Gangestad, 1993). All three models agree that perceivers should consistently detect and recognize attractiveness, both within and across cultures, because humans have evolved universal standards of facial attractiveness based on clues to health and reproductive fitness. Furthermore, as an evolved trait, agreement about attractiveness should be evident within as well as between cultures. As we have shown with reliability, this criterion has been met, and all three fitness-related theories have proven to be more predictively accurate than social theory in this regard.

Mate selection. Mate-selection theory makes clear predictions about the importance of attractiveness. The theory focuses many of its predictions on gender differences in the importance of attractiveness because the theory is concerned primarily with the devel- 
Table 11

Correspondence Between Hypotheses and Results

\begin{tabular}{|c|c|}
\hline Hypothesis & Prediction \\
\hline \multicolumn{2}{|l|}{ Social theory } \\
\hline 1. Within-culture agreement (high reliability) & Supported \\
\hline 2. Between-culture agreement (low reliability) & Not supported \\
\hline 3. Agreement higher for female than male faces & Not supported \\
\hline 4. Agreement higher for older than younger judges & Not supported \\
\hline 5. Differential judgment & Supported \\
\hline 6. Differential treatment & Supported \\
\hline 7. Differential behavior & Supported \\
\hline 8. Differential self-views & Partially supported \\
\hline 9. Attractiveness more important for females than males & Not supported \\
\hline 10. Differential judgment and treatment important during childhood & Supported \\
\hline 11. Behavioral differences cumulate and increase over time & Insufficient primary research to evaluate \\
\hline \multirow{2}{*}{\multicolumn{2}{|c|}{ Mate-selection theory }} \\
\hline & \\
\hline 1. Within-culture agreement (reliability) about attractiveness & Supported \\
\hline 2. Between-culture agreement (reliability) about attractiveness & Supported \\
\hline 3. Agreement higher for female than male faces & Not supported \\
\hline 4. Agreement higher for older than younger judges & Not supported \\
\hline 5. Differential judgment & Supported \\
\hline 6. Differential treatment & Supported \\
\hline 7. Differential behavior & Supported \\
\hline 8. Attractiveness more important for females than males & Not supported \\
\hline $\begin{array}{l}\text { 9. Adult-centered theory: attractiveness either not important for } \\
\text { children or ignored for children }\end{array}$ & Not supported \\
\hline 10. Judgment and treatment caused by target behavior & Insufficient primary research to evaluate \\
\hline \multicolumn{2}{|l|}{ Good-genes theory } \\
\hline 1. Within-culture agreement & Supported \\
\hline 2. Between-culture agreement & Supported \\
\hline 3. Similar (high) level of agreement for male and female faces & Supported \\
\hline 4. Similar (high) level of agreement for older and younger judges & Supported \\
\hline 5. Differential judgment & Supported \\
\hline 6. Differential treatment & Supported \\
\hline 7. Differential behavior & Supported \\
\hline $\begin{array}{l}\text { 8. Attractiveness more strongly related to status and fitness than } \\
\text { to other types of characteristics }\end{array}$ & Not supported \\
\hline 9. Attractiveness equally important for both sexes & Supported \\
\hline 10. Behavioral differences evident early & Partially supported: behavior differences present during childhood \\
\hline 11. Judgment and treatment caused by target behavior & Insufficient primary research to evaluate \\
\hline \multicolumn{2}{|l|}{ Differential parental solicitude theory } \\
\hline 1. Within-culture agreement & Supported \\
\hline 2. Between-culture agreement & Supported \\
\hline 3. Similar (high) level of agreement for male and female faces & Supported \\
\hline 4. Differential judgment & Supported \\
\hline 5. Differential treatment & Supported \\
\hline 6. Differential behavior & Supported \\
\hline 7. Attractiveness equally important for both sexes & Supported \\
\hline 8. Behavioral differences evident early & Partially supported: behavior differences present during childhood \\
\hline 9. Judgment and treatment caused by target behavior & Insufficient primary research to evaluate \\
\hline
\end{tabular}

opment of traits desired by each gender. The theory predicts that higher reliability should be obtained for female rather than male attractiveness because attractiveness is especially important as an indicator of reproductive fitness in women (L. A. Jackson, 1992). However, this is not what the data show. Instead, we found a surprising lack of gender differences in the four different metaanalyses of the reliability of attractiveness judgments.

Second, because men prefer and seek attractive women, by extension, men should also judge and treat them more positively (G. F. Miller, 1998). Women should favor men with resources more than they favor attractive men. Thus, attractiveness should be more important in how men judge and treat women than in how women judge and treat men (Buss \& Barnes, 1986; Buss \& Schmitt, 1993; L. A. Jackson, 1992). Our findings did not support these predictions for either judgment or treatment. We found no gender differences in the importance of attractiveness, contrary to the predictions of mate-selection theory but consistent with the findings of Eagly et al. (1991) in their meta-analysis of the stranger-attribution literature. We note, however, that for treatment, there were few studies in which men and women were directly compared or in which same-sex treatment was examined. Thus, this hypothesis has not yet received sufficient attention from primary research. Most of the extant primary research that supports mate-selection theory is almost entirely based on paper-and-pencil 
questionnaires of preferences-behavioral research must be conducted before the importance of gender differences can be either substantiated or refuted.

In contrast to the gender difference predictions for reliability, judgment, and treatment, mate-selection theory predicts an absence of gender differences in behavior/traits. Rather, it predicts that initially unrelated traits coevolve because of assortative mating (Buss, 1985). Our results show that attractiveness was generally related to status variables: Attractive individuals were more successful, had better social skills, and were more mentally healthy. Furthermore, we did not find any significant gender differences, consistent with the prediction.

Finally, mate-selection models ignore children, but we found large effects of attractiveness on the judgment, treatment, and behavior of children. Either some other mechanism must account for these findings or the theory needs revision to include an account of how and why it is relevant to children.

Good genes. Good-genes theory predicts differential judgment and treatment as a function of attractiveness, either as a response to preexisting differential behaviors and traits of attractive and unattractive people or because humans have evolved to prefer attractive people for their good health. In either case, humans should judge and treat attractive people more favorably than unattractive people. Our overall findings support this prediction.

Furthermore, because attractiveness accurately advertises health, quality, and heterozygosity, attractiveness should be more strongly associated with some target behaviors and traits than others. For example, attractiveness should signal health, intelligence, and other measures of competence, but it should not be correlated with characteristics such as traditional attitudes because such characteristics have no obvious link to survival. For adults, there is mixed support for this prediction. Because they were fairly large, the effect sizes for subcategories of behavior/traits such as occupational success, physical health, popularity, dating experience, and sexual experience support the prediction. However, the relatively small effect sizes for mental health and social skills provide little support for the theory. Furthermore, attractiveness was as highly related to traditional attitudes as to many of the indexes of status, undermining the discriminative utility of the theory.

Behavioral differences as a function of attractiveness should also be expressed very early in life because good health presumably is as important for young children as for adults. For children, attractiveness is strongly associated with popularity and moderately associated with intelligence and adjustment, consistent with good-genes theory. The age at which behavioral differences as a function of attractiveness become evident, however, is not clear because most of the extant research fails to investigate attractiveness effects in very young children.

Finally, because good health is critical to survival, attractiveness should be equally relevant and important to both genders (Thiessen, 1996; Thornhill \& Gangestad, 1993). Consistent with this prediction, we found no gender differences in the importance of attractiveness for either adults or children.

Differential parental solicitude. Differential parental solicitude theory claims that, to enhance their own reproductive success, parents invest differently in children depending on each child's fitness, quality, and reproductive potential (Daly, 1990; Daly \& Wilson, 1988, 1995). By extension, if attractiveness is an indicator of quality, parents and other adults should invest more in attractive than unattractive children (Barden et al., 1989; Buss, 1999; Field \& Vega-Lahr, 1984; Langlois et al., 1995). Thus, attractiveness should be very important for children, perhaps more important for children than for adults. Our highly significant effect sizes for children generally support this prediction.

Finally, because the theory assumes that attractiveness is an equally valid indicator of health and quality in boys and girls, no gender differences would be expected in how boys and girls are judged and treated as a function of attractiveness (Daly \& Wilson, 1995). This prediction is consistent with the lack of gender differences we obtained.

\section{Fitness-Related Evolutionary Theories: Evaluation and Future Directions}

Table 11 summarizes how well the aggregated data fit with predictions made by the various evolutionary perspectives. Not surprisingly, no single evolutionary theory provides a complete account of the obtained attractiveness effects. Rather, depending on the domain and situation, a combination of all three theories can provide a plausible explanation of our findings. Good-genes theory predicts and can reasonably explain our finding that attractiveness is equally important for males and females. The theory also predicts, and we found, health differences between attractive and unattractive targets. Differential parental solicitude theory predicts and can account for our finding that attractiveness is of considerable importance for children. Likewise, mate-selection theory is partially supported, although some important predictions about gender differences are not supported and the theory ignores children. Thus, although evolutionary mechanisms may have the potential to satisfactorily explain attractiveness effects, an important step for evolutionary theory is the creation and empirical testing of a model that more clearly specifies the exact situations and developmental trajectories of these various mechanisms. For example, is mate selection a modular mechanism that operates only when human beings are consciously seeking a mate, or is it a more general, constantly functioning mechanism that colors all human interactions? Does mate selection work in conjunction or competition with differential parental solicitude or good genes? These are only a few of the questions that remain to be addressed and empirically tested before a comprehensive and precise theory of evolution-driven attractiveness effects can be derived. Mathematical modeling specifically designed to assess the simultaneous impact of different evolutionary mechanisms (see, e.g., Kirkpatrick, 1996) may help answer these questions.

As mentioned earlier, these fitness-related evolutionary theories were not specifically designed to address the impact of attractiveness, except perhaps for mate-selection theory. Because our metaanalytic findings show that these theories are plausible explanations of attractiveness effects, it is time for a more constrained theory specific to attractiveness effects to be developed. Our findings suggest that a hybrid evolutionary account can plausibly explain a number of attractiveness effects. However, as with social theory, important pieces are missing from this hybrid evolutionary account. Because evolutionary theory specifies a causal relation between behavior, judgment, and treatment, the same deficiency in the research base that we noted above also applies here. Similarly, research investigating attractiveness effects in very young children 
is required. Finally, although our meta-analysis revealed a link between health and physical attractiveness, this finding was based on relatively few effect sizes and some questionable measures of health (e.g., blood pressure, which could be a result of unattractiveness because, as we have seen, unattractive people are judged and treated differently than attractive people). Additional research in this area is especially warranted given the central importance of health in fitness-related evolutionary theories.

\section{Limitations}

The strengths and weaknesses of these conclusions reflect the strength and weaknesses of the research we reviewed and of meta-analytic techniques in general (H. Cooper \& Hedges, 1994; Matt \& Cook, 1994). Much of the extant research on attractiveness is atheoretical and not conceptually driven. We hope that this review will stimulate primary research to evaluate theoretical mechanisms underlying attractiveness effects.

The analyses of moderator variables were often uninformative because of insufficiencies in the research. They revealed the need for research with children younger than 6 years of age, for research with adults older than college age, for research that evaluates male and female perceivers separately, and for research investigating children's informed judgments of adults following actual interactions. Thus, we caution the reader to reserve judgment about the importance of these moderator variables until more research is available.

Like the stranger-attribution research reviewed by Eagly et al. (1991), most of the research we reviewed categorized people into two levels of attractiveness, high or low. Even after reviewing over 900 effect sizes, we can conclude only that attractive and unattractive individuals are different in how they are judged, how they are treated, and how they behave. Because we do not know whether either group is significantly different from individuals of medium attractiveness, we cannot determine whether the differences between attractive and unattractive individuals occur because attractiveness is an advantage, because unattractiveness is a disadvantage, or both. Future research should not limit itself to investigating only two levels of attractiveness. ${ }^{10} \mathrm{We}$ did, however, compare studies investigating the effects of attractiveness when only dichotomous groups were selected (attractive vs. unattractive) and studies investigating the effects of attractiveness when the full range of attractiveness was represented. In no case was this variable significant, suggesting that attractiveness effects are not limited to only the extreme ends of the distribution.

We acknowledge that not all social or evolutionary theorists would agree with the details of all of our hypotheses. The evolutionary psychology of attractiveness is particularly complicated. For example, many predictions of mate-selection theory are relative. Attractiveness is more important for men than women when choosing a mate; attractiveness is also more important for choosing long-term mates than short-term mates. If attractiveness is somewhat important for women choosing long-term mates, would this finding falsify the theory? The answer is unclear. We hope that any disagreements of interpretation will lead to future efforts to bring theoretical clarity and specificity to the field.

Finally, no one theory is likely to be a single and unique explanation of attractiveness effects; rather, the theories should be viewed as complementary rather than competitive in explaining attractiveness effects. Even if all predictions of social theory are strongly supported by future primary research, the theory still begs the question of why and how stereotypes based on attractiveness originated in the first place. Perhaps most of the proximal effects of attractiveness are due to social expectancies and socialization, but the distal roots and origins of stereotypes about attractive and unattractive people are due to the evolutionary past. Perhaps the three maxims about beauty originated to compensate for underlying and largely unacknowledged and unconscious human dispositions to use facial appearance as an important cue for social interaction. After all, if humans were not biased to judge others on their appearance, they would not need to remind their children not to judge books by their covers. If people did not assume that beauty was an index of behaviors and traits, they would not need to be reminded that beauty is only skin-deep. However, despite their prevalence and history, these maxims apparently have not been successful in counteracting the effects of attractiveness on people's judgments, treatments, and, ultimately, behavior.

An alternative viewpoint concludes the opposite about the maxims. Perhaps they have been too successful. Perhaps, because children and adults have listened carefully to and assimilated these maxims, they are confident that they have unique standards of beauty, that they do not judge or treat people differently based on their appearance, and that beauty has nothing to do with a person's behaviors and traits. If people believe that they behave in accord with these principles of decency, they have no reason to recognize or change their behavior. Thus, the very research that identifies the powerful way in which people react to physical attractiveness might ameliorate these apparent unconscious and automatic processes. Being cognitive, humans have the behavioral plasticity and foresightedness to learn to oppose these influences, and the maxims can again remind people to behave more consciously and humanely.

\footnotetext{
${ }^{10}$ In many studies, level of attractiveness (high vs. low) was defined by a median split, thereby including individuals of medium attractiveness. Although our results do not allow us to determine if attractiveness is an advantage or unattractiveness a disadvantage, they do generalize to the entire population.
}

\section{References}

References marked with an asterisk indicate studies included in the meta-analyses.

*Abbott, A. R., \& Sebastian, R. J. (1981). Physical attractiveness and expectations of success. Personality and Social Psychology Bulletin, 7 , 481-486.

Adams, G. R., \& Crane, P. (1980). An assessment of parents' and teachers' expectations of preschool children's social preference for attractive or unattractive children and adults. Child Development, 51, 224-231.

*Alain, M. (1985). Help-seeking and attractiveness in cross-sex dyads. Canadian Joumal of Behavioral Science, 17, 271-275.

*Alcock, D., Solano, J., \& Kayson, W. A. (1998). How individuals responses and attractiveness influence aggression. Psychological Reports, 82, 1435-1438.

Ammer, C. (Ed.). (1992). A dictionary of cliches. New York: Dutton.

*Anderson, L. K. (1991, March). Self-esteem and facial attractiveness among learning-disabled children. Paper presented at the 37th annual 
meeting of the Southeastern Psychological Association, New Orleans, LA.

*Anderson, S. M., \& Bem, S. L. (1981). Sex typing and androgyny in dyadic interaction: Individual differences in responsiveness to physical attractiveness. Journal of Personality and Social Psychology, 41, 74-86.

Andersson, M. (1994). Sexual selection. Princeton, NJ: Princeton University Press.

*Babad, E. Y., Inbar, J., \& Rosenthal, R. (1982). Teachers' judgment of students' potential as a function of teachers' susceptibility to biasing information. Joumal of Personality and Social Psychology, 42, 541-547.

Barber, N. (1995). The evolutionary psychology of physical attractiveness: Sexual selection and human morphology. Ethology and Sociobiology, $16,395-424$.

Barden, R. C., Ford, M. E., Jensen, A. G., Rogers-Salyer, M., \& Salyer, K. E. (1989). Effects of craniofacial deformity in infancy on the quality of mother-infant interactions. Child Development, 60, 819-824.

*Barocas, R., \& Black, H. K. (1974). Referral rate and physical attractiveness in third-grade children. Perceptual and Motor Skills, 39, 731-734.

*Barocas, R., \& Vance, F. L. (1974). Physical appearance and personal adjustment counseling. Joumal of Counseling Psychology, 21, 96-100.

*Baugh, S. G., \& Parry, L. E. (1991). The relationship between physical attractiveness and grade point average among college women. Joumal of Social Behavior and Personality, 6, 219-228.

*Benson, P. L., Karabenick, S. A., \& Lerner, R. M. (1976). Pretty pleases: The effects of physical attractiveness, race, and sex on receiving help. Journal of Experimental Social Psychology, 12, 409-415.

*Berkowitz, L., \& Frodi, A. (1979). Reactions to a child's mistakes as affected by her/his looks and speech. Social Psychology Quarterly, 42, 420-425.

*Bernstein, I. H., Lin, T., \& McClellan, P. (1982). Cross- vs. within-racial judgments of attractiveness. Perception \& Psychophysics, 32, 495-503.

*Berscheid, E., Dion, K. K., Walster, E., \& Walster, G. W. (1971). Physical attractiveness and dating choice: A test of the matching hypothesis. Journal of Experimental Social Psychology, 7, 173-189.

Berscheid, E., \& Walster, E. (1974). Physical attractiveness. In L. Berkowitz (Ed.), Advances in experimental social psychology (pp. 157-215). New York: Academic Press.

*Brislin, R. W., \& Lewis, S. A. (1968). Dating and physical attractiveness: Replication. Psychological Reports, 22, 976.

*Brown, R. D. (1970). Experienced and inexperienced counselors' first impressions of clients and case outcomes: Are first impressions lasting? Journal of Counseling Psychology, 17, 550-558.

*Brown, T. A., Cash, T. F., \& Noles, S. W. (1986). Perceptions of physical attractiveness among college students: Selected determinants and methodological matters. Journal of Social Psychology, 126, 305-316.

*Brundage, L. E., Derlega, V. J., \& Cash, T. F. (1977). The effects of physical attractiveness and need for approval on self-disclosure. Personality and Social Psychology Bulletin, 3, 63-66.

*Brunswick, E. (1945). Social perception of traits from photographs. Psychological Bulletin, 45, 535-536.

*Bull, R., Jenkins, M., \& Stevens, J. (1983). Evaluations of politicians' faces. Political Psychology, 4, 713-716.

*Burns, G. L., \& Farina, A. (1987). Physical attractiveness and selfperception of mental disorder. Journal of Abnormal Psychology, 96, 161-163.

Buss, D. M. (1985). Human mate selection. American Scientist, 73, 47 51.

Buss, D. M. (1998). The psychology of human mate selection: Exploring the complexity of the strategic repertoire. In C. Crawford \& D. L. Krebs (Eds.), Handbook of evolutionary psychology (pp. 405-430). Mahwah, NJ: Erlbaum

Buss, D. M. (1999). Evolutionary psychology: The new science of the mind. Boston: Allyn \& Bacon.
Buss, D. M., \& Barnes, M. (1986). Preferences in human mate selection. Journal of Personality and Social Psychology, 50, 559-570.

Buss, D. M., \& Schmitt, D. P. (1993). Sexual strategies theory: An evolutionary perspective on human mating. Psychological Review, 100, 204-232.

"Byrne, D., Ervin, C. R., \& Lamberth, J. (1970). Continuity between the experimental study of attraction and real-life computer dating. Journal of Personality and Social Psychology, 16, 157-165.

*Campbell, K. E., Kleim, D. M., \& Olson, K. R. (1986). Gender, physical attractiveness, and assertiveness. Journal of Social Psychology, 126, 697-698.

Carson, K. P., Schriesheim, C. A., \& Kinicki, A. J. (1990). The usefulness of the "fail-safe" statistic in meta-analysis. Educational and Psychological Measurement, 50, 233-243.

Cash, T. F. (1981). Physical attractiveness: An annotated bibliography of theory and research in the behavioral sciences. Catalog of Selected Documents in Psychology, 11 (Ms. No. 2370), 83.

*Cash, T. F., \& Begley, P. J. (1976). Internal-external control, achievement orientation and physical attractiveness of college students. Psychological Reports, 38, 1205-1206.

*Cash, T. F., \& Burns, D. S. (1977). The occurrence of reinforcing activities in relation to locus of control, success-failure expectancies, and physical attractiveness. Joumal of Personality Assessment, 41, 387-391.

*Cash, T. F., \& Smith, E. (1982). Physical attractiveness and personality among American college students. Journal of Psychology, 111, 183-191.

*Cash, T. F., \& Soloway, D. (1975). Self-disclosure correlates of physical attractiveness: An exploratory study. Psychological Reports, 36, 579-586.

${ }^{*}$ Cavior, H. E., Hayes, S. C., \& Cavior, N. (1974). Physical attractiveness of female offenders: Effects on institutional performance. Criminal Justice and Behavior, 1, 321-331.

Cavior, N., \& Dokecki, P. R. (1971). Physical attractiveness self concept: A test of Mead's hypothesis. Proceedings of the Annual Convention of the American Psychological Association, 6, 319-320.

*Cavior, N., \& Dokecki, P. R. (1973). Physical attractiveness, perceived attitude similarity, and academic achievement as contributors to interpersonal attraction among adolescents. Developmental Psychology, 9, 44-54.

"Cavior, N., \& Howard, L. R. (1973). Facial attractiveness and juvenile delinquency among Black and White offenders. Journal of Abnormal Child Psychology, 1, 202-213.

*Cavior, N., Miller, K., \& Cohen, S. H. (1975). Physical attractiveness, attitude similarity, and length of acquaintance as contributors to interpersonal attraction among adolescents. Social Behavior and Personality, $3,133-141$.

*Chaiken, S. (1979). Communicator physical attractiveness and persuasion. Joumal of Personality and Social Psychology, 37, 1387-1397.

*Cheek, J. M., \& Buss, A. H. (1981). Shyness and sociability. Joumal of Personality and Social Psychology, 41, 330-339.

*Cherulnik, P. D. (1989, May). Physical attractiveness and judged suitability for leadership. Paper presented at the annual meeting of the Midwestern Psychological Association, Chicago, IL.

*Clark, M. L., \& Ayers, M. (1988). The role of reciprocity and proximity in junior high school friendships. Journal of Youth and Adolescence, 17, 403-411.

*Clifford, M. M. (1975). Physical attractiveness and academic performance. Child Study Journal, 5, 201-209.

Cohen, J. (1988). Statistical power analysis for the behavioral sciences. Hillsdale, NJ: Erlbaum.

*Cole, D. A. (1991). Preliminary support for a competency-based model of depression in children. Journal of Abnormal Psychology, 100, 181-190. *Cole, D. A., Martin, J. M., \& Powers, B. (1997). A competency-based 
model of child depression: A longitudinal study of peer, parent, teacher, and self-evaluations. Joumal of Child Psychology \& Psychiatry \& Allied Disciplines, 39, 505-514.

Cooper, H., \& Hedges, L. V. (1994). Potentials and limitations of research synthesis. In H. Cooper \& L. V. Hedges (Eds.), Handbook of research symthesis (pp. 521-529). New York: Russell Sage Foundation.

*Cooper, P. S. (1993). Self-esteem and facial attractiveness in learning disabled children. Child Study Journal, 23, 79-89.

*Critelli, J. W., \& Waid, L. R. (1980). Physical attractiveness, romantic love, and equity restoration in dating relationships. Joumal of Personality Assessment, 44, 624-629.

Cunningham, M. R. (1986). Measuring the physical in physical attractiveness: Quasi-experiments on the sociobiology of female facial beauty. Journal of Personality and Social Psychology, 50, 925-935.

*Cunningham, M. R., Barbee, A. P., \& Pike, C. L. (1990). What do women want? Facialmetric assessment of multiple motives in the perception of male facial physical attractiveness. Journal of Personality and Social Psychology, 59, 61-72.

Cunningham, M. R., Druen, P. B., \& Barbee, A. P. (1997). Angels, mentors, and friends: Trade-offs among evolutionary, social, and individual variables in physical appearance. In J. A. Simpson \& D. T. Kenrick (Eds.), Evolutionary social psychology (pp. 109-140). Mahwah, NJ: Erlbaum.

*Cunningham, M. R., Roberts, A. R., Barbee, A. P., Druen, P. B., \& Wu, C. H. (1995). "Their ideas of beauty are, on the whole, the same as ours": Consistency and variability in the cross-cultural perception of female physical attractiveness. Journal of Personality and Social Psychology, 68, 261-279.

*Curran, J. P. (1973). Correlates of physical attractiveness and interpersonal attraction in the dating situation. Social Behavior and Personality, $1,153-157$.

*Curran, J. P., \& Lippold, S. (1975). The effects of physical attraction and attitude similarity on attraction in dating dyads. Joumal of Personality, 43, 528-539.

*Curran, J. P., Neff, S., \& Lippold, S. (1973). Correlates of sexual experience among university students. Journal of Sex Research, 9, 124-131.

*Dailey, W. F., Allen, G. J., Chinsky, J. M., \& Veit, S. W. (1974). Attendant behavior and attitudes toward institutionalized retarded children. American Joumal of Mental Deficiency, 78, 586-591.

Daly, M. (1990). Evolutionary theory and parental motives. In N. A. Krasnegor \& R. S. Bridges (Eds.), Mammalian parenting, (pp. 25-39). New York: Oxford University Press.

Daly, M., \& Wilson, M. (1988). The Darwinian psychology of discriminative parental solicitude. In D. W. Leger (Ed.), Nebraska Symposium on Motivation 1987 (Vol. 35, pp. 91-144). Lincoln: University of Nebraska Press.

Daly, M., \& Wilson, M. (1995). Discriminative parental solicitude and the relevance of evolutionary models to the analysis of motivational systems. In M. S. Gassaniga (Ed.), The cognitive neurosciences, (pp. 1269-1286). Cambridge, MA: MIT Press.

Darley, J. M., \& Fazio, R. H. (1980). Expectancy confirmation processes arising in the social interaction sequence. American Psychologist, 35, 867-881.

Darwin, C. (1871). The descent of man and selection in relation to sex. London: Murray.

*DePaulo, B. M., Tang, J., \& Stone, J. I. (1987). Physical attractiveness and skill at detecting deception. Personality and Social Psychology Bulletin, 13, 177-187.

*Dickey-Bryant, L., Lautenschlager, G. J., Mendoza, J. L., \& Abrahams, N. (1986). Facial attractiveness and its relation to occupational success. Journal of Applied Psychology, 71, 16-19.

*Diener, E., Wolsic, B., \& Fujita, F. (1995). Physical attractiveness and subjective well-being. Journal of Personality and Social Psychology, 69, 120-129.
Dion, K. K. (1973). Young children's stereotyping of facial attractiveness. Developmental Psychology, 9, 183-188.

*Dion, K. K. (1974). Children's physical attractiveness and sex as determinants of adult punitiveness. Developmental Psychology, 10, 772-778.

*Dion, K. K. (1977). The incentive value of physical attractiveness for young children. Personality and Social Psychology Bulletin, 3, 67-70.

*Dion, K. K., \& Berscheid, E. (1974). Physical attractiveness and peer perception among children. Sociometry, 37, 1-12.

Dion, K. K., Berscheid, E., \& Walster, E. (1972). What is beautiful is good. Joumal of Personality and Social Psychology, 24, 285-290.

*Dion, K. K., \& Stein, S. (1978). Physical attractiveness and interpersonal influence. Journal of Experimental Social Psychology, 14, 97-108.

*Dipboye, R. L., Fromkin, H. L., \& Wiback, K. (1975). Relative importance of applicant sex, attractiveness, and scholastic standing in evaluation of job applicant resumes. Journal of Applied Psychology, 60, $39-43$.

Downs, A. C., \& Harrison, S. K. (1985). Embarrassing age spots or just plain ugly? Physical attractiveness stereotyping as an instrument of sexism on American television commercials. Sex Roles, 13, 9-19.

Eagly, A. H. (1995). The science and politics of comparing women and men. American Psychologist, 50, 145-158.

Eagly, A. H., Ashmore, R. D., Makhijani, M. G., \& Longo, L. C. (1991). What is beautiful is good, but. . . : A meta-analytic review of research on the physical attractiveness stereotype. Psychological Bulletin, 110, $109-128$.

*Efran, M. G., \& Patterson, E. W. J. (1974). Voters vote beautiful: The effect of physical appearance on a national election. Canadian Journal of Behavioral Science, 6, 352-356.

*Elder, G. H., Van Nguyen, T., \& Caspi, A. (1985). Linking family hardship to children's lives. Child Development, 56, 361-375.

*Farina, A., Fischer, E. H., Sherman, S., Smith, W. T., Groh, T., \& Mermin, P. (1977). Physical attractiveness and mental illness. Joumal of Abnormal Psychology, 86, 510-517.

Farkas, L. G., Munro, I. R., \& Kolar, J. C. (1987). Linear proportions in above- and below-average women's faces. In L. G. Farkas \& I. R. Munro (Eds.), Anthropometric facial proportions in medicine (pp. 119-129). Springfield, IL: Charles C Thomas.

*Feingold, A. (1982). Physical attractiveness and intelligence. Journal of Social Psychology, 118, 283-284.

*Feingold, A. (1984), Correlates of physical attractiveness among college students. Journal of Social Psychology, 122, 139-140.

Feingold, A. (1990). Gender differences in effects of physical attractiveness on romantic attraction: A comparison across five research paradigms. Journal of Personality and Social Psychology, 59, 981-993.

Feingold, A. (1992a). Gender differences in mate selection preferences: A test of the parental investment model. Psychological Bulletin, 112, 125-139.

Feingold, A. (1992b). Good-looking people are not what we think. $P_{s y-}$ chological Bulletin, 111, 304-341.

*Felson, R. B. (1980). Physical attractiveness, grades and teachers' attributions of ability. Representative Research in Social Psychology, 11, 64-71.

*Felson, R. B., \& Bohmstedt, G. W. (1979). "Are the good beautiful or the beautiful good?" The relationship between children's perceptions of ability and perceptions of physical attractiveness. Social Psychology Quarterly, 42, 386-392.

Field, T. M., \& Vega-Lahr, N. (1984). Early interactions between infants with cranio-facial anomalies and their mothers. Infant Behavior and Development, 7, 527-530.

Ford, C. S., \& Beach, F. A. (1951). Patterns of sexual behavior. New York: Harper \& Row.

*Foster, T. J., Pearson, J. C., \& Imahori, T. (1985, May). A study of two competing explanations for the effects of physical attractiveness upon 
evaluation of public speeches. Paper presented at the annual meeting of the International Communication Association, Honolulu, HI.

*Fridell, M. A., Zucker, K., Bradley, S., \& Maing, D. (1996). Physical attractiveness of girls with gender identity disorder. Archives of Sexual Behavior, 25, 17-31.

*Friedman, H. S., Riggio, R. E., \& Casella, D. F. (1988). Nonverbal skill, personal charisma, and initial attraction. Personality and Social Psychology Bulletin, 14, 203-211.

*Fugita, S. S., Agle, T. A., Newman, I., \& Walfish, N. (1977). Attractiveness, self-concept, and a methodological note about gaze behavior. Personality and Social Psychology Bulletin, 3, 240-243.

*Gabriel, M. T., Critelli, J. W., \& Ee, J. S. (1994). Narcissistic illusions in self-evaluations of intelligence and attractiveness. Journal of Personality, 62, 143-155.

*Gallucci, N. T., \& Meyer, R. G. (1984). People can be too perfect: Effects of subjects' and targets' attractiveness on interpersonal attraction. Psychological Reports, 55, 351-360.

*Gangestad, S. W., \& Buss, D. M. (1993). Pathogen prevalence and human mate preferences. Ethology and Sociobiology, 14, 89-96.

*Gangestad, S. W., \& Thornhill, R. (1997). Human sexual selection and developmental stability. In J. A. Simpson \& D. T. Kenrick (Eds.), Evolutionary social psychology (pp. 169-195). Mahwah, NJ: Erlbaum.

Gangestad, S. W., Thornhill, R., \& Yeo, R. A. (1994). Facial attractiveness, developmental stability, and fluctuating asymmetry. Ethology and Sociobiology, 15, 73-75.

*Garcia, S., Stinson, L., Ickes, W., Bisonette, V., \& Briggs, S. R. (1991). Shyness and physical attractiveness in mixed sex dyads. Journal of Personality and Social Psychology, 61, 35-49.

*Gifford, R., Ng, C. F., \& Wilkinson, M. (1985). Nonverbal cues in the employment interview: Links between applicant qualities and interviewer judgments. Joumal of Applied Psychology, 70, 729-736.

*Glasgow, R. E., \& Arkowitz, H. (1975). The behavioral assessment of male and female social competence in dyadic heterosexual interactions. Behavior Therapy, 6, 488-498.

Glass, G. V. (1978). In defense of generalization. Behavioral and Brain Sciences, 3, 394-395.

*Goldberg, P. A., Gottesdiener, M., \& Abramson, P. R. (1975). Another put-down of women? Perceived attractiveness as a function of support for the feminist movement. Joumal of Personality and Social Psychology, 32, 113-115.

*Goldman, W., \& Lewis, P. (1977). Beautiful is good: Evidence that the physically attractive are more socially skillful. Journal of Experimental Social Psychology, 13, 125-130.

*Greenwald, D. P. (1977). The behavioral assessment of differences in social skill and social anxiety in female college students. Behavior Therapy, 8, 925-937.

Guilford, J. P., \& Fruchter, B. (1973). Fundamental statistics in psychology and education. New York: McGraw-Hill.

*Hadjistavropoulos, T., Tuokko, H., \& Beattie, B. L. (1991). The role of physical attractiveness in the assessment of elderly patients. Social Science Medicine, 33, 95-96.

Halverson, C. F., \& Victor, J. B. (1976). Minor physical anomalies and problem behavior in elementary school children. Child Development, 47 , 281-285.

*Hamermesh, D. S., \& Biddle, J. E. (1994), Beauty and the labor market. American Economic Review, 84, 1174-1194.

*Hansell, S. J., Sparacino, J., \& Ronchi, D. (1982). Physical attractiveness and blood pressure: Sex and age differences. Personality and Social Psychology Bulletin, 8, 113-121.

*Harnish, R. J., Abbey, A., \& DeBono, K. G. (1989, March-April). Factors affecting the misperception of friendliness cues in initial interactions. Paper presented at the annual meeting of the Eastern Psychological Association, Boston, MA.
Hatfield, E., \& Sprecher, S. (1986). Mirror, mirror: The importance of looks in everyday life. Albany: State University of New York Press.

Hedges, L. V., \& Olkin, I. (1985). Statistical methods for meta-analysis. San Diego, CA: Academic Press.

*Hildebrandt, K. A., \& Cannan, T. (1985). The distribution of caregiver attention in a group program for young children. Child Study Joumal, 15, 43-55.

Hildebrandt, K. A., \& Fitzgerald, H. E. (1978). Adults' responses to infants varying in perceived cuteness. Behavioral Processes, 3, 159-172.

*Hollingworth, L. S. (1935). The comparative beauty of the faces of highly intelligent adolescents. Journal of Genetic Psychology, 47, 268-281.

*Hughs, J., Howell, J., \& Hall, D. (1983, August). A multimethod assessment of children's social competence. Paper presented at the 91 st Annual Convention of the American Psychological Association, Anaheim, CA.

*Jackson, D. J., \& Huston, T. L. (1975). Physical attractiveness and assertiveness. Journal of Social Psychology, 96, 79-84.

Jackson, L. A. (1992). Physical appearance and gender: Sociobiological and sociocultural perspectives. Albany: State University of New York Press.

Jackson, L. A., Hunter, J. E., \& Hodge, C. N. (1995). Physical attractiveness and intellectual competence: A meta-analytic review. Social Psychology Quarterly, 58, 108-122.

Johnson, B. T. (1989). Software for the meta-analytic review of research literatures. Hillsdale, NJ: Erlbaum.

*Johnson, R. W., Doiron, D., Brooks, G. P., \& Dickinson, J. (1978). Perceived attractiveness as a function of support for the feminist movement: Not necessarily a put-down of women. Canadian Journal of Behavioral Sciences, 10, 214-221.

Jones, D. (1996). Physical attractiveness and the theory of sexual selection. Ann Arbor: Museum of Anthropology, University of Michigan.

*Jones, D., \& Hill, K. (1993). Criteria of facial attractiveness in five populations. Human Nature, 4, 271-296.

*Jones, W. H., Briggs, S. R., \& Smith, T. G. (1986). Shyness: Conceptualization and measurement. Journal of Personality and Social Psychology, 51, 629-639.

*Jones, W. H., Freemon, J. E., \& Goswick, R. A. (1981). The persistence of loneliness: Self and other determinants. Journal of Personality, 49 27-48.

*Jovanovic, J., Lerner, R. M., \& Lerner, J. V. (1989). Objective and subjective attractiveness and early adolescent adjustment. Journal of Adolescence, 12, 225-229.

Jussim, L., \& Eccles, J. S. (1992). Teacher expectations II: Construction and reflection of student achievement. Journal of Personality and Social Psychology, 63, 947-961.

*Kaats, G. R., \& Davis, K. E. (1970). The dynamics of sexual behavior of college students. Journal of Marriage and the Family, 32, 390-399.

*Kahn, A., Hottes, J., \& Davis, W. L. (1971). Cooperation and optimal responding in the prisoner's dilemma game: Effects of sex and physical attractiveness. Journal of Personality and Social Psychology, 17, 267-279.

*Kalick, S. M., Zebrowitz, L. A., Langlois, J. H., \& Johnson, R. M. (1998). Does human facial attractiveness honestly advertise health? Longitudinal data on an evolutionary question. Psychological Science, 9, 8-13.

*Kanekar, S., \& Ahluwalia, R. B. (1975). Academic aspirations in relation to sex and physical attractiveness. Psychological Reports, 36, 834.

*Karraker, K. (1986). Adult attention to infants in a newborn nursery. Nursing Research, 35, 358-363.

*Kenealy, P., Frude, N., \& Shaw, W. (1987). Influence of children's physical attractiveness on teacher expectations. Journal of Social Psychology, 128, 373-383.

*Kenealy, P., Gleeson, K., Frude, N., \& Shaw, W. (1991). The importance of the individual in the "causal" relationship between attractiveness and self-esteem. Joumal of Community and Applied Social Psychology, 1, 45-56. 
Kirkpatrick, M. (1996). Good genes and direct selection in the evolution of mating preferences. Evolution, 50, 2125-2140.

*Kleck, R. E., Richardson, S. A., \& Ronald, C. (1974). Physical appearance cues and interpersonal attraction in children. Child Development, 45, 305-310.

*Kleck, R. E., \& Rubenstein, C. (1975). Physical attractiveness, perceived attitude similarity and interpersonal attraction in an opposite sex encounter. Journal of Personality and Social Psychology, 31, 107-114.

Knight, G. P., Fabes, R. A., \& Higgins, D. A. (1996). Concerns about drawing causal inferences from meta-analyses: An example in the study of gender differences in aggression. Psychological Bulletin, 119, $410-421$.

*Kowner, R. (1996). Susceptibility to physical attractiveness comparison: On the role of attributions in protecting self-esteem. Psychologia, 39, $150-162$.

*Kowner, R., \& Ogawa, T. (1995). The role of raters' sex, personality, and appearance in judgments of facial beauty. Perceptual and Motor Skills, $81,339-349$.

Krantz, M. (1987). Physical attractiveness and popularity: A predictive study. Psychological Reports, 60, 723-726.

*Krantz, M., Friedberg, J., \& Andrews, D. (1984). Physical attractiveness and popularity: The mediating role of self-perception. Journal of Psychology, 119, 219-223.

*Kuhlenschmidt, S., \& Conger, J. C. (1988). Behavioral components of social competence in females. Sex Roles, 18, 107-112.

Langlois, J. H. (1986). From the eye of the beholder to behavioral reality: The development of social behaviors and social relations as a function of physical attractiveness. In C. P. Herman, M. P. Zanna, \& E. T. Higgins (Eds.), Physical appearance, stigma, and social behavior: The Ontario Symposium (Vol. 3, pp. 23-51). Hillsdale, NJ: Erbaum.

*Langlois, J. H., Ritter, J. M., Casey, R. C., \& Sawin, D. B. (1995). Infant attractiveness predicts maternal behavior and attitudes. Developmental Psychology, 31, 462-472.

*Langlois, J. H., Ritter, J. M., Roggman, L. A., \& Vaughn, L. S. (1991). Facial diversity and infant preferences for attractive faces. Developmental Psychology, 27, 79-84.

Langlois, J. H., \& Roggman, L. A. (1990). Attractive faces are only average. Psychological Science, 1, 115-121.

*Langlois, J. H., Roggman, L. A., Casey, R. J., Ritter, J. M., RieserDanner, L. A., \& Jenkins, V. Y. (1987). Infant preferences for attractive faces: Rudiments of a stereotype? Developmental Psychology, 23, 363-369.

Langlois, J. H., Roggman, L. R., \& Musselman, L. (1994). What's average and not average about attractive faces? Psychological Science, S, 214-220.

*Langlois, J. H., Roggman, L. A., \& Rieser-Danner, L. A. (1990). Infants' differential social responses to attractive and unattractive faces. Developmental Psychology, 26, 153-159.

Langlois, J. H., \& Stephan, C. (1977). The effects of physical attractiveness and ethnicity on children's behavioral attributions and peer preferences. Child Development, 48, 1694-1698.

*Larrance, D. T., \& Zuckerman, M. (1981). Facial attractiveness and yocal likeability as determinants of nonverbal sending skills. Journal of Personality, 49, 349-362.

*Leinbach, M. D., \& Fagot, B. I. (1991). Attractiveness in young children: Sex-differentiated reactions of adults. Sex Roles, 25, 269-284.

*Lerner, R. M., Delaney, M., Hess, L. E., Jovanovic, J., \& von Eye, A. (1990). Early adolescent physical attractiveness and academic competence. Journal of Early Adolescence, 10, 4-20.

*Lerner, R. M., \& Lerner, J. V. (1977). Effects of age, sex, and physical attractiveness on child-peer relations, academic performance, and elementary school adjustment. Developmental Psychology, 13, 585-590.

*Lerner, R. M., Lerner, J. V., Hess, L. E., Schwab, J., Jovanovic, J., Talwar, R., \& Kucher, J. S. (1991). Physical attractiveness and psycho- social functioning among early adolescents. Journal of Early Adolescence, $11,300-320$.

*Lippitt, R. (1941). Popularity among preschool children. Child Development, 4, 305-333.

Lipsey, M. W., \& Wilson, D. B. (1993). The efficacy of psychological, educational, and behavioral treatment: Confirmation from meta-analysis. American Psychologist, 48, 1181-1209.

*Longo, L. C. (1990, March-April). The impact of pre-adult appearancerelated experiences on young adults' personality. Paper presented at the annual meeting of the Eastern Psychological Association, Philadelphia PA.

Mack, D., \& Rainey, D. (1990). Female applicants' grooming and personnel selection. Journal of Social Behavior \& Personality, 5, 399-407.

*Madden, R., \& Hollingworth, L. S. (1932). How one race judges another for physical attractiveness. Joumal of Social Psychology, 3, 463-469.

${ }^{*}$ Mandel, N. M., \& Shrauger, J. S. (1980). The effects of self-evaluative statements on heterosocial approach in shy and nonshy males. Cognitive Therapy and Research, 4, 369-381.

Mann, J. (1992). Nurturance or negligence: Maternal psychology and behavioral preference among preterm twins. In J. H. Barkow, L. Cosmides, \& J. Tooby (Eds.), The adapted mind: Evolutionary psychology and the generation of culture (pp. 367-390). New York: Oxford University Press.

*Markley, R. P., Kramer, J. J., Parry, K. D., \& Ryabik, J. E. (1982). Physical attractiveness and locus of control in elementary school children. Psychological Reports, 51, 723-726.

*Marlowe, C. M., Schneider, S. L., \& Nelson, C. E. (1996). Gender and attractiveness biases in hiring decisions: Are most experienced managers less biased? Joumal of Applied Psychology, 81, 11-21.

*Martin, J. G. (1964). Racial ethnocentrism and judgment of beauty. Journal of Social Psychology, 63, 59-63.

*Martindale, C., Ross, M., Hines, D., \& Abrams, L. (1978). Independence of interaction and interpersonal attraction in a psychiatric hospital population. Journal of Abnormal Psychology, 87, 247-255.

*Mathes, E. W., \& Edwards, L. L. (1978). Physical attractiveness as an input in social exchanges. Joumal of Psychology, 98, 267-275.

*Mathes, E. W., \& Kahn, A. (1975). Physical attractiveness, happiness, neuroticism, and self-esteem. Journal of Psychology, 90, 27-30.

Matt, G. E., \& Cook, T. D. (1994). Threats to the validity of research syntheses. In H. Cooper \& L. V. Hedges (Eds.), Handbook of research synthesis (pp. 513-520). New York: Russell Sage Foundation.

*McArthur, L. Z., \& Berry, D. S. (1987). Cross-cultural agreement in perceptions of babyfaced adults. Journal of Cross-Cultural Psychology, 18, 165-192.

*McGovern, R. J., Neale, M. C., \& Kendler, K. S. (1996). The independence of physical attractiveness and symptoms of depression in a female twin population. Journal of Psychology, 130, 209-219.

Miller, G. F. (1998). How mate choice shaped human nature: A review of sexual selection and human evolution. In C. Crawford \& D. L. Krebs (Eds.), Handbook of evolutionary psychology (pp. 87-129). Mahwah, NJ: Erlbaum.

*Miller, L. C., \& Cox, L. C. (1982). For appearance's sake: Public self-consciousness and makeup use. Personality and Social Psychology Bulletin, 8, 748-751.

*Mims, P. R., Hartnett, J. J., \& Nay, W. R. (1975). Interpersonal attraction and help volunteering as a function of physical attractiveness. Journal of Psychology, 89, 125-131.

${ }^{*}$ Mohr, A. M. (1932). Beauty as related to intelligence and scholarship. Psychological Bulletin, 29, 564-565.

*Mohr, A., \& Lund, F. H. (1933). Beauty as related to intelligence and educational achievement. Journal of Social Psychology, 4, 235-239.

*Moisan-Thomas, P. C., Conger, J. C., Zellinger, M. M., \& Firth, E. A (1985). The impact of confederate responsivity on social skills assess- 
ment. Journal of Psychopathology and Behavioral Assessment, 7, 23-35.

*Moran, J. D., \& McCullers, J. C. (1984). A comparison of achievement scores in physically attractive and unattractive students. Home Economics Research Journal, 13, 36-40.

*Murphy, M. J., Nelson, D. A., \& Cheap, T. L. (1981). Rated and actual performance of high school students as a function of sex and attractiveness. Psychological Reports, 48, 103-106.

*Nadler, A. (1980). "Good looks do not help:" Effects of helper's physical attractiveness and expectations for future interaction on help-seeking behavior. Personality and Social Psychology Bulletin, 6, 378-383.

*Napoleon, T., Chassin, L., \& Young, R. D. (1980). A replication and extension of "Physical Attractiveness and Mental Illness. "Joumal of Abnormal Psychology, 89, 250-253.

*Nelson, R. O., Hayes, S. C., Felton, J. L., \& Jarrett, R. B. (1985). A comparison of data produced by different behavioral assessment techniques with implications for models of social-skills inadequacy. Behaviour Research \& Therapy, 23, 1-11.

*Neumann, K. F., Critelli, J. W., \& Tang, C. (1986). Male physical attractiveness as a potential contaminating variable in ratings of heterosocial skill. Joumal of Social Psychology, 126, 813-814.

*Noles, S. W., Cash, T. F., \& Winstead, B. A. (1985). Body image, physical attractiveness, and depression. Journal of Consulting and Clinical Psychology, 53, 88-94.

Nunnally, J. C. (1978). Psychometric theory. New York: McGraw-Hill.

*O'Grady, K. E. (1982). Sex, physical attractiveness, and perceived risk for mental illness. Journal of Personality and Social Psychology, 43, 1064-1071.

*O'Grady, K. E. (1989). Physical attractiveness, need for approval, social self-esteem, and maladjustment. Journal of Social and Clinical Psychology, 8, 62-69.

*Pellegrini, R. J., Hicks, R. A., Meyers-Winton, S., \& Antal, B. G. (1978). Physical attractiveness and self-disclosure in mixed-sex dyads. Psychological Record, 28, 509-516.

*Pilkonis, P. A. (1977). The behavioral consequences of shyness. Journal of Personality, 45, 596-611.

*Pittenger, J. B., \& Baskett, L. M. (1984). Facial self-perception: Its relation to objective appearance and self-concept. Bulletin of the Psychonomic Society, 22, 167-170.

*Powell, P. H., \& Dabbs, J. M. (1976). Physical attractiveness and personal space. Joumal of Social Psychology, 100, 59-64.

*Raskin, R., \& Terry, H. (1988). A principle-components analysis of the narcissistic personality inventory and further evidence of its construct validity. Joumal of Personality and Social Psychology, 54, 890-902.

*Raza, S. M., \& Carpenter, B. N. (1987). A model of hiring decisions in real employment interviews. Journal of Applied Psychology, 72, 596-603.

*Reis, H. T., Nezlek, J., \& Wheeler, L. (1980). Physical attractiveness in social interaction. Journal of Personality and Social Psychology, 38, 604-617.

${ }^{*}$ Reis, H. T., Wheeler, L., Nezlek, J., Kernis, M. H., \& Spiegel, N. (1985). On specificity in the impact of social participation on physical and psychological health. Journal of Personality and Social Psychology, 48, 456-471.

*Reis, H. T., Wheeler, L., Spiegel, N., Kernis, M. H., Nezlek, J., \& Perri, M. (1982). Physical attractiveness in social interaction: II. Why does appearance affect social experience? Journal of Personality and Social Psychology, 43, 979-996.

*Rieser-Danner, L. A., Roggman, L., \& Langlois, J. H. (1987). Infant attractiveness and perceived temperament in the prediction of attachment classifications. Infant Mental Health Journal, 8, 144-155.

Ritter, J. M., Casey, R. J., \& Langlois, J. H. (1991). Adults' responses to infants varying in age-appearance and facial attractiveness. Child Development, $62,68-82$.
Ritter, J. M., \& Langlois, J. H. (1988). The role of physical attractiveness in the observation of adult-child interactions: Eye of the beholder or behavioral reality? Developmental Psychology, 24, 254-263.

*Romer, D., \& Berkson, G. (1980). Social ecology of supervised communal facilities for mentally disabled adults: II. Predictors of affiliation. American Journal of Mental Deficiency, 85, 229-242.

Rosenthal, R. (1979). The "file drawer problem" and tolerance for null results. Psychological Bulletin, 86, 638-641.

Rosenthal, R. (1991). Meta-analytic procedures for social research. Newbury Park, CA: Sage.

Rosenthal, R. (1995). Writing meta-analytic reviews. Psychological Bulletin, 118, 183-192.

*Roszell, P., Kennedy, D., \& Grabb, E. (1990). Physical attractiveness and income attainment among Canadians. Journal of Psychology, 123, 547-559.

*Rowe, D. C., Clapp, M., \& Wallis, J. (1987). Physical attractiveness and the personality resemblance of identical twins. Behavior Genetics, 17, 191-201.

*Salvia, J., Algozzine, R., \& Sheare, J. B. (1977). Attractiveness and school achievement. Journal of School Psychology, 15, 60-67.

*Salvia, J., Sheare, J. B., \& Algozzine, B. (1975). Facial attractiveness and personal-social development. Journal of Abnormal Child Psychology, 3, 171-178.

*Samuels, C. A., \& Ewy, R. (1985). Aesthetic perception of faces during infancy. British Journal of Developmental Psychology, 3, 221-228.

*Sarason, B. R., Sarason, I. G., Hacker, T. A., \& Basham, R. B. (1985). Concomitants of social support: Social skills, physical attractiveness, and gender. Journal of Personality and Social Psychology, 49, 469-480.

Scrimshaw, S. C. M. (1984). Infanticide in human populations: Societal and individual concerns. In G. Hausfater \& S. B. Hrdy (Eds.), Infanticide: Comparative and evolutionary perspectives, (pp. 439-462). Hawthorne, NY: Aldine.

*Serketich, W. J., \& Dumas, J. E. (1997). Adults' perceptions of competent and dysfunctional children based on the children's appearance. Behavior Modification, 21, 457-469.

*Shackelford, T. K., \& Larsen, R. J. (1999). Facial attractiveness and physical health. Evolution \& Human Behavior, 20, 71-76.

Shadish, W. R. (1996). Meta-analysis and the exploration of causal mediating processes: A primer of examples, methods, and issues. Psychological Methods, 1, 47-65.

*Shapiro, A. K., Struening, E., Shapiro, E., \& Barten, H. (1976). Prognostic correlates of psychotherapy in psychiatric outpatients. American Journal of Psychiatry, 133, 802-808.

*Shea, J., Crossman, S. M., \& Adams, G. R. (1978). Physical attractiveness and personality development. Journal of Psychology, 99, 59-62.

*Shea, J. A., \& Adams, G. R. (1984). Correlates of romantic attachment: A path analysis study. Journal of Youth and Adolescence, 13, 27-44.

*Singer, J. E. (1964). The use of manipulative strategies: Machiavellianism and attractiveness. Sociometry, 27, 128-150.

Singh, D. (1993). Adaptive significance of female physical attractiveness: Role of waist-to-hip ratio. Journal of Personality and Social Psychology, 65, 293-307.

*Slater, A., Von der Schulennurg, C., Brown, E., Badenoch, M., Butterworth, G., Parsons, S., \& Samuels, C. (1998). Newborn infants prefer attractive faces. Infant Behavior and Development, 21, 345-354.

*Smith, G. J. (1985). Facial and full-length ratings of attractiveness related to the social interactions of young children. Sex Roles, 12, 287-293.

*Smith, J., \& Krantz, M. (1986). Physical attractiveness and popularity in children: A methodological refinement and replication. Journal of $\mathrm{Ge}$ netic Psychology, 147, 419-420.

*Snyder, M., Berscheid, E., \& Glick, P. (1985). Focusing on the exterior and the interior: Two investigations of the initiation of personal relationships. Journal of Personality and Social Psychology, 48, 1427-1439. Snyder, M., Tanke, E. D., \& Berscheid, E. (1977). Social perception and 
interpersonal behavior: On the self-fulfilling nature of social stereotypes. Joumal of Personality and Social Psychology, 35, 656-666.

*Sparacino, J. (1980). Physical attractiveness and occupational prestige among male college graduates. Psychological Reports, 47, 1275-1280.

*Sparacino, J., \& Hansell, S. (1979). Physical attractiveness and academic performance: Beauty is not always talent. Journal of Personality, 47, 449-469.

Spears, R. A. (Ed.). (1993). NTC's dictionary of proverbs and clichés. Lincolnwood, IL: National Textbook.

*Sroufe, R., Chaikin, A., Cook, R., \& Freeman, V. (1977). The effects of physical attractiveness on honesty: A socially desirable response. Personality and Social Psychology Bulletin, 3, 59-62.

*Steffen, J. J., \& Redden, J. (1977). Assessment of social competence in an evaluation-interaction analogue. Human Communication Research, 4, 30-37.

*Steizer, C., Desmond, S. M., \& Price, J. H. (1987). Physical attractiveness and sexual activity of college students. Psychological Reports, 60 , 567-573.

*Stewart, J. E. (1980). Defendant's attractiveness as a factor in the outcome of criminal trials: An observational study. Journal of Applied Social Psychology, 10, 348-361.

*Stewart, J. E. (1984). Appearance and punishment: The attractionleniency effect in the courtroom. Journal of Social Psychology, 125, 373-378.

*Stokes, S. J., \& Bickman, L. (1974). The effect of the physical attractiveness and role of the helper on help seeking. Journal of Applied Social Psychology, 4, 286-294.

*Sussman, S., Marks, G., Freeland, J., Harris, J. K., Vernan, S., Alford, G., \& Mueser, K. T. (1987). Physical attractiveness and psychological adjustment among substance abuse inpatients: $A$ longitudinal study. Journal of Applied Social Psychology, 17, 699-709.

*Sussman, S., \& Mueser, K. T. (1983). Age, socioeconomic status, severity of mental disorder, and chronicity as predictors of physical attractiveness. Joumal of Abnormal Psychology, 92, 255-258.

Symons, D. (1979). The evolution of human sexuality. New York: Oxford University Press.

*Thakerar, J. N., \& Iwawaki, S. (1979). Cross-cultural comparisons in interpersonal attraction of females toward males. Journal of Social Psychology, 108, 121-122.

Thiessen, D. (1996). Bittersweet destiny: The stormy evolution of human behavior. New Brunswick, NJ: Transaction.

Thornhill, R. (1998). Darwinian aesthetics. In C. Crawford \& D. L. Krebs (Eds.), Handbook of evolutionary psychology (pp. 543-572). Mahwah, NJ: Erlbaum.

Thornhill, R., \& Gangestad, S. W. (1993). Human facial beauty: Averageness, symmetry and parasite resistance. Human Nature, 4, 237-269.

Townsend, J. M, \& Wasserman, T. (1997). The perception of sexual attractiveness: Sex differences in variability. Archives of Sexual Behavior, 26, 243-268.

Trivers, R. L. (1972). Parental investment and sexual selection. In B. Campbell (Ed.), Sexual selection and the descent of man (pp. 136-179). Chicago: Aldine.

*Tumer, R. G., Gilliland, L., \& Klein, H. M. (1981). Self-consciousness, evaluation of physical characteristics, and physical attractiveness. Journal of Research in Personality, 15, 182-190.

*Udry, J. R. (1965). Structural correlates of feminine beauty preferences in Britain and the United States: A comparison. Sociology and Social Research, 49, 330-342.
*Umberson, D., \& Hughes, M. (1987). The impact of physical attractiveness on achievement and psychological well-being. Social Psychology Quarterly, 50, 227-236.

*Vaughn, B. E., \& Langlois, J. H. (1983). Physical attractiveness as a correlate of peer status and social competence in preschool children. Developmental Psychology, 19, 461-467.

Waldrop, M. F., \& Halverson, C. F. (1971). Minor physical anomalies and hyperactive behavior in young children. In J. Hellmuth (Ed.), The exceptional infant, (Vol. 2, pp. 343-380). New York: Brunner/Mazel.

*Walster, E., Aronson, V., Abrahams, D., \& Rottmann, L. (1966). Importance of physical attractiveness in dating behavior. Journal of Personality and Social Psychology, 4, 508-516.

*Weisfeld, G. E., Bloch, S. A., \& Ivers, J. W. (1983). A factor analytic study of peer-perceived dominance in adolescent boys. Adolescence, 18 , 229-243.

*Weisfeld, G. E., Weisfeld, C. C., \& Callaghan, J. W. (1984). Peer and self perceptions in Hopi and African-American third-and sixth-graders. Ethos, 12, 64-82.

*Wessberg, H. W., Marriotto, M. J., Conger, A. J., Farrell, A. D., \& Conger, J. C. (1979). Ecological validity of role plays for assessing heterosexual anxiety and skill of male college students. Journal of Consulting and Clinical Psychology, 47, 525-535.

*West, S. G., \& Brown, T. J. (1975). Physical attractiveness, the severity of the emergency and helping: A field experiment and interpersonal simulation. Joumal of Experimental Social Psychology, 11, 531-538.

Wilkinson, P. R. (Ed.). (1993). Thesaurus of traditional English metaphors. London: Routledge.

*Williams, C. L., \& Ciminero, A. R. (1978). Development and validation of a heterosocial skills inventory: The survey of heterosexual interactions for females. Journal of Consulting and Clinical Psychology, 46, 1547-1548.

*Wilson, D. W. (1978). Helping behavior and physical attractiveness. Joumal of Sacial Psychology, 104, 313-314.

*Wilson, D. W., \& Donnerstein, E. (1977). Guilty or not guilty? A look at the "simulated" jury paradigm. Journal of Applied Social Psychology, 7, $175-190$.

*Zahr, L. (1985). Physical attractiveness and Lebanese children's school performance. Psychological Reports, 56, 191-192.

*Zakahi, W. R., \& Duran, R. L. (1988). Physical attractiveness as a contributing factor to loneliness: An exploratory study. Psychological Reports, 63, 747-751.

Zebrowitz, L. A. (1997). Reading faces: Window to the soul? Boulder, CO: Westview Press.

*Zebrowitz, L. A., Collins, M. A., \& Dutta, R. (1998). The relationship between appearance and personality across the life span. Personality and Social Psychology Bulletin, 24, 736-749.

*Zebrowitz, L. A., Montepare, I. M., \& Lee, H. K. (1993). They don't all look alike: Individuated impressions of other racial groups. Journal of Personality and Social Psychology, 65, 85-101.

*Zucker, K. J., Wild, J., Bradley, S. J., \& Lowry, C. B. (1993). Physical attractiveness of boys with gender identity disorder. Archives of Sexual Behavior, 22, 23-36.

Zuckerman, M., \& Driver, R. E. (1989). What sounds beautiful is good: The vocal attractiveness stereotype. Joumal of Nonverbal Behavior, 13, 67-82. 
Appendix A

Studies Included in Meta-Analyses of Cross-Cultural and Cross-Ethnic Reliability

\begin{tabular}{|c|c|c|c|c|c|}
\hline Study & $\begin{array}{l}\text { Type of } \\
\text { reliability }\end{array}$ & $\begin{array}{l}\text { Number of } \\
\text { raters }\end{array}$ & $\begin{array}{l}\text { Target } \\
\text { gender }\end{array}$ & $\begin{array}{c}\text { Mean } \\
\text { reliability }\end{array}$ & $\begin{array}{l}\text { Effective } \\
\text { reliability }\end{array}$ \\
\hline Bernstein, Lin, \& McClellan (1982), Study 1 & $\mathrm{CC}$ & 60 & B & .72 & .99 \\
\hline Bernstein, Lin, \& McClellan (1982), Study 2 & $\mathrm{CE}$ & 60 & $\mathrm{~B}$ & .83 & .99 \\
\hline N. Cavior \& Howard (1973) & $\mathrm{CE}$ & 90 & $\mathbf{M}$ & .89 & 99 \\
\hline Cunningham, Barbee, \& Pike (1990), Study 2 & $\mathrm{CE}$ & 60 & $\mathbf{M}$ & .04 & .71 \\
\hline Cunningham, Barbee, \& Pike (1990), Study 3 & $\mathrm{CE}$ & 90 & M & .06 & .86 \\
\hline Cunningham, Roberts, Barbee, Druen, \& Wu (1995) & $\mathrm{CC}$ & 52 & $\mathbf{F}$ & .92 & .99 \\
\hline Cunningham, Roberts, Barbee, Druen, \& Wu (1995) & $\mathrm{CE}$ & 63 & $\mathrm{~F}$ & .94 & .99 \\
\hline D. Jones \& Hill (1993) & $\mathrm{CC}$ & 376 & $\mathbf{F}$ & .36 & .99 \\
\hline D. Jones \& Hill (1993) & $\mathrm{CC}$ & 376 & $\mathbf{M}$ & .32 & 99 \\
\hline Madden \& Hollingworth (1932) & $\mathrm{CC}$ & 20 & B & .69 & .98 \\
\hline Martin (1964) & CE & 100 & $\mathrm{~F}$ & .06 & .86 \\
\hline Martin (1964) & $\mathrm{CC}$ & 100 & $\mathbf{F}$ & .01 & .44 \\
\hline Martin (1964) & $\mathrm{CC}$ & 100 & $\mathrm{~F}$ & .02 & .64 \\
\hline McArthur \& Berry (1987), Study 1 & $\mathrm{CC}$ & 64 & B & .95 & .99 \\
\hline McArthur \& Berry (1987), Study 2 & $\mathrm{CC}$ & 48 & $\mathbf{M}$ & .47 & .98 \\
\hline Thakerar \& Iwawaki (1979) & $\mathrm{CC}$ & 17 & $\mathbf{M}$ & .32 & .89 \\
\hline Udry (1965) & $\mathrm{CC}$ & 10,517 & $\mathrm{~F}$ & .75 & .99 \\
\hline Zebrowitz, Montepare, \& Lee (1993) & $\mathrm{CE}$ & 104 & B & .69 & 99 \\
\hline Zebrowitz, Montepare, \& Lee (1993) & $\mathrm{CC}$ & 128 & B & .47 & .99 \\
\hline Zebrowitz, Montepare, \& Lee (1993) & $\mathrm{CC}$ & 72 & B & .23 & .96 \\
\hline Zebrowitz, Montepare, \& Lee (1993) & $\mathrm{CE}$ & 48 & B & .74 & .99 \\
\hline Zebrowitz, Montepare, \& Lee (1993) & $\mathrm{CC}$ & 54 & B & .69 & .99 \\
\hline Zebrowitz, Montepare, \& Lee (1993) & $\mathrm{CC}$ & 54 & B & .75 & .99 \\
\hline Zebrowitz, Montepare, \& Lee (1993) & CE & 44 & $\bar{B}$ & .79 & .99 \\
\hline Zebrowitz, Montepare, \& Lee (1993) & $\mathrm{CC}$ & 54 & B & .72 & .99 \\
\hline Zebrowitz, Montepare, \& Lee (1993) & $\mathrm{CC}$ & 54 & B & .69 & .99 \\
\hline
\end{tabular}

Note. Studies included in the meta-analyses of within-culture reliability are noted in the References. $\mathrm{CC}=$ cross-cultural; $\mathrm{CE}=\mathrm{cross}-\mathrm{ethnic} ; \mathrm{M}=$ male; $\mathrm{F}=$ female $; \mathbf{B}=$ both 
Appendix B

Studies Included in the Meta-Analysis Assessing Within-Culture Reliability

Abbot \& Sebastian (1981)

Babad, Inbar, \& Rosenthal (1982)

Baugh \& Parry (1991)

Berscheid, Dion, Walster, \& Walster (1971)

T. A. Brown, Cash, Noles (1986)

Burns \& Farina (1987)

Campbell, Kleim, \& Olson (1986)

Cash \& Begley (1976)

Cash \& Burns (1977)

Cash \& Smith (1982)

N. Cavior \& Dokecki (1973)

N. Cavior \& Howard (1973)

Chaiken (1979)

Cheek \& Buss (1981)

Clifford (1975)

P. S. Cooper (1993)

Critelli \& Waid (1980)

Curran (1973)

Curran \& Lippold (1975)

DePaulo, Tang, \& Stone (1987)

Dickey-Bryant, Lautenschlager, Mendoza, \& Abrahams (1986)

Diener, Wolsic, \& Fujita (1995)

Dion \& Berscheid (1974)

Elder, Van Nguyen, \& Caspi (1985)

Farina et al. (1977)

Felson \& Bohmstedt (1979)

Friedman, Riggio, \& Casella (1988)

Gabriel, Critelli, \& Ee (1994)

Gallucci \& Meyer (1984)

Gangestad \& Thornhill (1997)

Garcia, Stinson, Ickes, Bisonette, \& Briggs (1991)

Gifford, $\mathrm{Ng}$, \& Wilkinson (1985)

Goldberg, Gottesdiener, \& Abramson (1975)

Goldman \& Lewis (1977)

Greenwald (1977)

Hadjistavropoulos, Tuokko, \& Beattie (1991)

Hansell, Sparacino, \& Ronchi (1982)

Hildebrandt \& Cannan (1985)

Hollingworth (1935)

D. J. Jackson \& Huston (1975)

R. W. Johnson, Doiron, Brooks, \& Dickinson (1978)

Kaats \& Davis (1970)
Kahn, Hottes, \& Davis (1971)

Kalick, Zebrowitz, Langlois, \& Johnson (1998)

Kenealy, Frude, \& Shaw (1987)

Kowner \& Ogawa (1995)

Langlois, Ritter, Roggman, \& Vaughn (1991)

Langlois et al. (1987)

Langlois, Roggman, \& Rieser-Danner (1990)

Larrance \& Zuckerman (1981)

Leinbach \& Fagot (1991)

Mandel \& Shrauger (1980)

Markley, Kramer, Parry, \& Ryabik (1982)

Martindale, Ross, Hines, \& Abrams (1978)

Mathes \& Kahn (1975)

McGovern, Neale, \& Kendler (1996)

L. C. Miller \& Cox (1982)

Moisan-Thomas, Conger, Zellinger, \& Firth (1985)

Napoleon, Chassin, \& Young (1980)

Noles, Cash, \& Winstead (1985)

O'Grady (1982)

Reis, Nezlek, \& Wheeler (1980)

Reis, Wheeler, Nezlek, Kernis, \& Spiegel (1985)

Rieser-Danner, Roggman, \& Langlois (1987)

Rowe, Clapp, \& Wallis (1987)

Salvia, Algozzine, \& Sheare (1977)

Samuels \& Ewy (1985)

Sarason, Sarason, Hacker, \& Basham (1985)

Shackelford \& Larsen (1999)

J. Shea, Crossman, \& Adams (1978)

G. J. Smith (1985)

J. Smith \& Krantz (1986)

Snyder, Berscheid, \& Glick (1985)

Sparacino (1980)

Sparacino \& Hansell (1979)

Steffen \& Redden (1977)

Stewart (1980)

Stewart (1984)

Sussman \& Mueser (1983)

Turner, Gilliland, \& Klein (1981)

Vaughn \& Langlois (1983)

Walster, Aronson, Abrahams, \& Rottmann (1966)

Wessberg, Marriotto, Conger, Farrell, \& Conger (1979)

Zakahi \& Duran (1988) 


\section{Appendix C}

Studies Included in Meta-Analysis of Judgment of Attractive and Unattractive Adults

\begin{tabular}{|c|c|c|c|c|c|c|c|c|}
\hline Study & $\begin{array}{c}\text { Sample } \\
\text { size }\end{array}$ & $\begin{array}{l}\text { Target } \\
\text { gender }\end{array}$ & $\begin{array}{l}\text { Perceiver } \\
\text { gender }\end{array}$ & Familiarity & $\begin{array}{l}\text { Rater } \\
\text { type }\end{array}$ & $\begin{array}{c}\text { Physical } \\
\text { attractiveness } \\
\text { measure }\end{array}$ & $\begin{array}{l}\text { Physical } \\
\text { attractiveness } \\
\text { range }\end{array}$ & $d$ \\
\hline R. D. Brown (1970) & 164 & $\mathbf{M}$ & $\mathbf{M}$ & 2 & $\mathbf{N}$ & $\mathbf{G}$ & $\mathrm{C}$ & 0.32 \\
\hline R. D. Brown (1970) & 61 & $\mathbf{F}$ & $\mathbf{M}$ & 2 & $\mathbf{N}$ & $G$ & $\mathrm{C}$ & 0.18 \\
\hline T. A. Brown, Cash, \& Noles (1986) & 30 & $\mathbf{M}$ & $\mathbf{M}$ & 1 & I & G & C & 1.08 \\
\hline T. A. Brown, Cash, \& Noles (1986) & 85 & $\mathbf{F}$ & $\mathbf{M}$ & 1 & I & $\mathrm{G}$ & $\mathrm{C}$ & 0.90 \\
\hline Byme, Ervin, \& Lamberth (1970) & 44 & $\mathbf{M}$ & $\mathbf{F}$ & 2 & I & $\mathrm{G}$ & $\mathrm{C}$ & 0.62 \\
\hline Byme, Ervin, \& Lamberth (1970) & 44 & $\mathbf{F}$ & $\mathbf{M}$ & 2 & I & G & C & 0.74 \\
\hline Carnpbell, Kleim, \& Olson (1986) & 41 & $\mathbf{F}$ & B & 1 & I & $G$ & $\mathrm{C}$ & 0.04 \\
\hline Chaiken (1979) & 272 & $\mathbf{M}$ & M & 2 & I & $\mathrm{F}$ & $\mathrm{D}$ & 0.02 \\
\hline Cherninik (1989) & 12 & B & B & 1 & $\mathbf{N}$ & G & $\mathrm{D}$ & 1.79 \\
\hline Cherulnik (1989) & 12 & B & B & 1 & $\mathrm{~N}$ & $\mathrm{G}$ & $\mathrm{D}$ & -0.12 \\
\hline Chenulnik (1989) & 6 & B & B & 1 & $\mathbf{N}$ & $\mathrm{G}$ & D & 2.08 \\
\hline Diener, Wolsic, \& Fujita (1995) & 221 & B & B & 3 & I & $\mathrm{F}$ & $\mathrm{C}$ & 0.24 \\
\hline Dipboye, Fromkin, \& Wiback (1975) & 12 & $\mathbf{M}$ & $\mathbf{F}$ & 1 & I & $\mathbf{F}$ & D & 2.06 \\
\hline Farina et al. (1977), Study 1 & 23 & $\mathbf{F}$ & $\mathbf{M}$ & 3 & I & $\mathrm{F}$ & $\mathrm{C}$ & 0.40 \\
\hline Foster, Pearson, \& Imahori (1985) & 33 & $\mathbf{M}$ & $\mathbf{M}$ & 2 & $\mathrm{~N}$ & G & $\mathrm{C}$ & 1.05 \\
\hline Friedman, Riggio, \& Casella (1988) & 231 & $\mathbf{M}$ & $\mathbf{M}$ & 1 & I & $\mathrm{G}$ & $\mathrm{C}$ & 0.18 \\
\hline Friedman, Riggio, \& Casella (1988) & 31 & $\mathbf{F}$ & $\mathbf{M}$ & 1 & 1 & $\mathrm{G}$ & $\mathrm{C}$ & 0.62 \\
\hline Gifford, $\mathrm{Ng}, \&$ Wilkinson (1985) & 34 & $\mathbf{M}$ & $\mathbf{M}$ & 1 & I & $\mathrm{G}$ & $\mathrm{C}$ & 0.53 \\
\hline Goldman \& Lewis (1977) & 60 & $\mathbf{M}$ & $\mathbf{M}$ & 2 & $\mathrm{~N}$ & $\mathbf{G}$ & $\mathrm{C}$ & 0.56 \\
\hline Goldman \& Lewis (1977) & 60 & F & M & 2 & $\mathrm{~N}$ & $\mathrm{G}$ & C & 0.26 \\
\hline Harnish, Abbey, \& DeBono (1989) & 187 & $\mathbf{M}$ & M & 2 & $\mathrm{~N}$ & $G$ & C & 0.80 \\
\hline W. H. Jones, Freemon, \& Goswick (1981), Study 4 & 25 & $\mathbf{M}$ & $\mathbf{M}$ & 3 & I & $\mathrm{G}$ & $\mathrm{C}$ & 0.44 \\
\hline W. H. Jones, Freemon, \& Goswick (1981), Study 4 & 31 & $\mathbf{F}$ & M & 3 & I & $\mathrm{G}$ & $\mathrm{C}$ & 0.47 \\
\hline Kleck \& Rubenstein (1975) & 48 & $\mathrm{~F}$ & M & 2 & $\mathbf{N}$ & G & D & 1.09 \\
\hline Kuhlenschmidt \& Conger (1988) & 15 & $\mathrm{~F}$ & M & 2 & I & G & $\mathrm{C}$ & 0.08 \\
\hline Marlowe, Schneider, \& Nelson (1996) & 112 & B & B & 1 & I & $\mathrm{F}$ & $\mathrm{D}$ & 0.79 \\
\hline Nelson, Hayes, Felton, \& Jarrett (1985) & 38 & M & $\mathbf{M}$ & 2 & $\mathbf{N}$ & G & $\mathrm{C}$ & 0.51 \\
\hline Neumann, Critelli, \& Tang (1986) & 20 & $\mathbf{M}$ & $\mathbf{F}$ & 1 & I & $\mathbf{F}$ & $\mathrm{C}$ & 1.29 \\
\hline Shapiro, Struening, Shapiro, \& Barten (1976) & 96 & $\mathbf{M}$ & $\mathbf{M}$ & 3 & $\mathbf{N}$ & $G$ & $\mathrm{C}$ & 1.03 \\
\hline Steffen \& Redden $(1977)$ & 40 & $\mathbf{M}$ & $\mathbf{F}$ & 1 & $\mathbf{N}$ & $G$ & C & 1.11 \\
\hline
\end{tabular}

Note. $\mathrm{M}=$ male; $\mathrm{F}=$ female; $\mathrm{B}=$ both; $1=$ less; $3=$ more; $\mathrm{NA}=$ not provided in primary article but either 1 or $2 ; \mathrm{I}=$ independent; $\mathrm{N}=$ nonindependent; $\mathrm{F}=$ facial measure; $\mathrm{G}=$ global measure; $\mathrm{C}=$ continuous; $\mathrm{D}=$ dichotomous.

\section{Appendix D}

Studies Included in Meta-Analysis of Judgment of Attractive and Unattractive Children

\begin{tabular}{|c|c|c|c|c|c|c|c|c|}
\hline Study & $\begin{array}{c}\text { Sample } \\
\text { size }\end{array}$ & $\begin{array}{l}\text { Target } \\
\text { gender }\end{array}$ & $\begin{array}{l}\text { Perceiver } \\
\text { gender }\end{array}$ & $\begin{array}{l}\text { Rater } \\
\text { type }\end{array}$ & $\begin{array}{l}\text { Perceiver } \\
\text { age }\end{array}$ & $\begin{array}{c}\text { Physical } \\
\text { attractiveness } \\
\text { measure }\end{array}$ & Familiarity & $d$ \\
\hline Dion \& Berscheid (1974) & 71 & B & B & I & $\mathrm{C}$ & F & 3 & 0.53 \\
\hline Felson \& Bohrnstedt (1979) & 209 & F & B & I & $\mathrm{C}$ & $\mathbf{F}$ & 3 & 1.12 \\
\hline Felson \& Bohrnstedt (1979) & 207 & $M$ & B & I & $\mathrm{C}$ & $\mathbf{F}$ & 3 & 1.56 \\
\hline Kenealy, Frude, \& Shaw (1987) & 503 & $\mathrm{~F}$ & B & $\bar{I}$ & A & $\mathbf{F}$ & 3 & 1.22 \\
\hline Kenealy, Frude, \& Shaw (1987) & 503 & $M$ & B & l & A & $\mathbf{F}$ & 3 & 1.25 \\
\hline Lippitt (1941) & 15 & B & F & $\mathbf{N}$ & A & $\mathrm{G}$ & 3 & -0.66 \\
\hline Lippitt (1941) & 21 & $\mathbf{B}$ & $F$ & $\mathbf{N}$ & A & $\mathbf{G}$ & 3 & -0.54 \\
\hline Lippitt (1941) & 9 & B & $\mathbf{F}$ & $\mathbf{N}$ & A & G & 3 & 4.50 \\
\hline Rieser-Danner, Roggmann, \& Langlois (1987) & 23 & $\mathbf{B}$ & $F$ & 1 & $\mathbf{A}$ & $\mathrm{F}$ & 3 & -0.14 \\
\hline Weisfeld, Block, \& Ivers (1983) & 50 & $\mathbf{M}$ & $F$ & $\mathbf{N}$ & C & $\mathrm{G}$ & 3 & 0.94 \\
\hline Weisfeld, Weisfeld, \& Callaghan (1984) & 25 & M & $\mathbf{B}$ & $\mathrm{N}$ & $\mathrm{C}$ & G & 3 & -0.18 \\
\hline Weisfeld, Weisfeld, \& Callaghan (1984) & 8 & $\mathrm{~F}$ & $\mathbf{B}$ & $\mathbf{N}$ & $\mathrm{C}$ & G & 3 & 0.16 \\
\hline Weisfeld, Weisfeld, \& Callaghan (1984) & 24 & $\mathbf{F}$ & B & $\mathbf{N}$ & $\mathrm{C}$ & $\mathrm{G}$ & 3 & 0.75 \\
\hline
\end{tabular}

Note. $\mathrm{M}=$ male $; \mathrm{F}=$ female $; \mathrm{B}=$ both $\mathrm{I}=$ independent $\mathrm{N}=$ nonindependent; $\mathrm{A}=$ adult $\mathrm{C}=$ child $\mathrm{F}=$ facial measure; $\mathrm{G}=$ global measure; $1=$ less; $3=$ more. 
Appendix E

Studies Included in Meta-Analysis of Treatment of Attractive and Unattractive Adults

\begin{tabular}{|c|c|c|c|c|c|c|c|c|}
\hline Study & $\begin{array}{c}\text { Sample } \\
\text { size }\end{array}$ & $\begin{array}{l}\text { Target } \\
\text { gender }\end{array}$ & $\begin{array}{l}\text { Agent } \\
\text { gender }\end{array}$ & $\begin{array}{l}\text { Rater } \\
\text { type }\end{array}$ & $\begin{array}{c}\text { Physical } \\
\text { attractiveness } \\
\text { measure }\end{array}$ & $\begin{array}{l}\text { Physical } \\
\text { attractiveness } \\
\text { range }\end{array}$ & Familiarity & $d$ \\
\hline Alain (1985) & 48 & B & B & I & $\mathbf{F}$ & $\mathrm{D}$ & 1 & 0.66 \\
\hline Alcock, Solano, \& Kayson (1998) & 80 & B & B & I & $G$ & $\mathrm{D}$ & 1 & 0.81 \\
\hline S. M. Anderson \& Bem (1981) & 24 & B & $\mathbf{M}$ & I & $\mathbf{F}$ & $\mathrm{D}$ & 2 & 0.39 \\
\hline S. M. Anderson \& Bem (1981) & 24 & B & $\mathbf{F}$ & I & F & $\mathrm{D}$ & 2 & 0.10 \\
\hline Benson, Karabenick, \& Lerner (1976) & 604 & B & B & I & $\mathrm{F}$ & D & 1 & 0.24 \\
\hline Brundage, Derlega, \& Cash (1977) & 32 & $\mathbf{M}$ & F & I & $\mathrm{F}$ & D & 1 & 0.44 \\
\hline Byme, Ervin, \& Lamberth (1970) & 44 & $\mathbf{M}$ & $\mathrm{F}$ & $\mathbf{N}$ & G & $\mathrm{C}$ & 2 & 0.12 \\
\hline Byrne, Ervin, \& Lamberth (1970) & 44 & $\mathbf{F}$ & $\mathbf{M}$ & $\mathbf{N}$ & $\mathbf{G}$ & $\mathrm{C}$ & 2 & 0.71 \\
\hline H. E. Cavior, Hayes, \& Cavior (1974) & 75 & $\mathbf{F}$ & B & $I$ & $\mathrm{~F}$ & $\mathrm{C}$ & 3 & 0.49 \\
\hline Chaiken (1979) & 68 & $\mathrm{~B}$ & B & I & $\mathrm{F}$ & $\mathrm{D}$ & 2 & 0.32 \\
\hline DePaulo, Tang, \& Stone (1987) & 8 & B & B & I & $\mathrm{F}$ & D & 1 & 0.88 \\
\hline Efran \& Patterson (1974) & 79 & NR & B & I & $\mathrm{F}$ & $\mathrm{D}$ & 1 & 0.86 \\
\hline Farina et al. (1977), Study 2 & 50 & $\mathbf{F}$ & B & I & $\mathrm{F}$ & C & 3 & 1.02 \\
\hline Kleck \& Rubenstein (1975) & 40 & $\mathbf{F}$ & $\mathbf{M}$ & I & G & $\mathrm{D}$ & 2 & 0.81 \\
\hline Langlois et al. (1987), Study 1 & 30 & $\mathbf{F}$ & B & I & $\mathbf{F}$ & $\mathrm{D}$ & 1 & 0.73 \\
\hline Langlois et al. (1987), Study 2 & 34 & $\mathbf{F}$ & B & I & $\mathbf{F}$ & $\mathrm{D}$ & 1 & 0.80 \\
\hline Langlois, Ritter, Roggman, \& Vaughan (1991), Study 1 ' & 60 & B & B & I & $\mathbf{F}$ & $\mathrm{D}$ & 1 & 0.55 \\
\hline Langlois, Ritter, Roggman, \& Vaughan (1991), Study 2 & 40 & $\mathbf{F}$ & B & I & $\mathbf{F}$ & D & 1 & 0.66 \\
\hline Langlois, Roggman, \& Rieser-Danner (1990), Study 1 & 60 & $\mathbf{F}$ & B & 1 & $\mathbf{F}$ & $\mathrm{C}$ & 2 & 0.60 \\
\hline Mathes \& Edwards (1978), Study 1 & 68 & B & $\mathbf{B}$ & $\mathbf{N}$ & $\mathrm{G}$ & $\mathrm{D}$ & 2 & 0.62 \\
\hline Mims, Hartnett, \& Nay (1975) & 40 & $\mathbf{F}$ & B & $\mathbf{N}$ & G & D & 2 & 0.99 \\
\hline Nadler (1980) & 40 & $\mathbf{F}$ & F & I & F & $\mathrm{D}$ & 1 & 0.66 \\
\hline Pellegrini, Hicks, Meyers-Winton, \& Antal (1978) & 96 & B & B & $\mathrm{N}$ & $\mathrm{G}$ & $\mathrm{D}$ & 2 & 0.85 \\
\hline Powell \& Dabbs (1976), Study 1 & 30 & B & $\mathbf{B}$ & NR & $\mathrm{F}$ & $\mathrm{C}$ & 1 & 1.96 \\
\hline Raza \& Carpenter (1987) & 171 & B & B & $\mathrm{N}$ & G & C & 2 & 0.70 \\
\hline Romer \& Berkson (1980) & 176 & B & B & $\mathbf{N}$ & G & $\mathrm{D}$ & 3 & 0.26 \\
\hline Samuels \& Ewy (1985) & 26 & B & B & I & F & $\mathrm{D}$ & 1 & 3.78 \\
\hline Samuels \& Ewy (1985) & 35 & B & B & I & $\mathrm{F}$ & C & 1 & 4.95 \\
\hline J. A. Shea \& Adams (1984) & 437 & $\mathbf{M}$ & $\mathrm{F}$ & $\mathbf{N}$ & $\mathrm{F}$ & C & 3 & 0.47 \\
\hline J. A. Shea \& Adams (1984) & 219 & $\mathbf{F}$ & $\mathbf{M}$ & $\mathrm{N}$ & $\mathrm{F}$ & $\mathrm{D}$ & 3 & 0.43 \\
\hline Slater et al. (1998) & 16 & $\mathbf{F}$ & B & I & $\mathrm{F}$ & $\mathrm{D}$ & 1 & 9.31 \\
\hline Sroufe, Chaikin, Cook, \& Freeman (1977), Study 1 & 90 & $\mathbf{F}$ & B & I & $\mathbf{F}$ & D & 1 & 0.53 \\
\hline Sroufe, Chaikin, Cook, \& Freeman (1977), Study 2 & 90 & $\mathbf{F}$ & B & I & $\mathbf{F}$ & C & 1 & 0.43 \\
\hline Stewart (1980) & 67 & B & NR & I & G & C & 1 & 0.62 \\
\hline Stewart (1984) & 60 & $\mathbf{B}$ & NR & I & G & $\mathrm{D}$ & 1 & 0.94 \\
\hline Stokes \& Bickman (1974) & 80 & $\mathbf{F}$ & $\mathbf{F}$ & I & G & $\mathrm{D}$ & 1 & 0.62 \\
\hline West \& Brown (1975), Study 1 & 60 & $\mathbf{F}$ & $\mathbf{M}$ & NR & $\mathrm{G}$ & $\mathrm{D}$ & 2 & 0.34 \\
\hline Wilson (1978) & 30 & $\mathrm{~F}$ & $\mathbf{M}$ & NR & $\mathbf{F}$ & $\mathrm{D}$ & 1 & 1.04 \\
\hline Wilson (1978) & 40 & F & $\mathbf{M}$ & NR & F & D & 1 & 1.29 \\
\hline
\end{tabular}

Note. $\mathrm{M}=$ male; $\mathrm{F}=$ female; $\mathrm{B}=$ both $\mathrm{I}=$ independent; $\mathrm{N}=$ nonindependent; $\mathrm{F}=$ facial measure; $\mathrm{G}=$ global measure; $\mathrm{C}=$ continuous; $\mathrm{D}=$ dichotomous; 1 = less; 3 = more. 
Appendix F

Studies Included in Meta-Analysis of Treatment of Attractive and Unattractive Children

\begin{tabular}{|c|c|c|c|c|c|c|c|c|}
\hline Study & $\begin{array}{l}\text { Sample } \\
\text { size }\end{array}$ & $\begin{array}{l}\text { Target } \\
\text { gender }\end{array}$ & $\begin{array}{c}\text { Perceiver } \\
\text { gender }\end{array}$ & $\begin{array}{c}\text { Target } \\
\text { age }\end{array}$ & Familiarity & $\begin{array}{c}\text { Physical } \\
\text { attractiveness } \\
\text { measure }\end{array}$ & $\begin{array}{c}\text { Physical } \\
\text { attractiveness } \\
\text { range }\end{array}$ & $d$ \\
\hline Barocas \& Black (1974) & 54 & $\mathbf{M}$ & F & NR & 3 & $\mathbf{F}$ & $\mathrm{C}$ & 0.67 \\
\hline Barocas \& Black (1974) & 46 & F & $\mathbf{F}$ & NR & 3 & $\mathbf{F}$ & $\mathrm{C}$ & 0.42 \\
\hline Berkowitz \& Frodi (1979), Study 1 & 56 & F & $\mathbf{F}$ & 10 & 1 & G & D & 0.89 \\
\hline Berkowitz \& Frodi (1979), Study 2 & 40 & $\mathbf{M}$ & $\mathbf{F}$ & 10 & 1 & G & D & 0.96 \\
\hline Dailey, Allen, Chinsky, \& Veit (1974) & 37 & B & B & 9.3 & 3 & F & $\mathrm{C}$ & 0.22 \\
\hline Dion (1974), Study 1 & 20 & M & $\mathrm{F}$ & 8 & 1 & $\mathrm{G}$ & D & 0.65 \\
\hline Dion (1974), Study 2 & 20 & F & $\mathrm{F}$ & 8 & 1 & G & D & -0.52 \\
\hline Dion (1977) & 58 & B & B & NR & 1 & $\mathrm{~F}$ & D & 0.58 \\
\hline Elder, Van Nguyen, \& Caspi (1985) & 55 & $\mathrm{~F}$ & $\mathrm{M}$ & NR & 3 & $\mathrm{G}$ & C & 0.58 \\
\hline Felson \& Bohrnstedt (1979)/Felson (1980) & 209 & $\mathbf{M}$ & NR & NR & 3 & $\mathbf{F}$ & $\mathrm{C}$ & 0.54 \\
\hline Felson \& Bohrnstedt (1979)/Felson (1980) & 204 & $\mathbf{F}$ & NR & NR & 3 & $\mathbf{F}$ & $\mathrm{C}$ & 0.28 \\
\hline Hildebrandt \& Cannan (1985) & 31 & B & B & NR & 3 & $\mathbf{F}$ & $\mathrm{C}$ & -0.06 \\
\hline Karraker (1986) & 45 & B & $\mathrm{F}$ & .007 & 2 & $\mathbf{F}$ & $\mathrm{C}$ & -0.64 \\
\hline Kenealy, Frude, \& Shaw (1987) & 504 & $\mathbf{M}$ & B & NR & 3 & F & $\mathrm{C}$ & 0.92 \\
\hline Kenealy, Frude, \& Shaw (1987) & 504 & $\mathbf{F}$ & B & NR & 3 & $\mathbf{F}$ & $\mathrm{C}$ & 1.10 \\
\hline Langlois, Ritter, Casey, \& Sawin (1995) & 173 & B & $\mathrm{F}$ & 0 & 3 & $F$ & $\mathrm{C}$ & 0.36 \\
\hline Langlois, Ritter, Roggman, \& Vaughn (1991), Study 3 & 39 & B & B & .25 & 1 & $\mathrm{~F}$ & D & 0.71 \\
\hline Leinbach \& Fagot (1991) & 17 & $\mathbf{M}$ & B & 1.9 & 3 & $\mathbf{F}$ & $\mathrm{C}$ & 0.27 \\
\hline Leinbach \& Fagot (1991) & 19 & $\mathbf{F}$ & B & 1.7 & 3 & $\mathrm{~F}$ & $\mathrm{C}$ & 0.21 \\
\hline Lerner, Delaney, Hess, Jovanovic, \& von Eye (1990) & 101 & B & $\mathbf{F}$ & 11.6 & 3 & $\mathrm{~F}$ & $\mathrm{C}$ & 0.58 \\
\hline Lerner \& Lemer (1977) & 104 & B & $\mathbf{F}$ & 10.4 & 3 & $\mathrm{~F}$ & $\mathrm{C}$ & 0.54 \\
\hline Salvia, Algozzine, \& Sheare (1977) & 84 & B & B & NR & 3 & $\mathrm{~F}$ & $\mathrm{C}$ & 0.67 \\
\hline G. J. Smith (1985) & 18 & $\mathbf{F}$ & B & 4.2 & 3 & G & D & 1.22 \\
\hline Vaughn \& Langlois (1983) & 34 & $\mathbf{M}$ & B & NR & 3 & $\mathrm{~F}$ & $\mathrm{C}$ & 0.57 \\
\hline Vaughn \& Langlois (1983) & 23 & F & B & NR & 3 & $\mathrm{~F}$ & $\mathrm{C}$ & 0.16 \\
\hline Zahr (1985) & 190 & B & NR & NR & 3 & $\mathbf{F}$ & C & 1.09 \\
\hline
\end{tabular}

Note. $\mathrm{M}=$ male; $\mathrm{F}=$ female; $\mathrm{B}=$ both; $1=$ less; $3=$ more; $\mathrm{F}=$ facial measure; $\mathrm{G}=$ global measure; $\mathrm{C}=$ continuous; $\mathrm{D}=$ dichotomous. 
Appendix G

Studies Included in Meta-Analysis of Adult Behavior/Trait Differences

\begin{tabular}{|c|c|c|c|c|c|}
\hline Study & Sample size & Gender & Rater type & Attractiveness measure & $d$ \\
\hline Barocas \& Vance (1974) & 12 & M & $\mathbf{N}$ & $\mathbf{G}$ & 0.34 \\
\hline Barocas \& Vance (1974) & 63 & $\mathbf{M}$ & $\mathrm{N}$ & G & 0.51 \\
\hline Barocas \& Vance (1974) & 57 & $\mathbf{F}$ & $\mathbf{N}$ & $\mathbf{G}$ & 0.79 \\
\hline Barocas \& Vance (1974) & 23 & $\mathbf{F}$ & $\mathbf{N}$ & G & 0.84 \\
\hline Baugh \& Parry (1991) & 39 & $\mathbf{F}$ & I & G & 0.20 \\
\hline Berscheid, Dion, Walster, \& Walster (1971), Study 2 & 56 & M & $\mathbf{I}$ & $\mathbf{G}$ & 0.40 \\
\hline Berscheid, Dion, Walster, \& Walster (1971), Study 2 & 56 & $\mathrm{~F}$ & $\mathbf{I}$ & G & 1.20 \\
\hline Brislin \& Lewis (1968) & 29 & $\mathbf{M}$ & I & G & 3.79 \\
\hline Brislin \& Lewis (1968) & 29 & $\mathrm{~F}$ & I & G & 3.79 \\
\hline R. D. Brown (1970) & 164 & $\mathbf{M}$ & $\mathbf{N}$ & G & 0.16 \\
\hline R. D. Brown (1970) & 61 & $\mathbf{F}$ & $\mathbf{N}$ & G & 0.38 \\
\hline Brunswick (1945) & 46 & M & I & $\mathbf{G}$ & 0.10 \\
\hline Burns \& Farina (1987) & 231 & $\mathbf{F}$ & I & $\mathbf{G}$ & 0.34 \\
\hline Campbell, Klein, \& Olson (1986) & 21 & $\mathbf{M}$ & $\mathrm{N}$ & G & 0.84 \\
\hline Campbell, Klein, \& Olson (1986) & 41 & $\mathbf{F}$ & $\mathrm{N}$ & G & 0.73 \\
\hline Cash \& Begley (1976) & 32 & $\mathbf{M}$ & $\mathrm{N}$ & G & 1.09 \\
\hline Cash \& Begley (1976) & 32 & $\mathbf{F}$ & $\mathbf{N}$ & G & 0.89 \\
\hline Cash \& Smith (1982) & 40 & $\mathbf{M}$ & $\mathrm{N}$ & $\mathrm{G}$ & 0.69 \\
\hline Cash \& Smith (1982) & 101 & $\mathbf{F}$ & $\mathrm{N}$ & G & 0.22 \\
\hline Cash \& Soloway (1975) & 24 & $\mathbf{M}$ & $\mathbf{N}$ & $\mathrm{G}$ & 0.16 \\
\hline Cash \& Soloway (1975) & 24 & $\mathrm{~F}$ & $\mathrm{~N}$ & G & -0.04 \\
\hline Chaiken (1979) & 68 & B & I & G & 0.45 \\
\hline Critelli \& Waid (1980) & 123 & $\mathbf{M}$ & I & $\mathrm{G}$ & 0.04 \\
\hline Critelli \& Waid (1980) & 123 & $\mathrm{~F}$ & I & $\mathrm{G}$ & 0.18 \\
\hline Curran (1973) & 75 & $\mathbf{M}$ & I & G & -0.02 \\
\hline Curran (1973) & 75 & $\mathrm{~F}$ & I & G & 0.60 \\
\hline Curran \& Lippold (1975), Study 1 & 294 & $\mathbf{M}$ & I & G & 0.49 \\
\hline Curran \& Lippold (1975), Study 1 & 294 & $\mathrm{~F}$ & I & G & 0.60 \\
\hline Curran \& Lippold (1975), Study 2 & 98 & $\mathbf{M}$ & I & G & 0.49 \\
\hline Curran \& Lippold (1975), Study 2 & 98 & $\mathrm{~F}$ & I & G & 0.65 \\
\hline Curran, Neff, \& Lippold (1973) & 195 & $\mathbf{M}$ & I & G & 0.45 \\
\hline Curran, Neff, \& Lippold (1973) & 161 & $\mathrm{~F}$ & I & G & 0.33 \\
\hline DePaulo, Tang, \& Stone (1987) & 68 & B & I & $\mathrm{F}$ & 0.02 \\
\hline Dickey-Bryant, Lautenschlager, Mendoza, \& Abrahams (1986) & 75 & $\mathbf{M}$ & I & $\mathbf{F}$ & 0.24 \\
\hline Farina et al. (1977), Study 1 & 23 & $\mathrm{~F}$ & I & $\mathbf{F}$ & 0.97 \\
\hline Farina et al. (1977), Study 2 & 50 & $\mathrm{~F}$ & I & $\mathbf{F}$ & 0.97 \\
\hline Feingold $(1982,1984)$ & 75 & $\mathbf{M}$ & I & $\mathbf{F}$ & -0.26 \\
\hline Feingold $(1982,1984)$ & 75 & $\mathrm{~F}$ & I & $\mathrm{F}$ & -0.20 \\
\hline Friedman, Riggio, \& Casella (1988) & 54 & B & I & G & 0.32 \\
\hline Gabriel, Critelli, \& Ee (1994) & 62 & $\mathbf{M}$ & I & $\mathbf{F}$ & 0.02 \\
\hline Gabriel, Critelli, \& Ee (1994) & 84 & $\mathrm{~F}$ & I & $\mathbf{F}$ & -0.04 \\
\hline Galluci \& Meyer (1984) & 48 & $\mathrm{~F}$ & I & $\mathbf{F}$ & 2.04 \\
\hline Gangestad \& Thornhill (1997) & 203 & $\mathrm{~F}$ & I & $\mathbf{F}$ & 0.16 \\
\hline Gangestad \& Thornhill (1997) & 203 & M & I & $\mathbf{F}$ & 0.04 \\
\hline Garcia, Stinson, Ickes, Bisonette, \& Briggs (1991) & 38 & $\mathbf{M}$ & I & G & -0.02 \\
\hline Garcia, Stinson, Ickes, Bisonette, \& Briggs (1991) & 38 & $\mathrm{~F}$ & I & G & 0.04 \\
\hline Glasgow \& Arkowitz (1975) & 59 & $\mathbf{M}$ & $\mathbf{N}$ & $\mathrm{G}$ & 0.86 \\
\hline Glasgow \& Arkowitz (1975) & 59 & $\mathrm{~F}$ & $\mathbf{N}$ & $\mathrm{G}$ & 1.02 \\
\hline Greenwald (1977) & 60 & $\mathbf{M}$ & I & $\mathrm{G}$ & 0.81 \\
\hline Greenwald (1977) & 45 & $\mathrm{~F}$ & I & G & 0.91 \\
\hline Hamermesh \& Biddle (1994) & 342 & $\mathbf{M}$ & I & G & 2.26 \\
\hline Hamermesh \& Biddle (1994) & 387 & $\mathbf{M}$ & I & G & 4.12 \\
\hline Hamermesh \& Biddle (1994) & 579 & $\mathrm{~F}$ & I & G & 0.85 \\
\hline Hamermesh \& Biddle (1994) & 258 & $\mathrm{~F}$ & I & G & 2.75 \\
\hline Hansell, Sparacino, \& Ronchi (1982), Study 1 & 118 & B & I & $\mathrm{F}$ & 0.43 \\
\hline Hansell, Sparacino, \& Ronchi (1982), Study 2 & 85 & $\mathrm{~F}$ & I & $\mathrm{F}$ & 0.51 \\
\hline Hansell, Sparacino, \& Ronchi (1982), Study 3 & 49 & $\mathrm{~F}$ & I & $\mathbf{F}$ & 0.81 \\
\hline D. J. Jackson \& Huston (1975), Study 1 & 10 & $\mathrm{~F}$ & $\mathbf{N}$ & G & 2.02 \\
\hline D. J. Jackson \& Huston (1975), Study 2 & 20 & $\mathrm{~F}$ & $\mathbf{N}$ & G & 1.87 \\
\hline R. W. Johnson, Doiron, Brooks, \& Dickinson (1978) & 30 & $\mathrm{~F}$ & I & $\mathbf{F}$ & 0.00 \\
\hline R. W. Johnson, Doiron, Brooks, \& Dickinson (1978) & 30 & $\mathrm{~F}$ & I & $\mathrm{F}$ & 0.02 \\
\hline W. H. Jones, Briggs, \& Smith (1986) & 39 & B & I & $\mathbf{G}$ & -0.57 \\
\hline W. H. Jones, Briggs, \& Smith (1986) & 30 & B & I & G & 0.30 \\
\hline Kaats \& Davis (1970) & 56 & $\mathrm{~F}$ & I & G & 0.60 \\
\hline Kalick, Zebrowitz, Langlois, \& Johnson (1998) & 125 & $\mathbf{M}$ & I & $\mathbf{F}$ & 0.10 \\
\hline
\end{tabular}


Appendix G (continued)

\begin{tabular}{|c|c|c|c|c|c|}
\hline Study & Sample size & Gender & Rater type & Attractiveness measure & $d$ \\
\hline Kalick, Zebrowitz, Langlois, \& Johnson (1998) & 127 & $\mathrm{~F}$ & I & $\mathbf{F}$ & 0.20 \\
\hline Kleck \& Rubenstein (1975) & 48 & M & I & $\mathbf{F}$ & 0.94 \\
\hline Kowner (1996) & 122 & B & $\mathrm{N}$ & $\mathbf{G}$ & 0.72 \\
\hline Kowner \& Ogawa (1995) & 49 & $\mathrm{M}$ & I & $\mathbf{F}$ & 0.43 \\
\hline Kowner \& Ogawa (1995) & 44 & $\mathrm{~F}$ & I & $\mathbf{F}$ & -0.314 \\
\hline Kuhlenschmidt \& Conger (1988) & 35 & $\mathrm{~F}$ & $\mathrm{I}$ & G & -0.06 \\
\hline Larrance \& Zuckerman (1981) & 60 & B & I & $\mathbf{F}$ & 0.97 \\
\hline Longo (1990) & 243 & B & I & G & -0.04 \\
\hline Mandel \& Shrauger (1980) & 37 & $\mathbf{M}$ & $\mathrm{N}$ & G & 0.34 \\
\hline Martindale, Ross, Hines, \& Abrams (1978) & 19 & B & I & $\mathrm{F}$ & 0.02 \\
\hline Martindale, Ross, Hines, \& Abrams (1978) & 19 & B & I & $\mathrm{F}$ & 0.31 \\
\hline Mathes \& Kahn (1975) & 110 & $\mathrm{M}$ & I & $\mathrm{G}$ & -0.08 \\
\hline Mathes \& Kahn (1975) & 101 & $\mathbf{F}$ & I & G & 0.49 \\
\hline McGovern, Neale, \& Kendler (1996) & 1,100 & $\mathrm{~F}$ & I & $\mathrm{F}$ & -0.02 \\
\hline L. C. Miller \& Cox (1982) & 42 & $\mathbf{F}$ & I & $\mathrm{F}$ & 0.57 \\
\hline Mohr (1932) & 25 & $\mathbf{M}$ & I & G & 0.59 \\
\hline Mohr (1932) & 25 & $\mathrm{~F}$ & I & G & 0.61 \\
\hline Mohr \& Lund (1933) & 50 & $\mathbf{M}$ & I & G & 0.10 \\
\hline Mohr \& Lund (1933) & 50 & $\mathrm{~F}$ & I & $\mathrm{G}$ & 0.51 \\
\hline Moisan-Thomas, Conger, Zellinger, \& Firth (1985) & 60 & $\mathbf{M}$ & I & G & 0.38 \\
\hline Murphy, Nelson, \& Cheap (1981) & 41 & $\mathbf{B}$ & I & $\mathbf{F}$ & 0.26 \\
\hline Napoleon, Chassin, \& Young (1980) & 28 & B & I & $\mathbf{F}$ & 0.20 \\
\hline Noles, Cash, \& Winstead (1985) & 77 & $\mathbf{B}$ & I & G & -0.16 \\
\hline O'Grady (1989) & 64 & $\mathbf{M}$ & I & $\mathbf{F}$ & -0.56 \\
\hline O'Grady (1989) & 63 & $\mathrm{~F}$ & I & $\mathrm{F}$ & 0.58 \\
\hline Pellegrini, Hicks, Meyers-Winton, \& Antal (1978) & 96 & $\mathbf{B}$ & $\mathrm{N}$ & G & -0.69 \\
\hline Pilkonis (1977) & 46 & $\mathbf{B}$ & 1 & G & 0.62 \\
\hline Raskin \& Terry (1988), Study 2 & 57 & $\mathbf{B}$ & $\mathrm{N}$ & $\mathrm{F}$ & -0.20 \\
\hline Raza \& Carpenter (1987) & 171 & B & $\mathbf{N}$ & G & 0.79 \\
\hline Reis, Nezlek, \& Wheeler (1980) & 35 & $\mathbf{M}$ & I & G & 0.24 \\
\hline Reis, Nezlek, \& Wheeler (1980) & 36 & $\mathbf{F}$ & I & G & 0.20 \\
\hline Reis et al. (1982) & 43 & $\mathbf{M}$ & I & G & 0.20 \\
\hline Reis et al. (1982)/Reis, Wheeler, Nezlek, Kernis, \& Spiegel (1985) & 51 & $\mathbf{F}$ & $\mathbf{I}$ & G & -0.10 \\
\hline Romer \& Berkson (1980) & 176 & $\mathbf{B}$ & $\mathrm{N}$ & $\mathrm{G}$ & 0.18 \\
\hline Roszell, Kennedy, \& Grabb (1990) & 1,141 & B & $\mathbf{N}$ & $\mathbf{F}$ & 0.16 \\
\hline Rowe, Clapp, \& Wallis (1987) & 28 & M & $\mathbf{I}$ & $\mathbf{F}$ & 0.38 \\
\hline Rowe, Clapp, \& Wallis (1987) & 22 & $\mathrm{~F}$ & I & $\mathbf{F}$ & 0.50 \\
\hline Sarason, Sarason, Hacker, \& Basham (1985) & 168 & B & I & $\mathbf{F}$ & 0.14 \\
\hline Shackelford \& Larsen (1999) & 34 & M & I & $\mathbf{F}$ & 0.28 \\
\hline Shackelford \& Larsen (1999) & 66 & $\mathrm{~F}$ & I & $\mathbf{F}$ & 0.22 \\
\hline Shapiro, Struening, Shapiro, \& Barten (1976) & 97 & B & $\mathrm{N}$ & G & 1.41 \\
\hline Shapiro, Struening, Shapiro, \& Barten (1976) & 97 & B & $\mathbf{N}$ & G & 1.18 \\
\hline Singer (1964) & 10 & F & I & $\mathrm{F}$ & 0.20 \\
\hline Singer (1964) & 14 & $\mathbf{F}$ & I & $\mathrm{F}$ & 0.63 \\
\hline Singer (1964) & 192 & $\mathbf{F}$ & I & $\mathrm{F}$ & 0.38 \\
\hline Snyder, Berscheid, \& Glick (1985) & 39 & $\mathbf{M}$ & I & $\mathrm{G}$ & 0.07 \\
\hline Sparacino $(1980)$ & 549 & $\mathbf{M}$ & I & F & -0.20 \\
\hline Sparacino \& Hansell (1979), Study 1 & 55 & $\mathbf{M}$ & 1 & $\mathbf{F}$ & 0.26 \\
\hline Sparacino \& Hansell (1979), Study 1 & 65 & $\mathbf{F}$ & I & $\mathrm{F}$ & 0.18 \\
\hline Sparacino \& Hansell (1979), Study 2 & 50 & $\mathbf{M}$ & I & F & -0.64 \\
\hline Sparacino \& Hansell (1979), Study 2 & 87 & $\mathbf{F}$ & I & $\mathrm{F}$ & -0.04 \\
\hline Sparacino \& Hansell (1979), Study 3 & 84 & $\mathbf{M}$ & I & $\mathrm{F}$ & 0.02 \\
\hline Sparacino \& Hansell (1979), Study 3 & 83 & $\mathbf{F}$ & I & $\mathrm{F}$ & -0.45 \\
\hline Steffen \& Redden (1977) & 40 & $\mathbf{M}$ & $\mathbf{N}$ & G & 0.83 \\
\hline Stelzer, Desmond, \& Price (1987) & 41 & $\mathbf{F}$ & I & G & 0.55 \\
\hline Stewart (1980) & 67 & B & I & G & 0.67 \\
\hline Stewart (1984) & 60 & B & I & $\mathrm{G}$ & 0.53 \\
\hline Sussman et al. (1987) & 50 & B & I & $\mathrm{G}$ & 0.94 \\
\hline Sussman \& Mueser (1983) & 43 & F & I & G & 0.26 \\
\hline Turner, Gilliland, \& Klein (1981) & 99 & B & I & G & 0.47 \\
\hline Turner, Gilliland, \& Klein (1981) & 103 & B & $\mathbf{N}$ & $\mathrm{G}$ & 0.47 \\
\hline Walster, Aronson, Abrahams, \& Rottmann (1966) & 376 & $\mathbf{M}$ & I & G & 1.77 \\
\hline Walster, Aronson, Abrahams, \& Rottmann (1966) & 376 & $\mathbf{F}$ & $\mathbf{I}$ & G & 0.98 \\
\hline Wessberg, Marriotto, Conger, Farrell, \& Conger (1979) & 45 & M & I & $\mathrm{G}$ & 0.60 \\
\hline Zakahi \& Duran (1988) & 20 & $\mathbf{M}$ & I & $\mathbf{F}$ & 1.23 \\
\hline Zakahi \& Duran (1988) & 27 & $\mathbf{F}$ & $\mathbf{I}$ & $\mathrm{F}$ & 0.27 \\
\hline Zebrowitz, Collins, \& Dutta (1998) & 80 & $\mathbf{F}$ & I & $\mathrm{G}$ & 0.38 \\
\hline
\end{tabular}

Note. $\mathrm{M}=$ male; $\mathrm{F}=$ female; $\mathrm{B}=$ both; $\mathrm{I}=$ independent; $\mathrm{N}=$ nonindependent; $\mathrm{F}=$ facial measure; $\mathrm{G}=$ global measure. 
Appendix $\mathbf{H}$

Studies Included in Meta-Analysis of Child Behavior/Trait Differences

\begin{tabular}{|c|c|c|c|c|c|c|}
\hline Study & Sample size & Gender & Age & Rater type & Attractiveness measure & $d$ \\
\hline L. K. Anderson (1991) & 20 & B & 10.74 & I & F & 1.08 \\
\hline Babad, Inbar, \& Rosenthal (1982) & 150 & B & 16 & $\mathrm{~N}$ & G & 0.54 \\
\hline N. Cavior \& Dokecki (1973) & 14 & M & 16.5 & I & G & 1.79 \\
\hline N. Cavior \& Dokecki (1973) & 18 & M & 10.5 & I & G & 4.82 \\
\hline N. Cavior \& Dokecki (1973) & 14 & $\mathbf{F}$ & 16.5 & I & $\mathrm{G}$ & 2.00 \\
\hline N. Cavior \& Dokecki (1973) & 12 & $\mathbf{F}$ & 10.5 & 1 & G & 2.98 \\
\hline N. Cavior \& Howard (1973), Study 1 & 104 & $\mathbf{M}$ & 18 & I & $\mathrm{F}$ & 0.47 \\
\hline N. Cavior \& Howard (1973), Study 2 & 99 & $\mathbf{M}$ & 18 & 1 & $\mathrm{~F}$ & 0.26 \\
\hline N. Cavior, Miller, \& Cohen $(1975)$ & 24 & $\mathbf{M}$ & 17.5 & $\mathrm{~N}$ & $\mathrm{G}$ & 1.15 \\
\hline N. Cavior, Miller, \& Cohen (1975) & 23 & $\mathrm{~F}$ & 15.5 & $\mathrm{~N}$ & G & 1.45 \\
\hline Clark \& Ayers (1988) & 136 & B & 12.7 & $\mathbf{N}$ & $\mathbf{G}$ & 0.41 \\
\hline Cole (1991) & 712 & $\mathbf{M}$ & 9.29 & I & $\mathrm{G}$ & 0.49 \\
\hline Cole (1991) & 710 & $\mathrm{~F}$ & 9.29 & I & G & 0.43 \\
\hline Cole, Martin, \& Powers (1997) & 617 & $\mathrm{~B}$ & 9.8 & $\mathrm{~N}$ & $\mathrm{G}$ & 0.28 \\
\hline P. S. Cooper (1993) & 55 & B & 10.4 & I & $\mathrm{F}$ & 1.14 \\
\hline Dailey, Allen, Chinsky, \& Veit (1974) & 37 & B & 9.3 & $\mathrm{~N}$ & $\mathrm{~F}$ & 1.29 \\
\hline Dion \& Berscheid (1974) & 39 & $\mathbf{M}$ & 5 & I & $\mathbf{F}$ & 0.55 \\
\hline Dion \& Berscheid (1974) & 18 & $\mathrm{~F}$ & 5 & I & $\mathbf{F}$ & -0.88 \\
\hline Felson (1980), Study 1 & 53 & $\mathbf{M}$ & 12.5 & I & G & 0.40 \\
\hline Felson (1980), Study 1 & 84 & $\mathrm{~F}$ & 12.5 & I & $\mathrm{G}$ & 0.04 \\
\hline Felson (1980), Study 2 & 2,201 & $\mathbf{M}$ & 15.5 & $\mathrm{~N}$ & G & 0.45 \\
\hline Fridell, Zucker, Bradley, \& Maing (1996) & 22 & $\mathrm{~F}$ & 6.6 & I & $\mathbf{F}$ & 0.45 \\
\hline Hollingworth (1935) & 40 & B & 14.5 & I & $\mathrm{F}$ & 0.70 \\
\hline Hughes, Howell, \& Hall (1983) & 23 & $\mathbf{M}$ & 11.5 & I & G & 0.19 \\
\hline Hughes, Howell, \& Hall (1983) & 28 & $\mathrm{~F}$ & 11.5 & I & $G_{\imath}$ & 0.04 \\
\hline Jovanovic, Lerner, \& Lerner (1989) & 139 & B & 11.6 & $\mathbf{I}$ & $\mathrm{G}$ & 0.12 \\
\hline Kenealy, Gleeson, Frude, \& Shaw (1991) & 801 & B & 11.5 & 1 & $\mathrm{~F}$ & 0.11 \\
\hline Kleck, Richardson, \& Ronald (1974), Study 2 & 30 & $\mathbf{M}$ & 11.5 & I & $\mathrm{F}$ & 0.46 \\
\hline Krantz, Friedberg, \& Andrews (1984) & 107 & B & 9.2 & I & F & 0.58 \\
\hline Leinbach \& Fagot (1991) & 26 & M & 1.9 & I & $\mathbf{F}$ & 0.02 \\
\hline Leinbach \& Fagot (1991) & 24 & $\mathbf{F}$ & 1.7 & I & $\mathrm{F}$ & 0.23 \\
\hline Lerner, Delaney, Hess, Jovanovic, \& von Eye (1990) & 101 & B & 11.6 & I & $\mathbf{F}$ & 0.65 \\
\hline Lerner \& Lerner (1977) & 104 & B & 10.6 & I & $\mathbf{F}$ & 0.47 \\
\hline Lerner et al. (1991) & 153 & B & 11.6 & I & F & 0.02 \\
\hline Lippitt (1941) & 15 & B & 4.1 & $\mathrm{~N}$ & G & 0.00 \\
\hline Lippitt (1941) & 21 & B & 3.6 & $\mathrm{~N}$ & G & 0.63 \\
\hline Lippitt (1941) & 9 & $\mathbf{B}$ & 5 & $\mathrm{~N}$ & G & 1.08 \\
\hline Moran \& McCullers (1984) & 34 & B & 17.5 & I & $\mathbf{F}$ & -0.96 \\
\hline Murphy, Nelson, \& Cheap (1981) & 41 & B & 17.5 & I & $\vec{F}$ & 0.26 \\
\hline Salvia, Algozzine, \& Sheare (1977) & 84 & B & 9.5 & I & $\mathbf{F}$ & 0.38 \\
\hline Serketich \& Dumas (1997) & 12 & B & NR & I & G & 1.67 \\
\hline J. Smith \& Krantz (1986) & 11 & $\mathbf{M}$ & 8.5 & I & $\mathbf{F}$ & 0.90 \\
\hline J. Smith \& Krantz (1986) & 12 & $\mathbf{F}$ & 8.5 & I & $\mathbf{F}$ & 0.81 \\
\hline Sparacino \& Hansell (1979), Study 3 & 84 & M & 15.5 & I & $\mathbf{F}$ & 0.02 \\
\hline Sparacino \& Hansell (1979), Study 3 & 83 & $\mathbf{F}$ & 15.5 & I & $\mathbf{F}$ & -0.45 \\
\hline Sparacino \& Hansell (1979), Study 3 & 83 & F & 15.5 & I & F & -0.45 \\
\hline Vaughn \& Langlois (1983) & 34 & $\mathbf{M}$ & 4 & I & $\mathbf{F}$ & 0.20 \\
\hline Vaughn \& Langlois (1983) & 25 & $\mathbf{F}$ & 4 & 1 & F & 0.72 \\
\hline Weisfeld, Weisfeld, \& Callaghan (1984) & 50 & $\mathbf{M}$ & 16.5 & $\mathrm{~N}$ & G & 1.40 \\
\hline Weisfeld, Weisfeld, \& Callaghan (1984) & 25 & $\mathbf{M}$ & 11.6 & $\mathrm{~N}$ & G & 1.03 \\
\hline Weisfeld, Weisfeld, \& Callaghan (1984) & 25 & $\mathbf{M}$ & 11.6 & $\mathbf{N}$ & G & 2.88 \\
\hline Weisfeld, Weisfeld, \& Callaghan (1984) & 24 & $\mathbf{F}$ & 11.5 & $\mathrm{~N}$ & G & 1.38 \\
\hline Weisfeld, Weisfeld, \& Callaghan (1984) & 24 & $\mathbf{F}$ & 11.5 & $\mathrm{~N}$ & $\mathbf{G}$ & 1.84 \\
\hline Weisfeld, Weisfeld, \& Callaghan (1984) & 8 & $\mathbf{F}$ & 8 & $\mathbf{N}$ & G & 0.41 \\
\hline Weisfeld, Weisfeld, \& Callaghan (1984) & 8 & $\mathbf{F}$ & 8 & $\mathrm{~N}$ & G & 0.19 \\
\hline Zucker, Wild, Bradley, \& Lowry (1993) & 17 & $\mathbf{M}$ & 8.1 & I & $\mathrm{F}$ & 0.62 \\
\hline
\end{tabular}

Note. $\mathrm{M}=$ male; $\mathrm{F}=$ female; $\mathrm{B}=$ both $\mathrm{I}=$ independent; $\mathrm{N}=$ nonindependent; $\mathrm{F}=$ facial measure; $\mathrm{G}=$ global measure. 
Appendix I

Studies Included in Meta-Analysis of Self-Perceived Traits in Attractive and Unattractive Adults

\begin{tabular}{|c|c|c|c|c|c|c|c|}
\hline Study & $\begin{array}{c}\text { Sample } \\
\text { size }\end{array}$ & $\begin{array}{l}\text { Target } \\
\text { gender }\end{array}$ & $\begin{array}{l}\text { Perceiver } \\
\text { gender }\end{array}$ & $\begin{array}{l}\text { Rater } \\
\text { type }\end{array}$ & $\begin{array}{c}\text { Physical } \\
\text { attractiveness } \\
\text { measure }\end{array}$ & $\begin{array}{l}\text { Physical } \\
\text { attractiveness } \\
\text { range }\end{array}$ & $d$ \\
\hline Abbott \& Sebastian (1981) & 60 & $\mathbf{F}$ & $\mathbf{F}$ & I & $\mathbf{F}$ & C & 0.22 \\
\hline Berscheid, Dion, Walster, \& Walster (1971), Study 1 & 137 & $\mathbf{M}$ & $\mathbf{M}$ & I & $\mathbf{G}$ & $\mathbf{C}$ & 0.39 \\
\hline Berscheid, Dion, Walster, \& Walster (1971), Study 2 & 56 & $\mathbf{M}$ & $\mathbf{M}$ & I & G & D & 0.04 \\
\hline Berscheid, Dion, Walster, \& Walster (1971), Study 2 & 56 & $\mathbf{F}$ & $\mathbf{F}$ & I & G & D & 0.12 \\
\hline Burns \& Farina (1987) & 280 & $\mathbf{F}$ & $\mathbf{F}$ & 1 & G & $\mathrm{C}$ & 0.41 \\
\hline Campbell, Kleim, \& Olson (1986) & 31 & F & $\mathrm{F}$ & I & G & C & 0.45 \\
\hline Cash \& Burns (1977) & 12 & $\mathbf{M}$ & M & I & G & $\mathrm{C}$ & 0.54 \\
\hline Cash \& Burns (1977) & 32 & $\mathrm{~F}$ & $\mathrm{~F}$ & I & G & $\mathrm{C}$ & -0.18 \\
\hline Chaiken (1979) & 272 & $\mathbf{M}$ & $\mathbf{M}$ & I & $\mathrm{F}$ & $\mathrm{D}$ & 0.02 \\
\hline Farina et al. (1977), Study 1 & 21 & $\mathbf{F}$ & $\mathbf{F}$ & I & $\mathrm{F}$ & $\mathrm{C}$ & 0.38 \\
\hline Farina et al. (1977), Study 2 & 50 & $\mathbf{F}$ & $\mathbf{F}$ & I & $\mathrm{F}$ & C & 0.38 \\
\hline Gabriel, Critelli, \& Ee (1994) & 62 & $\mathbf{M}$ & $\mathbf{M}$ & I & $\mathrm{F}$ & C & -0.47 \\
\hline Gabriel, Critelli, \& Ee (1994) & 83 & $\mathbf{F}$ & $\mathbf{F}$ & I & $\mathbf{F}$ & $\mathrm{C}$ & -0.34 \\
\hline Gifford, Ng, \& Wilkinson (1985) & 13 & $\mathbf{M}$ & $\mathbf{M}$ & I & G & $\mathrm{C}$ & 0.16 \\
\hline D. J. Jackson \& Huston (1975), Study 1 & 20 & $\mathbf{F}$ & $\mathbf{F}$ & I & G & $\mathrm{D}$ & 0.81 \\
\hline Kaats \& Davis (1970) & 56 & $\mathbf{F}$ & $\mathbf{F}$ & I & G & C & 0.71 \\
\hline O'Grady (1982) & 230 & $\mathbf{M}$ & $\mathbf{M}$ & I & G & C & 0.26 \\
\hline Reis, Nezlek, \& Wheeler (1980) & 15 & $\mathbf{M}$ & $\mathbf{M}$ & I & G & C & 0.12 \\
\hline Reis, Nezlek, \& Wheeler (1980) & 15 & $\mathbf{F}$ & $\mathbf{F}$ & I & $\mathrm{G}$ & $\mathrm{C}$ & 0.06 \\
\hline Reis et al. (1982) & 31 & $\mathbf{M}$ & $\mathbf{M}$ & I & G & C & 0.53 \\
\hline Reis et al. (1982) & 51 & $\mathbf{F}$ & $\mathbf{F}$ & I & G & $\mathrm{C}$ & 0.69 \\
\hline Sarason, Sarason, Hacker, \& Basham (1985) & 168 & $\mathbf{M}$ & $\mathbf{M}$ & I & $\mathbf{F}$ & $\mathrm{C}$ & 0.54 \\
\hline Umberson \& Hughes (1987) & 1,692 & $\mathbf{M}$ & $\mathbf{M}$ & $\mathbf{N}$ & G & $\mathrm{C}$ & 0.26 \\
\hline
\end{tabular}

Note. $\mathrm{M}=$ male; $\mathrm{F}=$ female $; \mathrm{B}=$ both $\mathrm{I}=$ independent; $\mathrm{N}=$ nonindependent; $\mathrm{F}=$ facial measure $\mathrm{G}=$ global measure; $\mathrm{C}=$ continuous; $\mathrm{D}=$ dichotomous.

\section{Appendix J}

Studies Included in the Meta-Analyses but Not Elsewhere Reported Because Nonsignificant Results Were Coded as Equal to Zero

Bull, Jenkins, \& Stevens (1983)

Cheek \& Buss (1981)

Clifford (1975)

Dion \& Stein (1978)

Fugita, Agle, Newman, \& Walfish (1977)

Goldberg, Gottesdiener, \& Abramson (1975)

Hadjistavropolous, Tuokko, \& Beattie (1991)

W. H. Jones, Freemon, \& Goswick (1981)

Kahn, Hottes, \& Davis (1971)
Kanekar \& Ahluwalia (1975)

Leinbach \& Fagot (1991)

Markley, Kramer, Parry, \& Ryabik (1982)

Pittenger \& Baskett (1984)

Salvia, Sheare, \& Algozzine (1975)

J. A. Shea \& Adams (1984)

Wessberg, Marriotto, Conger, Farrell, \& Conger (1979)

Williams \& Ciminero (1978)

Wilson \& Donnerstein (1977)
Received August 29, 1997

Revision received October 6, 1999

Accepted October 7, 1999 